\title{
4 Walter Benjamin: Der Engel als Träger eines „realen Humanismus“
}

Wie bei Rilke so spielt auch bei Walter Benjamin der Erste Weltkrieg eine zentrale Rolle für eine Epochentypologie der Moderne. Bei beiden steht der Befund eines umfassenden Erfahrungsverlusts, der über eine Technik- und Medienreflexion entwickelt wird. Die Fabel von einem alten Mann und seinem Weinberg führt Benjamin in „Erfahrungsarmut“ (1933) zu der Frage, wo diese Art der generationalen Weisheitsvermittlung noch zu finden sei: „Wer trifft noch auf Leute, die rechtschaffen etwas erzählen können?"“1 Mit diesem Traditionsbruch ist jene Generation konfrontiert, „die 1914-1918 eine der ungeheuersten Erfahrungen der Weltgeschichte gemacht hat“'2. Aus ihr sind die Leute „[n]icht reicher, ärmer an mitteilbarer Erfahrung ${ }^{\text {“3 }}$ hervorgegangen. Eine ähnlich toxische Wirkung wie Rilke bescheinigt Benjamin dabei dem „Zeitunglesen“, das ihm als „Todfeind“4 des Erzählens gilt. In seinem Aufsatz „Über einige Motive bei Baudelaire“ (1940) ergänzt er die Beobachtung der Erfahrungsverkümmerung um den Kontrast von Erzählen und (Presse-)Sensation:

In der Ablösung der älteren Relation durch die Information, der Information durch die Sensation spiegelt sich die zunehmende Verkümmerung der Erfahrung wider. Alle diese Formen heben sich ihrerseits von der Erzählung ab; sie ist eine der ältesten Formen der Mitteilung. Sie legt es nicht darauf an, das pure An-sich des Geschehenen zu übermitteln (wie die Information das tut); sie senkt es dem Leben des Berichtenden ein, um es als Erfahrung den Hörern mitzugeben. ${ }^{5}$

Die Diagnose eines verlorenen Einsenkens in die Zuhörenden, für das die tiefensemantische Voraussetzung in dem auf Schock-Bewältigung abgestellten modernen Nervensystem fehlt, führt zusammen mit der Kriegserschütterung zu einer „ganz

1 Walter Benjamin, Erfahrung und Armut. In: Benjamin, Gesammelte Schriften, Bd. II.1, hg. von Rolf Tiedemann u. Hermann Schweppenhäuser, Frankfurt am Main 1991, S. 213-219, hier S. 214 (der Titel, den Benjamin selbst verwendet hat, lautet „Erfahrungsarmut“).

2 Benjamin, Erfahrung und Armut, S. 214.

3 Benjamin, Erfahrung und Armut, S. 214.

4 Walter Benjamin, Druckvorlage: Benjamin-Archiv, Ms 658. In: Benjamin, Gesammelte Schriften, Bd. II.2, hg. von Rolf Tiedemann u. Hermann Schweppenhäuser, Frankfurt am Main 1991, S. 1284-1287, hier S. 1287.

5 Walter Benjamin, Über einige Motive bei Baudelaire. In: Benjamin, Gesammelte Schriften, Bd. I.2, hg. von Rolf Tiedemann u. Hermann Schweppenhäuser, Frankfurt am Main 1991, S. 607-653, hier S. 611.

Ә Open Access. () 2022 Lena Zschunke, publiziert von De Gruyter. (c) BY-SA Dieses Werk ist lizenziert unter einer Creative Commons Namensnennung - Weitergabe unter gleichen Bedingungen 4.0 International Lizenz. https://doi.org/10.1515/9783110552621-004 
neue[n] Armseligkeit“6. Laut Benjamin folgten Reaktionen, in denen die Erfahrung „geheuchelt oder erschlichen“" ${ }^{\text {, }}$, ihr Mangel durch eine Fülle an fragwürdigen spirituellen und körperlichen Praktiken übertüncht wurde. Mit der Emphase des „Wir“ bekennt Benjamin sich dagegen zur Armut und postuliert ein neues, positives Barbarentum, das den Mangel an Menschheitserfahrungen nachdrücklich bejaht. Interessanterweise steht bei Benjamin wie bei Rilke neben dem Befund der (Erfahrungs-)Armut auch die Forderung nach einer bewusst bejahten und gestalteten Armut. Für Rilke wie für Benjamin sind der Mensch und seine Beziehung zur Welt im Krieg fundamental in Frage gestellt. Beide greifen in dieser Situation auf die Engelsfigur als nichtmenschliches Reflexionsmedium zurück. Auch bei Benjamin spielt der Engel dabei eine sehr viel ambivalentere Rolle, als man zunächst annehmen könnte. So scheint es angesichts der Bedeutung des jüdischen Messianismus in Benjamins Werk naheliegend, den Engel der Seite des Jüdisch-Religiösen zuzuschlagen. Bei näherer Betrachtung findet sich allerdings auch hier die transdisziplinäre und ordnungszersetzende Dynamik des Engels wieder, der nicht nur als Bestandteil jüdischer Mystik, sondern auch als areligiöses „Geschöpf aus Kind und Menschenfresser“ ${ }^{* 8}$ in Erscheinung tritt.

Bei Rilke diente der Engel dazu, die Brüche der Moderne anschaulich zu machen und zugleich ihre Überwindung in Aussicht zu stellen. Bei Benjamin ist er innerhalb des kriegsgeprägten Moderne-Zusammenhangs eine ähnlich doppelgesichtige Figur, allerdings mit anderen Vorzeichen. Einerseits opponiert der Engel als dezidiert nichttechnisches, auratisches Medium einer technokratischen Fortschrittsbegeisterung. Andererseits radikalisiert er die sich mit zerstörerischer Wucht bahnbrechenden technischen und gesellschaftlichen Modernisierungen und stellt als anthropologische Reflexionsfigur den Menschen in Frage. Denn, und hier geht Benjamin deutlich über Rilke hinaus, der Mensch ist im Krieg in seiner humanistischen Form irreparabel beschädigt. Der Engel tritt daher anders als bei Rilke nicht als Figur der Heilung und ästhetischen Ausweitung des Sichtbaren ins Unsichtbare in Erscheinung. Er wirkt stattdessen als hybride Figur, die Tierisches und Monströses in sich trägt und den idealistischen Humanismus zerstört. Animalisches und Angelisches verbinden sich im Bild des Nicht-, ja Unmenschlichen, das verschiedene Konnotationen annehmen kann. Dergestalt macht der Engel die im Krieg unterbrochene Tradition anschaulich als eine Figur, die bereits innerhalb eines theologischen Traditionszusammenhangs Ordnungsgrenzen vielfach überschreitet. Anders als bei

6 Benjamin, Erfahrung und Armut, S. 214.

7 Benjamin, Erfahrung und Armut, S. 215.

8 Vgl. Walter Benjamin, Karl Kraus. In: Benjamin, Gesammelte Schriften, Bd. II.1, hg. von Rolf Tiedemann u. Hermann Schweppenhäuser, Frankfurt am Main 1991, S. 334-367, hier S. 367. 
Rilke, bei dem die bewahrende Dimension des Engels der unterbrechenden entgegengesetzt ist, ist der Engel bei Benjamin Teil jener allegorischen Gedankenfigur, dass gerade die Zerstörung Dauer ermöglicht. Benjamins Engel zerschlagen zwar Traditionszusammenhänge, bewahren aber zugleich deren Fragmente.

Diese Bewegung betrifft schließlich auch das im Exil unterbrochene Leben. Den Text „Erfahrungsarmut“ schrieb Benjamin im Sommer 1933 auf Ibiza, als die Weimarer Republik zusammengebrochen war und Benjamins Exil begann. Der Engel tritt hier in einer Situation verschärfter existentieller Unsicherheit in Erscheinung, in der sich biographische Krise, Epochendiagnose und theoretische Reflexionen untrennbar verbinden. Mit dem Papen-Putsch 1932 und schließlich der Flucht aus Deutschland schwinden Benjamins Publikationsmöglichkeiten. Er gerät finanziell in eine immer bedrohlichere Lage und ist auch sozial isoliert. Das Exil erscheint so in mehreren Facetten: als Abtrennung von ökonomisch überlebenswichtigen Bedingungen wie als zugespitzter Topos des entfremdeten Intellektuellen; als Folge einer weltpolitischen Aggression, der eine kriegerische sich anzuschließen droht, wie als Dreh- und Angelpunkt eines geschichtsphilosophischen Modells.

Das Exil setzt gesteigerte Bemühungen um Selbstvergewisserung frei. ${ }^{9}$ So schreibt Benjamin im Sommer 1933 auf Ibiza auch an der Berliner Kindheit um Neunzehnhundert, einer Sammlung von episodischen Erinnerungsstücken. Diese lassen sich nicht zu einer kohärenten Chronologie zusammenfügen und spiegeln damit das Schicksal das exilierten Subjekts, dessen Lebenserzählung von Brüchen und Fremdheitserfahrungen durchzogen ist. ${ }^{10}$ Im Schreiben auf der spanischen Insel verschwimmen autobiographische Verortungsbemühungen, politischer Kampf und geschichtsphilosophische Theoriebildung. Der Engel fungiert als Gelenkstelle der vielfältigen Exildiskurse, indem er als Schnittpunkt von individueller, historischer und überirdischer Zeit Autobiographie, Politik und Geschichtsphilosophie verbindet. Er grundiert dabei eine besondere Erzählstruktur, die sich dem modernen Erfahrungsverlust widersetzt. Dem Erzähler, der aus der Erfahrung schöpft und sie weitergibt, setzt Benjamin in seinem Essay „Der Erzähler. Betrachtungen zum Werk Nikolai Lesskows“ (1936) den modernen Romancier entgegen, „das Individuum in seiner Einsamkeit“11, das nichts Exemplarisches mehr mitzuteilen hat, ratlos ist und keinen Rat mehr geben kann. Im Gegensatz zu der Isolation des mo-

\footnotetext{
9 Vgl. Elisabeth Bronfen, Exil in der Literatur: Zwischen Metapher und Realität. In: Arcadia. Zeitschrift für Vergleichende Literaturwissenschaft, 28, 1993, S. 167-183, hier S. 170.

$10 \mathrm{Vgl}$. Wotschal, Schreiben und Reisen über Gattungsgrenzen hinweg, S. 60-61.

11 Walter Benjamin, Der Erzähler. Betrachtungen zum Werk Nikolai Lesskows. In: Benjamin, Gesammelte Schriften, Bd. II.2, hg. von Rolf Tiedemann u. Hermann Schweppenhäuser, Frankfurt am Main 1991, S. 438-465, hier S. 443.
} 
dernen Subjekts ist das mit Erinnerungen arbeitende Erzählen bei Benjamin ein chronistisches, da es durchlässig ist für historische Ereignisse und ihre „Einbettung in den großen unerforschlichen Weltlauf"“12. Der Erzähler als profaner Chronist ist bei Benjamin die Instanz, die „einen antiautobiographischen Umgang mit Erinnerungen"13 pflegt. Insofern geht es in den scheinbar autobiographischen Schriften nicht um isolierte individuelle Erinnerungen, sondern um ihre Verflochtenheit mit einer übergeordneten Geschichte, wie sie auch für die Notiz „Agesilaus Santander“ charakteristisch ist, die Benjamin ebenfalls im Sommer 1933 auf Ibiza verfasste.

Deren augenscheinlich autobiographischen Signale führten dazu, dass ihre vielfältigen theoretischen Implikationen in der Forschung unberücksichtigt blieben. Dass sich die Rezeption des Textes vornehmlich auf die Biographie des Verfassers konzentrierte, ist neben den prekären Lebensumständen des existentiell bedrohten Flüchtlings Benjamin wohl vor allem der für ihn unüblichen Ich-Form zuzuschreiben. ${ }^{14}$ So folgen die meisten Lektüren des Textes geschlossen dem Befund Gershom Scholems, dass es sich um ein „beunruhigendes“15 Selbstzeugnis handle. Benjamin beschreibe in diesem Text, wie seine Person sich in den satanischen Engel auf dem Bild „Angelus Novus“ von Paul Klee verwandle. ${ }^{16}$ Aufgrund der engen Verbindung, die Benjamin zu diesem Bild besaß, das sich seit 1921 in

12 Benjamin, Der Erzähler, S. 452.

13 Dieter Thomä, Vincent Kaufmann u. Ulrich Schmid, Walter Benjamin, Der heiße und der kalte Erzähler. In: Der Einfall des Lebens. Theorie als geheime Autobiographie, München 2015, S. 76-88, hier S. 82.

14 Vgl. Benjamins Äußerung: „Wenn ich ein besseres Deutsch schreibe als die meisten Schriftsteller meiner Generation, so verdanke ich das zum guten Teil der zwanzigjährigen Beobachtung einer einzigen kleinen Regel. Sie lautet: das Wort ,ich“ nie zu gebrauchen, außer in den Briefen“ (Walter Benjamin, Berliner Chronik. In: Benjamin, Gesammelte Schriften, Bd. VI, hg. v. Rolf Tiedemann u. Hermann Schweppenhäuser, Frankfurt am Main 1991, S. 465-519, hier S. 475).

15 Gershom Scholem, Walter Benjamin und sein Engel. In: Zur Aktualität Walter Benjamins, hg. von Siegfried Unseld, Frankfurt am Main 1972, S. 87-138, hier S. 91.

16 Vgl. Scholem, Walter Benjamin und sein Engel, S. 114. Für Jochen Hörisch findet in dieser Wandlung ein „,[v]ielfaches Schuldgefühl“ Benjamins Ausdruck, der nicht nur das Klee-Bild der Öffentlichkeit vorenthielt, sondern sich auch ,allen Anträgen entzogen [hat], durch unmittelbar öffentlich-politische Aktivitäten das größte Glück der größten Zahl zu fördern, ja überhaupt in der humanistisch aufgeklärten Tradition des Guten und Wahren zu denken, zu handeln und zu leben: der Angelus Satanas“ (Jochen Hörisch, Vom Geheimnis zum Rätsel. Die offenbar geheimen und profan erleuchteten Namen Walter Benjamins. In: Schleier und Schwelle. Archäologie der literarischen Kommunikation V, Bd. 2: Geheimnis und Offenbarung, hg. v. Aleida Assmann u. Jan Assmann, München 1998, S. 161-178, hier S. 173). Dass sich Benjamin die Maske des satanischen Engels aufziehe, folge aus „der grundsätzlichen Einsicht in die Paradoxien des Glücks“ (Hörisch, Vom Geheimnis zum Rätsel, S. 175). Für Verena Lenzen 
seinem Besitz befand, aber auch wegen seiner Exil-Situation ist eine autobiographische Lektüre naheliegend. Verdeckt bleibt dabei jedoch, dass Benjamins Engelsvorstellung eine epochale Bedrohungssituation anschaulich macht. Der Engel schreibt in die Fortschrittsgeschichte der Moderne ein unheimliches Moment ein und macht mit dem Warten und dem Verlust die prägenden Erfahrungen der Exilexistenz sichtbar. Und zwar sowohl im privaten Bereich, indem der Engel in „Agesilaus Santander“ als eine Art Gestaltenwandler dem ähnelt, was das Erzähler-Ich verloren hat, als auch gesamtgeschichtlich, wenn er in „Über den Begriff der Geschichte“ die Perspektive der Toten und Besiegten der Historie aus dem kollektiven Unbewussten hebt. Der Engel ist dabei allerdings keine melancholische Figur des Verlorenen, sondern durch seine besondere Zukunftsbindung mit einer messianisch-revolutionären Perspektive verknüpft.

Während sich die Engelkonzeption in „Agesilaus Santander“ vor allem aus der jüdischen Tradition speist, zwischen Geheimnis und Offenbarung steht und von der historischen Situation der Judenverfolgung gekennzeichnet ist, rückt in „Über den Begriff der Geschichte“ die technische und filmästhetische Dimension des Engels in den Vordergrund. Auch diese Umgewichtung ist historisch geprägt: „Über den Begriff der Geschichte“ schrieb Benjamin 1940, als sich die weltpolitische Lage mit dem Beginn des Zweiten Weltkriegs und dem Hitler-Stalin-Pakt bedrohlich zugespitzt hatte. Dies bedeutet keine Abkehr von religiöser Bildlichkeit und religiösen Strukturen, sie sind aber in einem völlig anderen Duktus gefasst als in „Agesilaus Santander“. Nicht mehr obskur und geheimnisvoll tritt der Engel auf, sondern mit dezidiert politischem Anstrich. Dabei verbinden sich technische und ästhetische Aspekte im Engel der Geschichte als einer Figur zwischen Apparatur und Apparition. ${ }^{17}$ Als unmenschliches Medium macht er so das sichtbar, was dem menschlichen Auge sonst verborgen bleibt.

mündet die Wandlung des Bilds hingegen „in die Selbstbespiegelung des Melancholikers“ (Verena Lenzen, Benjamins Engel. In: Verantwortung und Integrität heute. Theologische Ethik unter dem Anspruch der Redlichkeit, hg. von Jochen Sautermeister, Freiburg; Basel; Wien 2013, S. 437-454, hier S. 447). Nach Galili Shahar ist der neue Engel wiederum „the reflection (the representation, the image) of Benjamin's conditions as a writer, a thinker, and a lover“ und im weiteren Sinne dann auch Ausdruck der „dialectic of tradition and the paradoxes of the secular delivery characterized by fragmentation, distortion, and inversions of the origin“ (Galili Shahar, In the Name of the Devil: Reading Walter Benjamin's „Agesilaus Santander“. In: Secularism in Question. Jews and Judaism in Modern Times, hg. von Ari Joskowicz u. Ethan B. Katz, Philadelphia 2015, S. 98-114, hier S. 108).

17 Der Begriff der Apparition ist Adornos Ästhetischer Theorie entlehnt, in der er eine „Himmelserscheinung “ bezeichnet (Theodor W. Adorno, Ästhetische Theorie, Frankfurt am Main 1970, S. 125). 


\subsection{Der Engel zwischen Autobiographie und Theorie: „Agesilaus Santander“ (1933)}

Ein weitsichtiges Elternpaar gab seinem Sohn, so erzählt dieser rückblickend, bei seiner Geburt zusätzlich zu seinem Rufnamen zwei weitere Namen. Diese sollten bei späteren Publikationen seine jüdische Identität verbergen. Der Sohn verwendet sie aber genau entgegen dieser Intention, macht sie nämlich nicht öffentlich, sondern hält sie geheim. Im Zuge dieser Verbergungsbewegung entwickeln die zwei Namen eine Art Eigenleben und verschmelzen zu einem einzigen, geheimen. Aus diesem tritt ein neuer Name oder der „Neue Engel“ (als dessen Bild) hervor. Der Engel schickt, um dem Erzähler die Störung seines Lobgesangs vor Gottes Thron zu entgelten, sein weibliches Pendant auf Umwegen im Bild nach. Dergestalt herausgefordert, vermag sich die besondere Stärke des Erzählers zu erweisen: Mit großer Geduld begabt, wartet er so lange auf eine geliebte Frau, bis sie ihm schließlich zufällt. Der Engel ähnelt allen Menschen und Dingen, von denen der Erzähler sich hat trennen müssen. Mit seinem Blick zieht der Engel denjenigen, den er (oder der ihn) gesichtet hat, in eine/die Zukunft, aus der er kam.

Auf diese Weise ließe sich, ziemlich unzureichend, das Geschehen in Walter Benjamins hintersinnigem Text „Agesilaus Santander“ paraphrasieren, den er auf Ibiza im Exil schrieb und der in zwei Fassungen, datiert auf den 12. und 13. August 1933, vorliegt. Offenkundig ist der Engel hier Teil eines ziemlich sonderbaren Geschehens. Die Dunkelheit des Textes wurde oft beschworen und hat den Enträtselungsbemühungen seiner Leserinnen und Leser seit jeher Widerstand geleistet. So nimmt die Überlegung nicht wunder, ob er nicht vielleicht einer Fieberphantasie entsprungen sei. ${ }^{18}$ Dessen ungeachtet wurden erhebliche hermeneutische Anstrengungen unternommen. Ihr gemeinsamer Bezugspunkt ist „der Angelus Satanas“, den Scholem als Anagramm von „Agesilaus Santander“ entschlüsselt hat: „Unversehens verwandelt sich nun die menschliche Person Benjamins in die so unbegreiflich tief, ja magisch mit ihm zusammenhängende angelisch-luziferische

18 Vgl. Scholem, Walter Benjamin und sein Engel, S. 92. Am 31. Juli 1933 schreibt Benjamin an Scholem, dass er seit etwa 14 Tagen krank sei (vgl. Walter Benjamin, Brief an Gershom Scholem, 31. Juli 1933. In: Benjamin, Briefe II, hg. von Gershom Scholem u. Theodor W. Adorno, Frankfurt am Main 1978, S. 588-590, hier S. 588). Im Oktober meldet er: „Ich bin schwer krank in Paris angekommen. Das will sagen, daß ich auf Ibiza überhaupt nicht mehr gesund gewesen bin, und der Tag meiner endlichen Abreise fiel mit dem ersten einer Folge schwerster Fieberanfälle zusammen. [...] Und hier wurde dann gleich nach meiner Ankunft Malaria festgestellt“ (Walter Benjamin, Brief an Gershom Scholem, 16. Oktober 1933. In: Benjamin, Briefe II, hg. von Gershom Scholem u. Theodor W. Adorno, Frankfurt am Main 1978, S. 593-594, hier S. 593). 
Natur des Engels auf dem Bilde von Paul Klee. “19 Eine weitere Spur legte Scholem mit seiner Deutung der erotisch-amourösen Stellen, die er auf reale Frauen in Benjamins Leben bezog. In seiner Interpretation von 1972 firmieren noch Jula Cohn und Asja Lacis als Adressatinnen, bevor dann Benjamins Verbindung zu der Malerin Anna Maria Blaupot ten Cate publik wurde. ${ }^{20}$ Fortan richteten sich die Entschlüsselungsbemühungen an ihr aus, mit Konsequenzen für die Lektüre. So ist nach Wil van Gerwen die Semantik des Textes nachrangig, in erster Linie sei er nämlich zu verstehen als ein „Geburtstagsgeschenk“21 für die Geliebte. Aber auch kontingente lebensweltliche Bezüge wurden bemüht. So wird in dem Verweis auf den lahmenden Spartanerkönig Agesilaus II. nicht nur eine Parallele zu dem nach dem Kampf mit dem Engel hinkenden Jakob (vgl. 1 Mos 32,24-31), ${ }^{22}$ sondern auch zu dem während der Text-Abfassung aufgrund einer schweren Wundentzündung am Oberschenkel respektive eines Furunkels lahmenden Benjamin erkannt. ${ }^{23}$

In jedem Fall handelt es sich laut Scholem um eine der vielen Schriften Benjamins, hinter denen „persönliche, ja persönlichste Erfahrungen [stehen], die in der Projektion auf die Gegenstände seiner Arbeiten verschwunden oder aber gänzlich verschlüsselt worden sind, so daß sie dem Außenstehenden nicht erkennbar oder auch nur erahnbar werden konnten“ ${ }^{24}$. Nur innerhalb eines eingeweihten Kreises, so die Botschaft, ist eine Entschlüsselung dieses privaten Textes möglich. Auf die konstitutive Offenheit und Uneindeutigkeit des Textes wurde vielfach mit einer Veräußerlichungsbewegung reagiert: Der „satanische Charakter“ Walter Benjamins sowie die potentiell adressierten Geliebten und damit vermeintliche Gewissheiten privater Natur sollten den Text verständlich machen. Diese Lektüren haben die konstitutive Ambiguität des Textes zwar

19 Scholem, Walter Benjamin und sein Engel, S. 114.

20 Vgl. Wil van Gerwen, Walter Benjamin auf Ibiza. Biographische Hintergründe zu „Agesilaus Santander“. In: global benjamin, Bd. 2, hg. von Klaus Garber u. Ludger Rehm, München 1999, S. 969-981. Otto Karl Werckmeister hingegen verbindet Erotik und Politik synergetisch über die Figur des Engels, der eine „Selbstprojektion“ des Menschen, eine „absolute Verkörperung seines Willens“ darstelle (Otto Karl Werckmeister, Benjamins „Engel der Geschichte“ oder Die Läuterung des Revolutionäres zum Historiker. In: global benjamin, Bd. 1, hg. von Klaus Garber u. Ludger Rehm, München 1999, S. 597-624, hier S. 606).

21 Van Gerwen, Walter Benjamin auf Ibiza, S. 979.

22 Vgl. Jürgen Ebach, Agesilaus Santander und Benedix Schönflies. Die verwandelten Namen Walter Benjamins. In: Antike und Moderne. Walter Benjamins „Passagen“, hg. von Norbert W. Bolz u. Richard Faber, Würzburg 1986, S. 148-153, hier S. 151.

23 Zur Wundentzündung vgl. Werckmeister, Benjamins „Engel der Geschichte“, S. 605, außerdem Tilman Lang, Mimetisches oder semiologisches Vermögen? Studien zu Walter Benjamins Begriff der Mimesis, Göttingen 1998, S. 261; zum Furunkel Hörisch, Vom Geheimnis zum Rätsel, S. 162.

24 Scholem, Walter Benjamin und sein Engel, S. 90. 
nicht ausgeblendet, aber doch als Mittel der Verschleierung gelesen, das es rückgängig zu machen gilt. Als konstitutive Semantik des Textes selbst wurde sie nicht anerkannt.

Die folgende Lektüre stellt die Kehrseite zu diesen Deutungen dar. Statt hinter den Undurchsichtigkeiten des Textes ein privates Liebesspiel, eine Enträtselung von Benjamins Namen oder umgekehrt eine Strategie der autobiographischen Mystifikation zu erblicken, soll die Vieldeutigkeit des Textes als programmatische gelesen und der autobiographische Deutungsrahmen auf eine theoretische Ebene hin geöffnet werden. Diese Bewegung ist gerechtfertigt durch die prominente Position von Name, Engel, Bild, Ähnlichkeit, Blick, Neuem und Glück in „Agesilaus Santander“, die für Benjamins ganzes Euvre von theoretischer Relevanz sind und die hier eine Art Isotopie bilden. Insbesondere hinsichtlich des Namens ist auffällig, dass er im Text selbst als Platzhalter fungiert und die in den Interpretationen eingesetzten konkreten Namen (Walter Benjamin, Agesilaus Santander, Benedix Schönfließ, der Angelus Satanas) kein einziges Mal fallen. In dieser Ausstellung des Namens in seiner Namenhaftigkeit liegt ein Verweis auf Benjamins Sprachphilosophie, in der der Name einen Knotenpunkt diverser Diskurse darstellt. ${ }^{25}$ So kommt dem Eigennamen bei Benjamin eine eminente Bedeutung zu, er verbindet Sprachphilosophie, Geschichtsphilosophie und Literaturtheorie. ${ }^{26}$

Nach Benjamin gibt es für die der „bürgerlichen Auffassung der Sprache“ entgegengesetzte Ansicht weder Mittel noch Gegenstand noch Adressat einer Mitteilung - „[s]ie besagt: im Namen teilt das geistige Wesen des Menschen sich Gott mit“'27. Das Benennen der Dinge durch den Menschen ist nichts weniger als die Vollendung von Gottes Schöpfung und auch die Ausgangssituation von „Agesilaus Santander“ bezeichnet mit der Verleihung der Namen eine Konsekration („Mit der Gebung des Namens weihen die Eltern ihre Kinder Gott“28). ${ }^{29}$

25 Ulrich Welbers stellt eine Verbindung zwischen dem Namen als Kristallisationspunkt von Benjamins Sprachphilosophie und seiner Verwendung in Agesilaus Santander fest, reißt diese aber nur kurz an (vgl. Ulrich Welbers, Sprachpassagen. Walter Benjamins verborgene Sprachwissenschaft, München; Paderborn 2009, S. 330-331).

26 Vgl. Bernd Stiegler, Die Aufgabe des Namens. Untersuchungen zur Funktion der Eigennamen in der Literatur des 20. Jahrhunderts, München 1994, S. 21.

27 Walter Benjamin, Über Sprache überhaupt und über die Sprache des Menschen. In: Benjamin, Gesammelte Schriften, Bd. II.1, hg. von Rolf Tiedemann u. Hermann Schweppenhäuser, Frankfurt am Main 1991, S. 140-157, hier S. 144. An Benjamins Ablehnung der „bürgerlichen Auffassung“ kann kein Zweifel bestehen, schickt er seinen Ausführungen doch voraus, dass „deren Unhaltbarkeit und Leere sich mit steigender Deutlichkeit im folgenden ergeben“ soll (Benjamin, Über Sprache überhaupt, S. 144).

28 Benjamin, Über Sprache überhaupt, S. 149-150.

29 Vgl. Benjamin, Über Sprache überhaupt, S. 144. 
Religionsphilosophie und Anthropologie sind bei Benjamin also ebenfalls untrennbar mit dem Namen verbunden. Mit all diesen Diskursen ist, wie bis hierhin immer wieder deutlich geworden, auch der Engel verknüpft. So ist es nicht verwunderlich, dass Benjamin ihn und den Namen in einer Notiz zu seinem Essay „Karl Kraus“ (1931) im Zusammenhang mit der „Entwicklung des Allmenschen zum Unmenschen“ explizit verknüpft: „Eros und Sprache in diesem Zusammenhang aus der kindlichen Welt zu entwickeln. Der Reim ihr Indifferenzpunkt. Dagegen der Name im Unmenschlichen - engelhaften - zuständig. “30 Name und Engel gehen beide über das Menschliche hinaus. Beide sind, wie im Folgenden deutlich wird, Ausdruck einer durch den Menschen nicht instrumentalisierbaren Medialität, die auf einen prälapsarischen Zustand hin- und auf einen posthistorischen hinausweist. Mit dem Engel und den bei ihm zusammenlaufenden Theoremen wird in „Agesilaus Santander“ schließlich eine Theorie der Moderne sichtbar, der der Erste Weltkrieg, eine bejahte Unmenschlichkeit und Technikaffinität sowie Ausblicke in eine Zukunft zugrunde liegen. Das Besondere ist, dass diese Theoreme nicht in Form einer Abhandlung präsentiert werden, sondern in eine autobiographische Erzählung eingebunden sind.

Um die medienästhetische und geschichtsphilosophische Dimension sowie den sie grundierenden Moderne-Diskurs herauszuarbeiten und den Engel als performatives Medium der Theoriebildung zu erfassen, muss die Absolutheit der autobiographischen Lektüre aufgebrochen und eine andere Lesart der Textform selbst in Anschlag gebracht werden. In „Agesilaus Santander“ wird - so der methodische Ausgangspunkt - in der Narrativierung eines durch die partielle Ich-Form verbürgten Erlebens ein autobiographisches Setting entworfen, das durchzogen ist von sprachphilosophischen, theologischen, anthropologischen, medienästhetischen, geschichtsphilosophischen und erinnerungspoetischen Versatzstücken, die wesentlich bildlogisch vermittelt sind. Zu Beginn einer Lektüre, deren Fokus nicht auf biographischen Referenzen, sondern auf Benjamins Werk liegt, steht der Befund, dass dieser Text, der mit ,als ich geboren war“31 einsetzt, in hohem Maße theoriefähig ist, ja, dass das Autobiographische hier offensichtlich in besonderer Weise für die Versammlung und Verhandlung von Theoremen geeignet zu sein scheint.

30 Walter Benjamin, Anmerkungen [Karl Kraus]. In: Benjamin, Gesammelte Schriften, Bd. II.3, hg. von Rolf Tiedemann u. Hermann Schweppenhäuser, Frankfurt am Main 1991, S. 10781130, hier S. 1102.

31 Walter Benjamin, Agesilaus Santander. In: Benjamin, Gesammelte Schriften, Bd. VI.1, hg. von Rolf Tiedemann u. Hermann Schweppenhäuser, Frankfurt am Main 1991, S. 520-523, hier S. 520. Im Folgenden AS. 
Damit soll nicht behauptet werden, dass Benjamins Schriften sich zu einer kohärenten Systematik fügten und auch nicht, dass sich aus seinen Bildern und Geschichten ein theoretischer Gehalt 1:1 herausdestillieren ließe. Vielmehr geht es um die Möglichkeit einer theoretischen Weitung des Interpretationshorizontes und eine Profilierung der Engelsfigur in der Moderne aus dieser konkreten Konstellation heraus. Ein solches Vorgehen scheint legitim angesichts Benjamins eigenem Verfahren, das darin besteht, Dinge aus ihrem angestammten Zusammenhang zu reißen und neu zusammenzufügen. Darüber hinaus verdichten sich während jenes Exilaufenthalts auf Ibiza Benjamins sprachphilosophische und zeitdiagnostische Reflexionen. Mehrfach fordert er Gershom Scholem in dieser Zeit auf, ihm den erheblich älteren Text „Über Sprache überhaupt und über die Sprache des Menschen“ (1916) zu schicken, der in der folgenden Lektüre einen tragenden Referenzpunkt bildet. ${ }^{32}$ Diesen wollte Benjamin für seine Arbeit an dem Text „Über das mimetische Vermögen“ (1933) nutzen, der wiederum in unmittelbarem zeitlichen und, wie zu zeigen sein wird, auch inhaltlichen Zusammenhang mit „Agesilaus Santander“ entstanden ist. In Benjamins Aufenthalt auf Ibiza 1933 verbinden sich so theoretische, zeitdiagnostische und autobiographische Versatzstücke, die das Exil in seiner Mehrfachkodierung als existenzbedrohende biographische Realität, als Charakteristikum der Moderne sowie als zentralen Bestandteil von Benjamins Geschichts- und Sprachphilosophie kennzeichnen.

$\mathrm{Zu}$ der diesem Phänomen adäquaten weiten Lektüre gehört auch, die zwei Fassungen von „Agesilaus Santander“ zu berücksichtigen. Beide werden daher als gleichberechtigt gelesen, das heißt, weder werden die vorliegenden Fassungen als Vorstufen einer nicht überlieferten Endfassung verstanden, ${ }^{33}$ noch wird die zweite Fassung als endgültige Fassung privilegiert. ${ }^{34}$ Auf diese Weise wird das Phänomen der Zweiheit des Textes als Teil seiner semantischen Strategie

32 Vgl. Walter Benjamin, Brief an Gershom Scholem, 23. Mai 1933. In: Benjamin, Briefe II, hg. von Gershom Scholem u. Theodor W. Adorno, Frankfurt am Main 1978, S. 575-576, hier S. 575; vgl. Walter Benjamin, Brief an Gershom Scholem, 16. Juni 1933. In: Benjamin, Briefe II, hg. von Gershom Scholem u. Theodor W. Adorno, Frankfurt am Main 1978, S. 576-579, hier S. 576.

33 Vgl. Manfred Schneider, Aufzeichnungen. In: Benjamin-Handbuch. Leben - Werk - Wirkung, hg. von Burkhardt Lindner, Stuttgart 2011, S. 663-679, hier S. 670.

34 Vgl. Scholem, Walter Benjamin und sein Engel, S. 114. Dieser Annahme folgen auch Jochen Hörisch (vgl. Hörisch, Vom Geheimnis zum Rätsel, S. 169) und Jürgen Ebach (vgl. Ebach, Agesilaus Santander und Benedix Schönflies, S. 148). Die Annahme der Gleichberechtigung geht hingegen mit der Einsicht einher, dass der Text „ein Doppelgängertum, a doubling“ darstellt (Shahar, In the Name of the Devil, S. 100), das sich im Nachleben von „Agesilaus Santander“ als Nachlassfund potenziert. Denn der von Scholem erst Anfang der 1970er Jahre veröffentlichte Text wird nach Galili Shahar begleitet von Scholems erotisch-theologischer Lektüre, die 
sichtbar. Denn aus der weitgehenden Parallelität bei gleichzeitig entscheidenden Abweichungen erwächst eine Zweistimmigkeit, die einstimmigen Bedeutungszuweisungen bereits auf der Ebene der Textorganisation den Boden entzieht. Diffuse Verwandlungsprozesse und Ähnlichkeitsverhältnisse, eine schwankende Zuordnung von Subjekt und Objekt, unstete Identitäten und Bezüglichkeiten, mediale Transpositionen und die allegorische Gebrochenheit von Sein, Bild und Erscheinen werden auf diese Weise teils gespiegelt, teils erst erzeugt. Um grammatikalische wie semantische Eigenheiten zu berücksichtigen, wird der Text daher im Folgenden in seinen Wendungen nachvollzogen und an den jeweiligen Stellen für Theoriehorizonte von Benjamins Werk geöffnet.

Um der Geheimnishaftigkeit der Namen in „Agesilaus Santander“, die zunächst dezidiert nichtjüdische sind und durch ihre Verbergung jüdische Attribute annehmen, Rechnung zu tragen, soll in der folgenden Lektüre weder eine Ausschaltung der Ambiguitäten und damit eine Zerstörung des Namensgeheimnisses über Identifizierungen vorgenommen noch der suggestive Duktus nichtevidenter Behauptungen reproduziert werden. Vielmehr gilt es, den Modus schwebender Bedeutungen als textkonstitutiv für die bedingte Partizipation am Geheimnis anzuerkennen und auszuleuchten. Diese Mehrschichtigkeit findet sich in vielfacher Form: in der Verschlungenheit von semiotischen und magischen Anteilen, die in der Figur der unsinnlichen Ähnlichkeit theoretisch reflektiert wird, in Benjamins „Epistemologie der Schwelle“35, und zwar sowohl in ihrer geschichtsphilosophischen Ausprägung mit dem „Sündenfall des Sprachgeistes“36 als auch in ihrer biographischen Relevanz der rites de passage, und nicht zuletzt in der Verkörperung des Engels an der Schwelle zwischen irdisch-historischer und göttlich-transhistorischer Sphäre. Die Schwelle zwischen dem durch die Namenssprache verbürgten harmonischen Einheitszustand von Mensch und Natur und der historischen Zeit des Bruchs hat ihre Entsprechung in dem krisenhaften Umstand des realhistorischen Exils, das in „Agesilaus Santander“ mehrfach durchscheint und in der folgenden Lektüre als Bezugspunkt der individuell-lebensweltlichen Dimension herangezogen wird. Damit soll nicht „de[r] Exilbegriff auf eine durch die Zeitumstände bedingte Politisierung“37 ${ }^{*}$ reduziert werden, wie

so dominant sei, dass auch hier „,a doubling“ vorliege, nämlich „the Doppelgängertum of Benjamin's and Scholem's writing“" (Shahar, In the Name of the Devil, S. 101).

35 Weigel, Die Grammatologie der Bilder, S. 12.

36 Benjamin, Über Sprache überhaupt, S. 153.

37 Markus Bauer, Imagination und Politik. Zum Begriff des Exils bei Walter Benjamin. In: global benjamin, Bd. 3, hg. von Klaus Garber u. Ludger Rehm, München 1999, S. 1569-1583, hier S. 1570 . 
sie Markus Bauer kritisiert. Vielmehr lässt sich gerade durch die Untersuchung von exilischen Gedankenfiguren in ihrer theoretischen Relevanz die Bedeutung des Exils als ein strukturelles Moment in Benjamins Denken auch vor 1933 konturieren. So soll an den jeweiligen Stellen in einer doppelten Lektüre sowohl die geschichtsphilosophische Bedeutung des Exils als auch die biographische Dimension der Exilerfahrung eingeholt werden. Während im ersten Teil von „Agesilaus Santander“ der Fokus auf dem Namen liegt, ist im zweiten Teil des Textes der Engel Kristallisationspunkt des Geschehens.

\subsubsection{Geheimnis und Veröffentlichung als angelische Formen}

Als ich geboren wurde, kam meinen Eltern der Gedanke, ich könnte vielleicht Schriftsteller werden. Dann sei es gut, wenn nicht gleich jeder merke, daß ich Jude sei. Darum gaben sie mir außer meinem Rufnamen noch zwei weitere, ausgefallene, an denen man weder sehen konnte, daß ein Jude sie trug, noch daß sie ihm als Vornamen gehörten. Weitblickender konnte vor vierzig Jahren ein Elternpaar sich nicht erweisen. Was es nur entfernt für möglich hielt, ist eingetroffen. Nur die Vorkehrungen, mit denen es dem Schicksal hatte begegnen wollen, setzte der, den es betraf, beiseite. Anstatt ihn nämlich mit den Schriften, die er verfaßte, öffentlich zu machen, hielt er es wie die Juden mit dem zusätzlichen ihrer Kinder, der geheim verbleibt. Ja, diesen selber teilen sie ihnen erst mit, wenn sie mannbar werden.

(AS 521/522, zweite Fassung)

Das hier entworfene, scheinbar private Szenario wird sogleich durch die antisemitische Bedrohung auf die aktuellen politischen Zeitumstände des Nationalsozialismus hin transparent. ${ }^{38}$ Diese stellen die Rahmung des Folgenden dar: Was die Eltern „entfernt für möglich hielten, ist eingetroffen“. Allerdings greift ihre Schutzvorrichtung nicht, denn der Sohn verwendet die Namen eigenmächtig in entgegengesetzter Weise, macht sie nämlich nicht öffentlich, sondern verbirgt sie. Diese Bewegung ist in der ersten Fassung von „Agesilaus Santander“ noch prononcierter, hier werden die Namen auch bewacht: „Er [der Erzähler, L.Z.] wachte über sie [die Namen, L.Z.] wie einst die Juden überm geheimen Namen, den sie jedem von ihren Kindern gaben.“ (AS 520, erste Fassung) Dergestalt der öffentlichen Einsicht entzogen, werden die Namen in die Nähe des Numinos-Religiösen gestellt, ${ }^{39}$ verstärkt durch das „einst“, das diese Praktik

38 Zum Verhältnis von Name und Antisemitismus vgl. Dietz Bering, Der Name als Stigma. Antisemitismus im deutschen Alltag 1812-1933, Stuttgart 1987.

39 Vgl. zu diesem Zusammenhang Giorgio Agamben: „Nicht nur gibt es keine Religion ohne Absonderung, sondern jede Absonderung enthält oder bewahrt in sich einen genuin religiösen Kern“ (Giorgio Agamben, Lob der Profanierung. In: Agamben, Profanierungen, Frankfurt am Main 2005, S. 70-91, hier S. 71). In „Karl Kraus“ wird das Verhältnis von Name und Numino- 
mythisch entrückt. Auch gegenüber Rezipientinnen und Rezipienten waltet diese Verschwiegenheit: „Ich will sie [die Namen, L.Z.] nicht verraten“ (erste Fassung, AS 520). Auf diese Weise wird die Opposition von christlich-öffentlich und jüdisch-geheim zementiert und zugleich unterlaufen. Denn die nichtjüdischen Namen der vorsorglichen Eltern werden eben nicht publik gemacht, sondern behandelt als seien sie jüdisch, das heißt geheim. Dass mit dieser Verkehrung ein substantieller Wandel verbunden ist, wird angedeutet durch den Wechsel vom Plural in den Singular. In der Entzugsbewegung wird das Innere des Erzählers zu einer Art hermetischen Blackbox, in der die „zwei sehr ungewöhnliche[n]“ (AS 520, erste Fassung) Namen zu einem geheimen verschmelzen. Dabei lässt sich fragen, inwieweit die Unterminierung der ursprünglichen Absicht nicht bereits im elterlichen Tun selbst angelegt ist. Der ungewöhnliche beziehungsweise „ausgefallene“ Charakter der Namen scheint den Verhüllungsabsichten entgegenzulaufen, und zwar sowohl in der Lesart des Extravaganten als auch in der des Ausfalls. ${ }^{40}$

Aleida und Jan Assmann sprechen von der „naturwüchsige[n] Solidarität“41, die zwischen dem Geheimnis und dem Heiligen bestehe. Das Geheimnis stellt demnach einen „Schutzraum für das Heilige“42 dar, das es vor verunreinigendem beziehungsweise profanisierendem Zugriff von außen zu bewahren gilt. Dieser Logik gemäß sind es in „Agesilaus Santander“ die „Unberufenen“ (AS 520, erste Fassung), vor denen, je nach Variante, der geheime Name (zweite Fassung) respektive die von ihm bewahrten „Lebenskräfte“ (AS 520, erste Fassung) $\mathrm{zu}$ behüten ist beziehungsweise sind. ${ }^{43}$ Im Zuge seiner Arkanisierung, die den Namen nicht nur von der Öffentlichkeit, sondern auch von seinem Trä-

sem explizit gemacht, wenn es über Kraus’ Sprache heißt, sie sei „der Schauplatz für die Heiligung des Namens“ (Benjamin, Karl Kraus, S. 359). Dabei handle es sich um eine „jüdisch[e] Gewißheit“, die der „Theurgie des ,Wortleibs““ der Sprache Stefan Georges entgegengestellt wird (Benjamin, Karl Kraus, S. 359).

40 Scholem bemerkt hier, dass die Namen Benedix Schönflies nicht dazu angetan seien, ein Jüdischsein zu verbergen: „Jeder Jude hätte damals sofort gewußt, daß nur ein Jude Benedix Schönflies heißen könne“ (Gershom Scholem, Die geheimen Namen Walter Benjamins (1978). In: Walter Benjamin und sein Engel. Vierzehn Aufsätze und kleine Beiträge, hg. von Rolf Tiedemann, Frankfurt am Main 1983, S. 73-77, hier S. 74). Anders sehen dies Jürgen Ebach (vgl. Ebach, Agesilaus Santander und Benedix Schönflies, S. 148) und Tilman Lang (vgl. Lang, Mimetisches oder semiologisches Vermögen?, S. 257).

41 Aleida Assmann u. Jan Assmann, Geheimnis und Offenbarung. In: Schleier und Schwelle. Archäologie der literarischen Kommunikation V, Bd. 2: Geheimnis und Offenbarung, hg. von Aleida Assmann u. Jan Assmann, München 1998, S. 7-14, hier S. 7.

42 Aleida Assmann u. Jan Assmann, Geheimnis und Offenbarung, S. 7.

43 Um Heiliges vor unbefugtem Zugriff zu schützen, wird nicht zuletzt die Dunkelheit der Sprache eingesetzt (vgl. Walter Haug, Geheimnis und dunkler Stil. In: Schleier und Schwelle. 
ger absondert, entwickelt er eine Affinität zum Unheimlichen, das als eine Seite des Heiligen gilt. ${ }^{44}$ So kann sich, „mit einem neuen Mannbarwerden“ (AS 520, erste Fassung), die Verwandlung des Namens „offenbaren“ (AS 520, erste Fassung). Da sich aber „dieses Mannbarwerden im Leben mehr als einmal ereignen“ (AS 522, zweite Fassung) kann, ist auch eine mehrfache Offenbarung der Wandlung möglich und folglich die mit der Singularität der Offenbarung einhergehende Abgeschlossenheit und Verlässlichkeit nicht gegeben. Weiter ist zu vermuten, dass „vielleicht auch nicht jeder geheime Name sich stets gleich und unverwandelt bleibt“ (AS 520, erste Fassung). In der zweiten Fassung wird aus dieser fraglichen Selbstidentität des Namens im Modus des An-Sich ein an die Lebensführung seines Trägers geknüpftes Für-Diesen. So ist anzunehmen, dass „vielleicht auch der geheime Name gleich und unverwandelt nur dem Frommen bleibt“ (AS 522, zweite Fassung).

Der Begriff der Offenbarung hat sich nach Benjamin ,immer wieder wie von selbst im Zentrum der Sprachphilosophie erhoben [...] und ihre innigste Verbindung mit der Religionsphilosophie ausgemacht“45 . Die Offenbarung stellt hier wie der Name einen Modus reiner Medialität dar, wobei „[d]as Mediale [...] die Unmittelbarkeit aller geistigen Mitteilung “46 bedeutet. Diese Vorstellung folgt nicht der üblichen Gleichsetzung von Unmittelbarkeit und Medienlosigkeit. Sie setzt diese Verbindung vielmehr außer Kraft, indem sie den Gedanken des Mediums von dem des Mittels löst. Daher ist das Paradies bei Benjamin auch nicht medienlos, vielmehr wirkt Medialität hier in ihrer ungebrochenen Form. Über das Verhältnis von geistigem und sprachlichem Wesen lautet in „Über Sprache“ „die Thesis: je tiefer, d. h. je existenter und wirklicher der Geist, desto aussprechlicher und ausgesprochener“47, und: „Das höchste Geistesgebiet der Religion ist (im Begriff der Offenbarung) zugleich das einzige, welches das Unaussprechliche nicht kennt. “48

Archäologie der literarischen Kommunikation V, Bd. 2: Geheimnis und Offenbarung, hg. von Aleida Assmann u. Jan Assmann, München 1998, S. 203-217, hier S. 207).

44 Vgl. Dietmar Kamper u. Christoph Wulf, Einleitung. In: Das Heilige. Seine Spur in der Moderne, hg. von Dietmar Kamper u. Christoph Wulf, Frankfurt am Main 1987, S. 1-30, hier S. 7. Aleida und Jan Assmann bemerken, dass das Geheimnis nicht nur als Schutz für das Heilige wirkt, sondern auch als einer vor diesem: „Das Geheimnis als Schutz vor dem Heiligen - in diesem Fall wird es als eine bedrohliche Energie dargestellt, von der unmittelbare Gefahr ausgeht“ (A. Assmann u. J. Assmann, Geheimnis und Offenbarung, S. 7-8).

45 Benjamin, Über Sprache überhaupt, S. 146.

46 Benjamin, Über Sprache überhaupt, S. 142.

47 Benjamin, Über Sprache überhaupt, S. 146.

48 Benjamin, Über Sprache überhaupt, S. 147. Übrigens ebenso wenig wie das Unübersetzbare („Aber es gibt ein Halten [für den Absturz des Sinns, L.Z.]. Es gewährt es jedoch kein Text außer dem heiligen, in dem der Sinn aufgehört hat, die Wasserscheide für die strömende Spra- 
Es „wird angesprochen im Namen und spricht sich aus als Offenbarung“49. Die Offenbarung im Judentum vollzieht sich über das Medium der Sprache beziehungsweise des veröffentlichten Textes und ist darin der Offenbarung im Modus des Geheimnisses im Medium der Welt gegenübergestellt. ${ }^{50}$

Zwischen den Polen des Offenbaren und des Geheimen, die den in jeder „sprachlichen Gestaltung“ waltenden „Widerstreit des Ausgesprochenen und Aussprechlichen mit dem Unaussprechlichen und Unausgesprochenen“51 spiegeln, oszilliert „Agesilaus Santander“ nicht nur aufgrund der Verkehrung von öffentlichem in geheimen Namen und dessen (mehrfach möglicher) Offenbarung. Die „autoritäre Haltung von Offenbarungsworten“ ${ }^{52}$, die Scholem einer Vielzahl benjaminscher Sätze attestiert und die sich in der Rezeption benjaminscher Texte potenziert, ${ }^{53}$ zeigt sich hier in Aussagen, die im Modus völliger Gewissheit präsentiert werden. Sie verleihen dem Text den Anstrich eines Offenbarungsmediums, das „das Unaussprechliche nicht kennt“54. Dem Ges-

che und die strömende Offenbarung zu sein. Wo der Text unmittelbar, ohne vermittelnden Sinn, in seiner Wörtlichkeit der wahren Sprache, der Wahrheit oder der Lehre angehört, ist er übersetzbar schlechthin“ (Walter Benjamin, Die Aufgabe des Übersetzers. In: Benjamin, Gesammelte Schriften, Bd. IV.1, hg. von Tillman Rexroth, Frankfurt am Main 1991, S. 9-21, hier S. 21).

49 Benjamin, Über Sprache überhaupt, S. 147.

50 Zur Offenbarung im Judentum über die Sprache vgl. Alfred Hirsch, Der Dialog der Sprachen. Studien zum Sprach- und Übersetzungsdenken Walter Benjamins und Jacques Derridas, München 1995, S. 106. Aleida und Jan Assmann sprechen von dem geoffenbartem Text als „eine[r] Selbstveröffentlichung Gottes“ (A. Assmann u. J. Assmann, Geheimnis und Offenbarung, S. 9). Andrea Polaschegg verweist darauf, dass „der Monotheismus ausschließlich in Begleitung der Schrift auf der welt- und religionsgeschichtlichen Bühne aufgetreten ist“ (Andrea Polaschegg, Moses in Wonderland oder Warum Literatur (nicht) fetischisierbar ist. In: Der Code der Leidenschaften. Fetischismus in den Künsten, hg. von Hartmut Böhme u. Johannes Endreß, München 2010, S. 70-95, hier S. 87). Inszeniert wird dies etwa in der Übergabe der Gesetzestafeln: „Und als der HERR mit Mose zu Ende geredet hatte auf dem Berge Sinai, gab er ihm die beiden Tafeln des Gesetzes; die waren aus Stein und beschrieben von dem Finger Gottes“ (Ex 31,18). Vgl. zur Offenbarung im Modus des Geheimniss A. Assmann u. J. Assmann, Geheimnis und Offenbarung, S. 8-9.

51 Benjamin, Über Sprache überhaupt, S. 146.

52 Scholem, Walter Benjamin und sein Engel, S. 87. Vgl. auch Winfried Menninghaus, Schwellenkunde. Walter Benjamins Passage des Mythos, Frankfurt am Main 1986, S. 56.

53 So spricht Sami Khatib von „[d]em mittlerweile kanonischen Charakter des Benjaminschen Texts, der sich im permanenten Aufrufen des autoritären Zitats bestätigt und endlos verdoppelt“ (Sami Khatib, „Teleologie ohne Endzweck“. Walter Benjamins Ent-stellung des Messianischen, Marburg 2013, S. 23).

54 Benjamin, Über Sprache überhaupt, S. 147. So erfolgen die Erklärungen teils, ihrem okkulten Charakter gemäß, personenungebunden; sie überschreiten das biographische Erleben und 
tus der Veröffentlichung stehen allerdings unklare Referenzen, die Wiederholbarkeit und damit einhergehende Differenz der Offenbarung und nicht zuletzt der für die Rezipientinnen und Rezipienten geheim bleibende Name entgegen. Indem dieser nicht für Publikationen verwendet, vielmehr nach seiner Verbergung gewandelt „laut wird“ (AS 522, zweite Fassung), ist er dezidiert nicht mit der Schrift verbunden, sondern mit dem Hören als zentraler Figur der Offenbarung. ${ }^{55}$ Auch der Text selbst weist eine Widerständigkeit gegenüber seiner Publikation auf: Von Benjamin nicht für die Öffentlichkeit bestimmt, ${ }^{56}$ wurde er dieser erst vierzig Jahre nach seiner Abfassung zugänglich. ${ }^{57}$

Nicht ohne Grund also fallen in der Rezeption von „Agesilaus Santander“ immer wieder Begriffe aus dem Sinnbezirk des Geheimnisses und der Verschlüsselung. Gleichzeitig geht es in dem Text um Publikationen, also Veröffentlichungen, Offenbarungsgeschehen und Ans-Licht-Treten. Hier wird deutlich, dass der Engel nicht nur für die Semantik, sondern auch für den Modus des Textes prägend ist. Denn im „Engelhaften“ ist nicht nur der Name, sondern auch das Geheimnis „zuständig“. Der Engel versinnlicht das göttliche Mysterium, das in der lateinischen Übersetzung sacramentum - Geheimnis - heißt. Er ist Träger des Geheimnisses, trägt dieses aber zugleich nach außen und veröffentlicht es damit. Wenn man so will „publiziert“ der Engel göttliche Inhalte, die bis dahin verborgen waren, insbesondere in seiner Funktion als Verkündigungsengel. Diese Ambivalenz zwischen Geheimnis und Veröffentlichung ist der Form des Geheimnisses selbst eingeschrieben, denn von einem absoluten Geheimnis weiß niemand. Damit das Geheimnis als Geheimnis bekannt ist, braucht es Eingeweihte und Nichteingeweihte.

Die entgegengesetzte Bewegung des Geheimhaltens ist das Offenbaren von etwas, das bisher verborgen war. Das im Tanach dafür verwendete Verb lautet גלה , das häufig in nichttheologischem Sinn gebraucht wird. Neben „offenba-

transportieren eine Form höheren Wissens: „Er [der Name, L.Z.] bleibt darum [trotz der Offenbarung des Wandels des Namens, L.Z.] nicht weniger der Name, der alle Lebenskräfte in sich faßt, bei welchem sie beschworen und vor Unberufenen behütet werden“ (AS 520, erste Fassung).

55 Vgl. Weigel, Grammatologie der Bilder, S. 423.

56 Vgl. van Gerwen, Walter Benjamin auf Ibiza, S. 971.

57 Schließlich reflektiert diese Ausstellung von (Nicht-)Öffentlichkeit auch Benjamins komplexes Selbstverständnis als Kritiker. So stellt Heinrich Kaulen fest: „Sein Denken bewegt sich offenbar zwischen zwei verschiedenen, ja entgegengesetzten Polen, zwischen der esoterischen Abkehr von der Öffentlichkeit und dem um so entschiedeneren Bekenntnis zu unbeschränkter exoterischer Geltung“ (Heinrich Kaulen, Der Kritiker und die Öffentlichkeit. Wirkungsstrategien im Frühwerk und im Spätwerk Walter Benjamins. In: global benjamin, Bd. 2, hg. von Klaus Garber u. Ludger Rehm, München 1999, S. 918-942, hier S. 920). 
ren“ heißt es so viel wie „(sich) aufdecken“, „(sich) entblößen“, aber auch „in die Verbannung gehen (müssen)“.$^{58}$ In dieser letzten Bedeutung wird es im Zusammenhang mit dem babylonischen Exil verwendet. Auch auf sprachlicher beziehungsweise religiöser Ebene wird also der Exilkontext aufgerufen, der die Abfassung von „Agesilaus Santander“ prägt. Der Verbindung des Engels zum Geheimnis entgegengesetzt ist die Tätigkeit des angelus interpres, der bei der Entschlüsselung dunkler göttlicher Worte behilflich ist. Mit diesem Oszillieren zwischen dem Modus des Geheimnisses im Sinne verdunkelten Entzogenseins und dem Modus der Veröffentlichung als veräußerlichte Klarheit spiegelt der Engel die konstitutive Form von „Agesilaus Santander“.

Damit hängt auch eine mediale Differenz zusammen. Die Angelophanie lässt sich nicht entschlüsseln, sie ist geprägt durch den ästhetischen Überschuss, der für das Geheimnis charakteristisch ist. Die hermeneutische Praxis des Deuteengels hingegen richtet sich auf Wörter, deren dunkle Bedeutung sich in dem menschlichen Verstand zugängliche Botschaften übersetzen lässt. Mit diesem Dualismus verwandt ist die Spannung von Geheimnis und Rätsel. Während das Geheimnis Teil der visuellen Sphäre ist und sich im Zuge einer Entschleierung offenbart, handelt es sich bei dem Rätsel um ein „Sprachereignis“59, das auf sein Lösungswort wartet. Dem Geheimnis wird sakraler Ernst zugeschrieben, es ist verbunden mit einer Initiation, die die Nichtwissenden ausschließt. Das Rätsel hingegen ist profan, voll Witz und öffentlich allen Rätselfreudigen zugänglich. ${ }^{60}$ Jochen Hörisch vertritt die These, dass sich im 19. Jahrhundert das Kräfteverhältnis von dem für die Epoche der Transzendentalphilosophie charakteristischen Geheimnis hin zum Rätsel als Paradigma „eines (de-)chiffriersüchtigen Zeitalters“61 verschiebe. Dass in „Agesilaus Santander“ entgegen diesem Trend das Geheimnis so unleugbar am Werk ist, liegt an der ästhetischen Dimension des Engels, die sich der auslegenden entgegenstellt. Teil des Geheimnis-Paradigmas sind außerdem Name, Bild und Blick

58 Vgl. Hebräisches und aramäisches Wörterbuch zum Alten Testament, hg. von Georg Fohrer, Berlin; New York 1997, S. 49.

59 Hörisch, Vom Geheimnis zum Rätsel, S. 162.

60 Vgl. Hörisch, Vom Geheimnis zum Rätsel, S. 162. Ohne dies explizit zu machen, verwendet Galili Shahar die entsprechenden Begriffe secret und riddle gemäß eben dieser Bedeutungsabgrenzung, die zugleich die unterschiedlichen Zugänge zu „Agesilaus Santander“ illustriert: „[T]he literary ,value of Benjamin's text, its poetic possibilities, its openness, ist autonomy, its readability, depend upon the secret of the names. Scholem, however, attempts to solve Benjamin's poetic riddle in historical and biographical contexts" (Shahar, In the Name of the Devil, S. 104).

61 Hörisch, Vom Geheimnis zum Rätsel, S. 163. 
sowie die Ähnlichkeit, die einer begrifflichen Entzauberung des Geheimnisses den Weg versperren. ${ }^{62}$

Benjamin selbst thematisiert das Verhältnis von Rätsel und Geheimnis in dem Fragment „Über das Rätsel und das Geheimnis“ (etwa 1920/1921). Im Gegensatz zum Geheimnis ist das Rätsel Ausdruck des menschlichen Mutwillens: „Das Rätsel entsteht da, wo mit Nachdruck eine Intention darauf sich regt, ein Gebild oder einen Vorfall, der nichts Sonderbares oder schlechterdings überhaupt garnichts zu enthalten scheint, der symbolisch-bedeutenden Sphäre anzunähern.“63 Der „Schein des Geheimnisses“"64 vermag sich nur so lange zu halten, wie das Rätsel nicht gelöst ist. Für diesen subjektiven Schein gibt es aber doch einen objektiven Grund, der nicht in der Geheimnishaftigkeit von „Gebild“ oder „Vorfall“, sondern darin liegt, „daß sie 〈,〉 wie alles Seiende, am Geheimnis Anteil haben“65. Dieser Anteil gilt Benjamin im Bereich des Profanen als ein bedingter - im Rätsel ist er an die Lösung gebunden, im Wort an die Bedeutung. Das Rätselwort ist daher nicht nur die Lösung des Rätsels und damit das, was den subjektiven Schein des Geheimnisses zerstört, „sondern Intention, 〈nämlich〉 zugleich auch deren Bedingung, deren Grundlage und die ,Erlösung“ der versteckten Intention aufs Unlösbare in ihm“"66. Der Grund für diese Doppelheit liegt darin, dass im Wort, „,welches als solches schon ,Rätselwort' ist, ein symbolischer $\langle$,$\rangle jenseits des in ihm mitgeteilten gründender Kern, das$ Symbol einer Nicht-Mitteilbarkeit ruht“67. Indem alles Seiende im (Rätsel-)Wort am Geheimnis teilhat und dieses Wort in sich einen symbolischen und damit geheimnisvollen Kern trägt, sind Rätsel und Geheimnis miteinander verwoben. Die Differenz zwischen beiden wird in den letzten Sätzen des Fragments verhandelt, und zwar, für „Agesilaus Santander“ entscheidend, in Relation zum Namen:

Die Namengebung des Adam an die Tiere in der Genesis richtet sich gegen die mythische Auffassung des Namens als eines Rätsels, das zu raten aufgegeben wird, wie z. B. in der ,Regentrude، von 〈Theodor〉 Storm und sonst in Märchen es vorkommt. Der jüdische Name (der hebräische) ist ein Geheimnis. ${ }^{68}$

62 Jochen Hörisch verweist etwa auf das „herrschende Blick-Paradigma und die ihm liierte Hochschätzung des Geheimnisses“ um 1800 (Hörisch, Vom Geheimnis zum Rätsel, S. 163).

63 Walter Benjamin, Über das Rätsel und das Geheimnis. In: Benjamin, Gesammelte Schriften, Bd. VI, hg. von Rolf Tiedemann u. Hermann Schweppenhäuser, Frankfurt am Main 1991, S. $17-18$, hier S. 17.

64 Benjamin, Über das Rätsel und das Geheimnis, S. 17.

65 Benjamin, Über das Rätsel und das Geheimnis, S. 17.

66 Benjamin, Über das Rätsel und das Geheimnis, S. 18.

67 Benjamin, Über das Rätsel und das Geheimnis, S. 18.

68 Benjamin, Über das Rätsel und das Geheimnis, S. 18. 


\subsubsection{Unmittelbarkeit von Name und Engel}

Die Konsequenzen, die mit dem Lautwerden des gewandelten geheimen Namens in „Agesilaus Santander“ einhergehen, lassen sich nicht letztgültig bestimmen. Das liegt daran, dass die maskulinen Personalpronomen sich auf den alten Namen, den neuen Namen, den männlichen Erzähler und den Engel (als Bild des Namens oder als eigenständigen Akteur) beziehen können:

Doch keineswegs ist dieser Name eine Bereicherung dessen, der ihn führt. Vieles entzieht er ihm, vor allem aber die Gabe, ganz der Alte zu erscheinen. Im Zimmer, welches ich zuletzt bewohnte, hat jener, eh er aus dem alten Namen gerüstet und geschient ans Licht trat, sein Bild bei mir befestigt: Neuer Engel.

(AS 520/521, erste Fassung)

Doch keineswegs ist dieser Name eine Bereicherung dessen, den er nennt. Im Gegenteil, von dessen Bild fällt vieles ab wenn er laut wird. Es verliert $\langle$,$\rangle vor allem, die Gabe, men-$ schenähnlich zu erscheinen. Im Zimmer, das ich in Berlin bewohnte, hat jener, ehe er aus meinem Namen gerüstet und geschient ans Licht trat, sein Bild an der Wand befestigt: Neuer Engel.

(AS 522, zweite Fassung)

Das irisierende Verhältnis von Name und Träger zeigt sich in der Inversion der Subjekt-Objekt-Beziehung. Während der Träger in der ersten Fassung Subjekt ist („Doch keineswegs ist dieser Name eine Bereicherung dessen, der ihn führt“), verkehrt sich diese Relation in der zweiten (,Doch keineswegs ist dieser Name eine Bereicherung dessen, den er nennt“). ${ }^{69}$ Die Ambiguisierung, die der geheime Name bewirkt, bezieht sich in der ersten Fassung auf eine identitäre, in der zweiten hingegen auf eine generische Einheit: Der Träger des Namens (erste Fassung) oder dessen Bild beziehungsweise das Bild des Namens (zweite Fassung, verschiedene Lesarten) verliert vieles, vor allem „die Gabe, ganz der Alte zu erscheinen“ (erste Fassung) respektive „die Gabe, menschenähnlich zu erscheinen“ (zweite Fassung). Zu der Spaltung von Sein und Bild tritt eine weitere. In beiden Versionen trifft der mit dem Namen einhergehende Verlust nicht das Sein, sondern das Erscheinen. Das erste Bild der zweiten Fassung ist doppeldeu-

69 Auch das diffuse Verhältnis von Subjekt und Objekt folgt der Logik des Geheimnisses: Es ist „gerade das Unauflösliche zwischen Objekt und Subjekt, Allgemeinem und Individuellem im Geheimnis beschlossen [...], dem auch durch keine methodische Reflexion entkommen werden kann“ (Manfred Voigts, Thesen zum Verhältnis von Aufklärung und Geheimnis. In: Schleier und Schwelle. Archäologie der literarischen Kommunikation V, Bd. 2: Geheimnis und Offenbarung, hg. von Aleida Assmann u. Jan Assmann, München 1998, S. 65-80, hier S. 76). Die wiederholte Diffundierung von Subjekt-Objekt-Verhältnissen lässt sich als programmatischer Verweis auf Benjamins epistemische Aushebelung dieser Trennung lesen (vgl. Hermann Schweppenhäuser, Physiognomie eines Physiognomikers. In: Zur Aktualität Walter Benjamins, hg. von Siegfried Unseld, Frankfurt am Main 1972, S. 139-171, hier S. 153). 
tig. Es lässt sich auf den Träger des Namens beziehen, was als erneutes Aufgreifen des ersten „dessen“ sowie aufgrund der Satzsemantik durchaus plausibel erscheint, aber auch auf den (neuen) Namen selbst, wie Scholem es tut. ${ }^{70}$ Sowohl der angelisch-auratische Modus der Erscheinung als auch die Ebenenpotenzierung durch das Bild weisen auf den Engel, dessen Auftritt mit einer weiteren Verunklarung der Bezüge einhergeht. Nach Scholems Lesart vollzieht sich hier die luziferische Verwandlung, da das Bild sich nicht Angelus Satanas nennt, „obwohl es das ist, sondern: Neuer Engel“"71, wodurch der Topos der satanischen Engelstäuschung aufgegriffen wird. ${ }^{72}$ Nachdem Werner Fuld 1978 gezeigt hatte, dass die zusätzlichen Namen Benjamins keine Fiktion sind, ${ }^{73}$ wird das Ganze noch einmal komplizierter: Der Name Benedix Schönflies wird nach Scholem nun anlässlich der Liebesbeziehung zu Jula Cohn von dem Namen Agesilaus Santander mit der wahren Bedeutung „der Angelus Satanas“ verdrängt. Als Bild dieses Namens gilt Scholem das Klee-Bild, in dem der neue Name sich „niederließ“74, wobei der Name zugleich auch im Namen dieses Bilds, nämlich Angelus Novus, „verhüllt“"75 sein soll.

Auch die Frage, wer das Bild aufhängt, ist strittig: So liest Jochen Hörisch die Stelle folgendermaßen: „Im Zimmer, das ich in Berlin bewohnte, hat jener [geheime anagrammatische Name, J.H.], ehe er aus meinem Namen gerüstet und geschient ans Licht trat, sein Bild an der Wand befestigt: Neuer Engel.“76 In dieser anaphorischen Lesart wird das „jener“ rückbezogen auf den (gehei-

70 Vgl. Scholem, Walter Benjamin und sein Engel, S. 114. Vgl. auch van Gerwen, Walter Benjamin auf Ibiza, S. 973.

71 Scholem, Walter Benjamin und sein Engel, S. 115.

72 Vgl. die folgende Bibelstelle: „[...] denn er selbst, der Satan, verstellt sich als Engel des Lichts“ (2. Kor 11,14). Die Behauptung, „[d]aß dies in Benjamins Sinne nicht der wahre Name war“, begründet Scholem so: „Denn der Engel ,gab sich als neuer aus‘, der zu denen gehörte, deren einzige Funktion in einer Hymne vor Gottes Thron besteht, ,ehe er sich nennen wollte““ (Scholem, Walter Benjamin und sein Engel, S. 115). Für sein Argument muss er allerdings die zweite Fassung etwas abwandeln. Die Formulierung „gab sich als neuer aus“ findet sich in seiner eigenen Transkription nicht, dort heißt es (wie auch in der Druckfassung von Tiedemann und Schweppenhäuser): „Als solchen [einen der hymnensingenden und vergehenden, L.Z.] Engel gab der Neue sich aus ehe er sich nennen wollte“ (Scholem, Walter Benjamin und sein Engel, S. 101). Hier ist das Attribut des Neuen also keine Behauptung des Engels, sondern wird diesem im Text selbst zugesprochen.

73 Vgl. Werner Fuld, Agesilaus Santander oder Benedix Schönflies. Die geheimen Namen Walter Benjamins. In: Neue Rundschau, 89, 1978, S. 253-263.

74 Scholem, Walter Benjamin und sein Engel, S. 115.

75 Scholem, Die geheimen Namen Walter Benjamins, S. 76. Vgl. auch Lang, Mimetisches oder semiologisches Vermögen?, S. 259.

76 Hörisch, Vom Geheimnis zum Rätsel, S. 173. 
men) Namen. Nach Manfred Schneider hingegen hat „,[d]iesen Angelus [...] der Träger des alten Namens (erg. Benedix Schönflies) als sein Bild an der Wand des Zimmers, das er in Berlin bewohnte, befestigt, ehe er ,aus meinem Namen gerüstet und geschient ans Licht trat' (VI, 522). Der Angelus ist mithin das Bild des alten Namens. “77 In diesen verschiedenen Lesarten, die ihre Kontingenz nicht reflektieren, potenziert sich die in Benjamins Text angelegte Uneindeutigkeit. Denn nach Jochen Hörisch ist der anagrammatische Name der Akteur, der aus dem alten Namen ans Licht tritt (dieser Vorgang wäre dann die anagrammatische Verwandlung) und zuvor den Engel als sein Bild an der Wand befestigt hat. Nach Manfred Schneider hingegen ist es der Träger des alten Namens, der den Engel als Bild des alten Namens an der Wand befestigt; wer oder was aus diesem hervortritt, ist hier mindestens so rätselhaft wie in Benjamins Text: „Dann aber trat aus diesem alten Namen derjenige ,gerüstet und geschient‘ ans Licht, der jetzt als ein anderer spricht.“78 Schneider scheint hier implizit für eine innere Spaltung des Namensträgers zu plädieren, da sich für seine Lesart sowohl das „ich“ (als Zimmerbewohner - „[i]m Zimmer, das ich in Berlin bewohnte“) als auch das ,jener“ (als Bilderbefestiger - „hat jener [...] sein Bild an der Wand befestigt“) auf den Namensträger beziehen müssten. Das erscheint nicht völlig abwegig in Anbetracht dessen, dass auf den erlebenden Mann sowohl in Ich- als auch in Er-Form rekurriert wird; es wird aber nicht unbedingt nahegelegt, denn in diesem Fall würde sich der Wechsel innerhalb eines Satzes unmarkiert vollziehen.

Neben diesen Lesarten lässt sich aber auch grammatikalisch stimmig die Perspektive auf den Engel als Akteur einnehmen. Dieser wäre dann nicht, wie bei Scholem, Hörisch und Schneider, nur als Bild zu verstehen, sondern als Handelnder, der sein eigenes Bild (weder das des alten noch des neuen Namens) an der Wand befestigt und als Kulminationspunkt erst zum Schluss genannt wird (nach dieser Lesart wären „,jener“, „er“ und „sein“ kataphorisch zu verstehen): „Im Zimmer, das ich in Berlin bewohnte, hat jener, ehe er aus meinem Namen gerüstet und geschient ans Licht trat, sein Bild an der Wand befestigt: Neuer Engel." Hier wäre weniger die Wandlung des Namens als vielmehr das In-Erscheinung-Treten des Engels das Thema. Diese Lesart hat den Vorzug, dass sich sämtliche maskulinen Pronomen auf ein Referenzobjekt beziehen, nämlich den Engel. Allerdings wirft sie mit der Trennung von Engel und seinem Bild ontologische Fragen auf. Der Name als eine Art Geburtsstätte des Engels und das Ans-Licht-Treten als Seinswerdung evozieren eine Vorstellung von Ursprung und Vorgängigkeit, die hier nicht greift.

77 Schneider, Aufzeichnungen, S. 671.

78 Schneider, Aufzeichnungen, S. 671. 
Die hierarchische Ordnung von Sein und Bild, von Signifikat und Signifikant kollabiert: Nicht der Engel ist zuerst - im emphatischen Sinne des Ans-Licht-Tretens - da, sondern sein Bild, das er gleichwohl selbst befestigt hat (insofern tritt vor das Bild die Dynamik der Handlung), und dessen Vorrangigkeit gegenüber der Nachträglichkeit des Ans-Licht-Tretens als Ursprung auch durch die Satzstruktur betont wird. Diese Unbestimmtheit der Pronomen im Zusammenhang mit einem Engel hat einen biblischen Vorläufer. In der Episode von Jakobs Kampf mit einer unbekannten Macht, die häufig als Engel identifiziert wird, findet sich dieselbe „Verworrenheit“, die „dem austauschbaren Charakter der Pronomen [entspringt]“"79, wie Roland Barthes feststellt. In der Unschärfe des Textes verschleiert die Grammatik, wer in Jakobs Kampf wem nicht beizukommen vermag. Semantische Klarheit entsteht nur rückwirkend über den Schluss: „Du hast Gott besiegt. Derjenige, der zu dir spricht, ist der, den du besiegt hast. Der zu dir spricht, ist also Gott. “80 Auf diese Weise verläuft „die Lesbarkeit über Umwege“81 und damit über ein Paradigma, das in „Agesilaus Santander“ noch eine wichtige Rolle spielen wird.

Auch der Engel gehört zu diesem Umwegdenken. Indem Engel zunächst einer immateriellen Sphäre Gestalt verleihen und dann in einem zweiten Schritt bildlich dargestellt werden, sind sie Teil einer doppelten Bildwerdung. ${ }^{82}$ Entsprechend verschwimmen in „Agesilaus Santander“ im Engel Sein, Bild und Name, da offen bleibt, auf welcher Ebene von ihm die Rede ist. Gibt es ihn nur innerhalb seines Bilds (oder im Namen, das heißt im Titel dieses Bilds) beziehungsweise als Bild (des alten oder neuen Namens) oder auch losgelöst von diesem in anderer Seinsweise? Darüber hinaus werden aber auch diese Kategorien selbst dynamisiert. So löst sich das Bild, als das sich der Engel als Visualisierungsform des Göttlichen immer schon verstehen lässt, aus der subalternen Position des Verweisens auf ein Original. Diese Bewegung steht im Einklang mit der im Folgenden entwickelten Lesart der gesamten Textbewegung sowie Benjamins mit einem Urbild-Abbild-Schema allegorisch brechenden Bildverständnis. ${ }^{83} \mathrm{Zu}$ einer solchen bildhaften Konstellation verdichtet sich an dieser

79 Barthes, Der Kampf mit dem Engel, S. 256.

80 Barthes, Der Kampf mit dem Engel, S. 256.

81 Barthes, Der Kampf mit dem Engel, S. 256.

82 Vgl. Weigel, Grammatologie der Bilder, S. 324.

83 Vgl. etwa Sigrid Weigel, Entstellte Ähnlichkeit. Walter Benjamins theoretische Schreibweise, Frankfurt am Main 1997, S. 57, Stefano Marchesoni, Walter Benjamins Konzept des Eingedenkens. Über Genese, Stellung und Bedeutung eines ungebräuchlichen Begriffs in Benjamins Schriften, Trient; Berlin 2013, S. 59-61 oder Dominik Finkelde, Benjamin liest Proust. Mimesislehre - Sprachtheorie - Poetologie, München 2003, S. 16. 
Stelle auch der Text, dessen grammatikalische Un- eine semantische Überdeterminiertheit erzeugt.

Unabhängig von der präferierten Lesart sollte deutlich geworden sein, dass sich in der entscheidenden Wandlungsszene von „Agesilaus Santander“ syntaktisch verschiedene Verbindungen herstellen lassen. Sie können durch den Gesamtkontext weder verifiziert noch falsifiziert werden, da ein konsistenter semantischer Zusammenhang fehlt. Dies ist, so die These, Ausdruck einer theoretischen Grammatik, die hier im Modus der autobiographischen Erzählung entwickelt wird. In der unauflösbaren strukturellen Mehrdeutigkeit spiegelt sich die Schwellenerfahrung (wiederholbaren) Mannbarwerdens als Übergang, der mit Unsicherheit verbunden ist. Das gilt gleichermaßen für die Sprache, die für Benjamin „nicht allein Mitteilung des Mitteilbaren, sondern zugleich Symbol des Nicht-Mitteilbaren“"84 ist. Bei der Frage, wie genau das Verhältnis von Name, Namensträger, Bild und Engel beschaffen ist, stößt ein referentielles Lesen, das auf Eindeutigkeit abzielt, an seine Grenzen. ${ }^{85}$ In der Fokussierung der Schwelle zwischen Öffentlichkeit und Geheimnis sowie zwischen den Medien Schrift, Laut und Bild sind vermeintlich klare Hierarchien, repräsentationslogische Strukturen und damit verbundene ontologische Wertigkeiten außer Kraft gesetzt. Name, Bild und Engel, alle mit mimetischem Vermögen ausgestattet und für gewöhnlich in Abhängigkeit von einer anderen Größe gedacht (Name und Bild von etwas beziehungsweise jemandem, der Engel als Medium Gottes), haben sich hier aus ihren angestammten Bezugsverhältnissen gelöst. In dieser Emanzipierung mimetischer Figuren liegt eine autoreflexive Bewegung, die sich gegen die Rückführung auf textexterne Wesens- und Anfangsgründe durch eine hermeneutische Domestizierung von Name, Bild und Engel wendet.

Das Bestreben, dem Namen in „Agesilaus Santander“ einen eindeutigen Aussagegehalt abzugewinnen, richtete sich, wie gezeigt, vornehmlich auf Benjamins Privatleben. Derartige Lesarten folgen der Annahme, dass hinter dem Namen im Text eine tiefere Bedeutungsebene liegt, die eine Art hermeneutischen Generalschlüssel zum Wesen des Namensträgers wie der Interpretation des Textes darstellt. ${ }^{86}$ Eine solche Identität zwischen Name und Träger dementiert Benjamin aber in seiner Lektüre des ersten Genesiskapitels in „Über Spra-

84 Benjamin, Über Sprache überhaupt, S. 156.

85 Vgl. die Beschreibung von Verena Lenzen: „Im Stil der meditativen Bildbetrachtung lässt Benjamin den Engel im Agesilaus Santander aus dem Rahmen in den Raum zu seinem Betrachter schweben und identifiziert sich gleichzeitig mit dem Neuen Engel“ (Lenzen, Benjamins Engel, S. 448). In einer solchen Lesart bleiben die wichtigen Fragen der Zuordnung, der zeitlichen Relation, der nichtidentitären Beziehungen und der Widerständigkeit des Engels unberücksichtigt.

86 Vgl. Stiegler, Die Aufgabe des Namens, S. 14. 
che“: „Es sollte im strengen Geist auch kein Mensch dem Namen (nach seiner etymologischen Bedeutung) entsprechen, denn der Eigenname ist Wort Gottes in

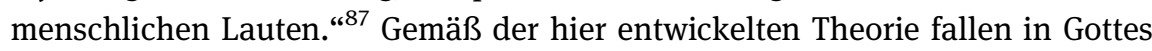
Sprache schöpferisches Wort und erkennender Name zusammen. Daher ist es möglich, dass in der Schöpfung durch Gottes Wort die Dinge in ihrem Namen für den Menschen erkennbar werden und er sie auf der Grundlage dieser Erkenntnis benennt. ${ }^{88}$ Die Relation zwischen schaffendem Gott und erkennendem Menschen ist über das Bild vermittelt: „Gott schuf ihn [den Menschen, L.Z.] sich zum Bilde, er schuf den Erkennenden zum Bilde des Schaffenden." ${ }^{899}$ Auch der Eigenname ist (Ab-)Bild, wenngleich nicht im Sinne eines strengen Entsprechungsverhältnisses: „Das tiefste Abbild dieses göttlichen Wortes und der Punkt, an dem die Menschensprache den innigsten Anteil an der göttlichen Unendlichkeit des bloßen Wortes erlangt, der Punkt, an dem sie nicht endliches Wort und Erkenntnis nicht werden kann: das ist der menschliche Namen.“90

Die Bildlichkeit ist hier im Wirkungsbereich des Göttlichen eine vor jedem Bruch der Repräsentation. Wie die Offenbarung ist nämlich „[d]er Name [...] dasjenige, durch das sich nichts mehr, und in dem die Sprache selbst und absolut sich mitteilt“91. Neben dem Modus des Bilds als privilegiertem Medium von Wahrnehmung und Erkenntnis, die bei Benjamin im Kern der Sprache statthat, ${ }^{92}$ besteht eine weitere Ähnlichkeit zwischen Engel und Name in ihrer Figuration von (Meta-)Medialität. Während es sich bei Engelsdarstellungen um Darstellungen der Darstellung des Undarstellbaren handelt, heißt es in „Über Sprache“: „Man kann den Namen als die Sprache der Sprache bezeichnen

87 Benjamin, Über Sprache überhaupt, S. 150.

88 Vgl. Benjamin, Über Sprache überhaupt, S. 148. Benjamin verweist später darauf, dass das Benennen des Menschen ein eigenständiger Vorgang ist: „Aber offenbar ist diese [Gottes, L.Z.] Benennung nur der Ausdruck der Identität des schaffenden Wortes und des erkennenden Namens in Gott, nicht die vorhergenommene Lösung jener Aufgabe, die Gott ausdrücklich dem Menschen selbst zuschreibt: nämlich die Dinge zu benennen“ (Benjamin, Über Sprache überhaupt, S. 151). Nur in Gottes Wort erhalten die Dinge einen Eigennamen, in der menschlichen Sprache hingegen sind sie ,überbenannt“ (Benjamin, Über Sprache überhaupt, S. 155).

89 Benjamin, Über Sprache überhaupt, S. 149.

90 Benjamin, Über Sprache überhaupt, S. 149.

91 Benjamin, Über Sprache überhaupt, S. 144.

92 Vgl. die Erläuterung von Stephanie Waldow: „Bildlichkeit meint in diesem Zusammenhang [Benjamins Bildbegriff, L.Z.] nicht ein vor- oder außersprachliches Phänomen, sondern bezeichnet vielmehr jene der Sprache innewohnenden Kräfte, die aufgrund der Inanspruchnahme durch die bloße Mitteilungsfunktion verborgen sind“ (Stephanie Waldow, Der Mythos der reinen Sprache. Walter Benjamin, Ernst Cassirer, Hans Blumenberg. Allegorische Intertextualität als Erinnerungsschreiben der Moderne, München 2006, S. 105-106). 
(wenn der Genitiv nicht das Verhältnis des Mittels, sondern des Mediums bezeichnet).“93 Auch in „Agesilaus Santander“ haben „Bild und Sprache [...] den Vortritt“, und das „[n]icht nur vor dem Sinn. Auch vor dem Ich“94, wie Benjamin über die Frühphase des Surrealismus schreibt. Der Eigenname entzieht sich seinem Träger ebenso wie jedem Sinnkorsett. Darin stellt er „eine Zäsur oder ein[en] Bruch im Prozeß der Signifikation“95 dar. In dieser Unterbrechung lässt sich mit Ernesto Laclau zugleich der Ermöglichungsgrund von Signifikation überhaupt erkennen:

Wie auch immer besteht das Problem darin, daß die eigentliche Voraussetzung der Signifikation das System ist und die eigentliche Voraussetzung des Systems dessen Grenzen sind. [...] Aber wenn wir über die Grenzen eines Bezeichnungssystems sprechen, ist klar, daß dessen Grenzen nicht selbst bezeichnet werden können, sondern sich selbst zeigen müssen als die Unterbrechung oder der Zusammenbruch des Prozesses der Signifikation. So stehen wir vor der folgenden paradoxen Situation: Was die Bedingung der Möglichkeit eines Bezeichnungssystems bildet - seine Grenzen -, bildet auch die Bedingung seiner Unmöglichkeit - eine Blockade der fortgesetzten Ausweitung des Bezeichnungsprozesses. ${ }^{96}$

Die Konsequenz liegt darin, dass das „Geheimnis des Personennamens“97 nicht nur der Aufrechterhaltung der „poetic texture of language“98 oder der Rettung einer Schwundstufe des Arkanen in der Moderne dient, sondern auch die Voraussetzung von bedeutungstragender Sprache überhaupt ist. Die programmatische Offenheit des Textes und die irreduzible Vordergründigkeit von Medialität, die sich in der Vordergründigkeit von Name, Bild und Engel kristallisiert, verweist auf Sprache in ihrer Unendlichkeit und epistemologischen Unhintergehbarkeit. ${ }^{99}$ Dies drückt sich aus im Prinzip des Umwegs, das Name, Bild und Engel in den

93 Benjamin, Über Sprache überhaupt, S. 144-145. Bernd Stiegler sieht in dem Eigennamen als der „Idealform“ des Namens eine weitere Ebenenpotenzierung realisiert (Stiegler, Die Aufgabe des Namens, S. 27); ist „der Name Sprache der Sprache, so ist der Eigenname Sprache der Sprache der Sprache oder Name des Namens“ (Stiegler, Die Aufgabe des Namens, S. 30).

94 Walter Benjamin, Der Sürrealismus. Die letzte Momentaufnahme der europäischen Intelligenz. In: Benjamin, Gesammelte Schriften, Bd. II.1, hg. von Rolf Tiedemann u. Hermann Schweppenhäuser, Frankfurt am Main 1991, S. 295-310, hier S. 297.

95 Stiegler, Die Aufgabe des Namens, S. 30.

96 Ernesto Laclau, Was haben leere Signifikanten mit Politik zu tun? In: Laclau, Emanzipation und Differenz, Wien; Berlin 2010, S. 65-78, hier S. 66.

97 Walter Benjamin, Das Passagen-Werk. Gesammelte Schriften, Bd. V, hg. von Rolf Tiedemann, Frankfurt am Main 1982, S. 1036.

98 Shahar, In the Name of the Devil, S. 110.

99 Die Unendlichkeit der Sprache hängt für Benjamin mit ihrer Unmittelbarkeit zusammen, denn ,weil durch die Sprache sich nichts mitteilt, kann, was in der Sprache sich mitteilt, nicht von außen beschränkt oder gemessen werden, und darum wohnt jeder Sprache ihre inkommensurable einziggeartete Unendlichkeit inne“ (Benjamin, Über Sprache überhaupt, S. 143). 
Text tragen. Gleichzeitig unterbrechen und (zer-)stören sie Sinnzusammenhänge und stellen so eine notwendige Begrenzung der Sprache her. Nimmt man Benjamins sprachphilosophische Konzeption des Eigennamens ernst, dann kann der Name in „Agesilaus Santander“ ebenso wenig aufgehen in einer Auflösung ohne Rest, wie er sich funktional über eine geliebte Adressatin stillstellen lässt. Folglich resultieren die Schwierigkeiten, anhand des ungenannten Namens zu einer definiten Bedeutung vorzudringen, nicht aus fehlenden Informationen. Vielmehr ist es der Name selbst, der diese Versuche in seiner nichtinstrumentellen Medialität zum Scheitern verurteilt.

\subsubsection{Der Engel als Zerstörer und Bewahrer des Humanen}

Dominiert im ersten Teil von „Agesilaus Santander“ der Name, so tritt im zweiten Teil der Engel in den Vordergrund. In Benjamins Essay „Karl Kraus“ (1931) sind beide im Zitat verbunden: „Ein Wort zitieren heißt es beim Namen rufen“100, und im Zitat selbst „spiegelt sich [...] die Engelsprache, in welcher alle Worte, aus dem idyllischen Zusammenhang des Sinnes aufgestört, zu Motti in dem Buch der Schöpfung geworden sind“101. Sowohl im Zitat als auch in der Engelsprache geht es darum, das Wort „aus dem mythischen Zusammenhang des Bedeutens [zu] rufen“ ${ }^{102}$, wie Bettine Menke formuliert, und in diesem Zurückrufen an seinen Ursprung in der reinen Sprache eine Zerstörung des (Sinn-)Zusammenhangs vorzunehmen. Das Wort steht „als Name [...] einsam und ausdruckslos“103.

Das Ausdruckslose bestimmt Benjamin in „Goethes Wahlverwandtschaften“ (1922) als „kritische Gewalt“, die im Kunstwerk dem schönen Schein „Einhalt gebietet, die Bewegung bannt und der Harmonie ins Wort fällt“"104. Es

100 Benjamin, Karl Kraus, S. 362.

101 Benjamin, Karl Kraus, S. 363.

102 Bettine Menke, Sprachfiguren. Name - Allegorie - Bild nach Benjamin, Weimar 2001, S. 505 .

103 Benjamin, Karl Kraus, S. 363. Auch das Ausdruckslose verweist auf die Nähe des Namens zur reinen Sprache, „die nichts mehr meint und nichts mehr ausdrückt, sondern als ausdrucksloses und schöpferisches Wort das in allen Sprachen Gemeinte ist“ (Benjamin, Die Aufgabe des Übersetzers, S. 19). Bernd Stiegler bezeichnet die Namenssprache der Menschen als „eine Art Palimpsest der reinen Sprache“, wobei besonders im Eigennamen „die von Benjamin angenommene ursprüngliche (R)Einheit“ durchscheine (Stiegler, Die Aufgabe des Namens, S. 31).

104 Walter Benjamin, Goethes Wahlverwandtschaften. In: Benjamin, Gesammelte Schriften, Bd. I.1, hg. von Rolf Tiedemann u. Hermann Schweppenhäuser, Frankfurt am Main 1991, S. 125-201, hier S. 181. 
destruiert „die falsche, irrende Totalität“ und macht das Werk so zum „Fragmente der wahren Welt“105. Erst in seiner Zerstörung erfährt es Vollendung. Zwar stört das Ausdruckslose den Schein, allerdings bedeutet diese Stillstellung zugleich, dass das Schöne ins Unvergängliche gehoben wird: „In dieser Verewigung muß sich das Schöne verantworten, aber nun scheint es in eben dieser Verantwortung unterbrochen und so hat es denn die Ewigkeit seines Gehalts eben von Gnaden jenes Einspruchs. “106 Die Denkfigur, dass nur aus der Zerstörung Dauer entsteht, ist strukturell derjenigen verwandt, dass nur die Störung der Signifikation ihr Funktionieren ermöglicht. Sie verbindet Zitat und Engelssprache. Indem sie Wörter aus ihrem instrumentellen Sinn- und Referenzzusammenhang schlägt, trägt die Engelssprache ebenso wie das Zitat in sich die Kraft, „nicht zu bewahren, sondern zu reinigen, aus dem Zusammenhang zu reißen, zu zerstören; die einzige, in der noch Hoffnung liegt, daß einiges aus diesem Zeitraum überdauert - weil man es nämlich aus ihm herausschlug،107.

Dieses aktualisierende Herausschlagen aus dem Zusammenhang ereilt in „Agesilaus Santander“ auch ein Narrativ der mystischen Tradition: „Die Kabbala erzählt, daß Gott in jedem Nu eine Unzahl neuer Engel schafft, die alle nur bestimmt sind, ehe sie in Nichts zergehen, einen Augenblick vor seinem Thron sein Lob zu singen.“ (AS 521, erste Fassung) Hier ist es also der Engel, der zunächst einen unendlichen Kreislauf begründet. Was erst so entrückt klingt, wird im nächsten Satz sogleich gestört und profanisiert: „Meiner war dabei unterbrochen worden: seine Züge hatten nichts Menschenähnliches.“ (AS 521, erste Fassung) Das Zitat als das, was textuell herausgeschlagen wurde, spiegelt sich hier in der Figur der Unterbrechung auf inhaltlicher Ebene. Die Unterbrechung bestimmt Benjamin als „eines der fundamentalen Verfahren aller Formgebung“(108. In „Agesilaus Santander“ scheint die Unterbrechung

105 Benjamin, Goethes Wahlverwandtschaften, S. 181.

106 Benjamin, Goethes Wahlverwandtschaften, S. 181.

107 Benjamin, Karl Kraus, S. 365. So bezeichnet Benjamin das zerstörerische Dasein Karl Kraus' in seiner „gewaltige[n] Dialektik“ als „das heißeste Gebet um Erlösung [...], das heute über jüdische Lippen kommt“ (Walter Benjamin, Karl Kraus [Ästhetische Fragmente]. In: Benjamin, Gesammelte Schriften, Bd. II.2, hg. von Rolf Tiedemann u. Hermann Schweppenhäuser, Frankfurt am Main 1991, S. 624-625, hier S. 625). Ihren deutlichsten Ausdruck finde diese Dialetik darin, „daß dieser Mann, einer der verschwindend wenigen, die eine Anschauung von Freiheit haben, ihr nicht anders dienen kann, denn als oberster Ankläger“ (Walter Benjamin, Karl Kraus [Ästhetische Fragmente], S. 625).

108 Walter Benjamin, Was ist das epische Theater? (2) Eine Studie zu Brecht. In: Benjamin, Gesammelte Schriften, Bd. II.2, hg. von Rolf Tiedemann u. Hermann Schweppenhäuser, Frankfurt am Main 1991, S. 532-539, hier S. 536. Der Unterbrechung eignet bei Benjamin eine revolutionärmessianische Qualität („Die klassenlose Gesellschaft ist nicht das Endziel des Fortschritts in der Geschichte sondern dessen so oft mißglückte, endlich bewerkstelligte Unterbrechung“ (Walter 
eine erwartbare oder zumindest mögliche Menschenähnlichkeit als Resultat eines ungestörten Lobgesangs verhindert zu haben. Zuvor hieß es bereits über das Bild des Namens oder des Namensträgers, dass es bei dem Lautwerden des Namens die Gabe der menschenähnlichen Erscheinung einbüßt.

Auch der Verlust der Menschenähnlichkeit und die Kategorie des Unmenschlichen, die über den Engel als unmenschliche Figur aufgerufen werden, stehen in dem größeren Zusammenhang der in „Erfahrungsarmut“ entwickelten Zeitdiagnose, die wie „Agesilaus Santander“ im Sommer 1933 verfasst wurde. Die Armut als Signatur der Gegenwart ist „mit dieser ungeheuren Entfaltung der Technik über die Menschen gekommen“109. Aus dem Bekenntnis zu dem Mangel an Menschheitserfahrungen speist sich die Forderung nach Klarheit und Einfachheit als Gestaltungsprinzipen. Als Vertreter dieser Bewegung nennt Benjamin jene Denker und Künstler, die zerstören, um dann von und aus Neuem zu konstruieren, wie Descartes, Einstein, Klee oder Loos. ${ }^{110}$ Was technische Entwicklungen aus „den ehemaligen Menschen für gänzlich neue sehens- und liebeswerte Geschöpfe machen“"111, beschäftige Scheerbart in seinen Romanen; „die Menschenähnlichkeit - diesen Grundsatz des Humanismus - lehnen sie ab“112.

Folglich lässt sich die mangelnde Menschenähnlichkeit in „Agesilaus Santander“ nicht nur als Verweis auf dämonische Wesenszüge lesen, sondern kann vielmehr im Zusammenhang mit (technik-)geschichtlichen Entwicklungen und entsprechenden Reaktionsformen verstanden werden. ${ }^{113}$ In „Karl Kraus“ ist diese Ablehnung des klassischen Humanismus explizit mit dem Engel verbunden. Der Porträtierte selbst wird als eine Figur der Schwelle skizziert, die anthropologische Halbtonschritte des All-, Zwischen-, Unter- und Unmenschlichen bespielt. Er, der wie Shakespeares Timon „mit Menschen nichts mehr gemein haben“114 will, ist einerseits in seiner ahistorischen „Naturverhaftung“115 ein „Überläufer in das Lager der Kreatur“116, andererseits wird seinem Werk attestiert, es sei der „schnell

Benjamin, Druckvorlage: Benjamin-Archiv, Ms I098v. In: Benjamin, Gesammelte Schriften, Bd. I.3, hg. von Rolf Tiedemann u. Hermann Schweppenhäuser, Frankfurt am Main 1991, S. 1231).

109 Benjamin, Erfahrung und Armut, S. 214.

110 Vgl. Benjamin, Erfahrung und Armut, S. 215-216.

111 Benjamin, Erfahrung und Armut, S. 216.

112 Benjamin, Erfahrung und Armut, S. 216.

113 Insofern wäre hier Geret Luhr zu widersprechen, für den „Agesilaus Santander“ entgegen dem Postulat eines „neuen Barbarentums“ Ausdruck davon ist, dass Benjamin „der zurückgelassenen Tradition verhaftet“ bleibe (Geret Luhr, „was noch begraben lag“. Zu Walter Benjamins Exil. Briefe und Dokumente, Berlin 2000, S. 18).

114 Benjamin, Karl Kraus, S. 357.

115 Benjamin, Karl Kraus, S. 353.

116 Benjamin, Karl Kraus, S. 341. 
verfliegenden Stimme“ ${ }^{\text {117 }}$ der talmudischen Engel nachgebildet. Dem klassischen Humanismus Weimarer Prägung setzt Benjamin mit Marx einen „reale[n] Humanismus“"118 entgegen, der in seiner zerstörerisch-reinigenden Kraft die bürgerliche Hypostasierung des Natürlichen demaskiert. Diese Radikalisierungsbewegung wird anhand der Kraus zugeschriebenen Entwicklung nachgezeichnet. Als „große[r] bürgerliche[r] Charakter“119 habe dieser zunächst im Bann der Weimarer Humanität gestanden und sich erst spät von ihr gelöst - „daß es keine idealistische, sondern nur eine materialistische Befreiung vom Mythos gibt und nicht Reinheit im Ursprung der Kreatur steht, sondern die Reinigung, das hat in dem realen Humanismus von Kraus seine Spuren am spätesten hinterlassen““120 .

Da die Zeitung auch in ihren Mitteln von der Macht korrumpiert werde, „ist eine neue Blüte paradiesischer Allmenschlichkeit von einer ihm [dem Hochkapitalismus, L.Z.] obsiegenden Macht so wenig zu gewärtigen, wie eine Nachblüte goethescher oder claudiusscher Sprache“121. Stattdessen wird die Macht, die den Kapitalismus bezwingt, „Ideale, die jene [die herrschende Macht, L.Z.] entwürdigte, außer Kurs setz[en]“122. In der Suspendierung des entwürdigten Ideals ,paradiesischer Allmenschlichkeit“ ist das Gesicht dieses „realen Humanismus“ nicht mehr menschenähnlich. Folgerichtig wirkt „der Unmensch als der Bote realeren Humanismus unter uns“123. Er ,ist die Überwindung des mythischen Menschen (und daher Engel)“124. Diese Form der „Humanität [...], die sich an der Zerstörung bewährt“, verkörpert sich in Klees „Neue[m] Engel““125 als Figur des Unmenschlichen, der die Befreiung von dem mythischen Bann durch Zerstörung gegen das vermeintliche Glück des Besitzens setzt - er ist der Engel, der „die Menschen lieber befreite, indem er ihnen nähme, als beglückte, indem er ihnen gäbe“"126. Er stellt den Zustand der positiv gewendeten Armut her und zwar in der Vernichtung des „Zwischen- oder Untermenschliche[n]“"127 des Dämons mit seinen Zweideutigkeiten. ${ }^{128}$

117 Benjamin, Karl Kraus, S. 367.

118 Benjamin, Karl Kraus, S. 364.

119 Benjamin, Karl Kraus, S. 365.

120 Benjamin, Karl Kraus, S. 365.

121 Benjamin, Karl Kraus, S. 344.

122 Benjamin, Karl Kraus, S. 344.

123 Benjamin, Karl Kraus, S. 366/367.

124 Walter Benjamin, Zur Theorie des Unmenschen. In: Benjamin, Gesammelte Schriften, Bd. II.3, hg. von Rolf Tiedemann u. Hermann Schweppenhäuser, Frankfurt am Main 1991, S. 1106.

125 Benjamin, Karl Kraus, S. 367.

126 Benjamin, Karl Kraus, S. 367.

127 Benjamin, Karl Kraus, S. 358.

128 Vgl. die Beschreibung in „Karl Kraus“: „Sein Schwert und Schild - Begriff und Schuld sind ihm [dem Dämon, L.Z.] entsunken, um zu Emblemen unterm Fuß des Engels zu werden, 
Über den „menschenfresserische[n] Engel“129 wird der Mensch in Frage gestellt, der nach dem Ersten Weltkrieg als Entität obsolet geworden ist: Die erfahrungsarmen Leute „haben das alles ,gefressen“, ,die Kultur` und den ,Menschen“ und sie sind übersatt daran geworden und müde“130. Die Klammer von Barbarischem und Angelischem ist in Benjamins Sprachphilosophie zu suchen, in der beide auf den Zustand der Unmittelbarkeit, verstanden als Abwesenheit von Instrumentalisierung, verweisen. In der geschichtlichen Logik, die von einem idealistischen Humanismus über dessen Korrumpierung durch Kapitalismus und Krieg bis zu einem realen Humanismus führt, erscheint der „Neue Engel“ als Zielpunkt oder wenigstens als nächste Station. Klees Engelbild fügt sich aus mehreren Gründen ein in diese Reihe: Zum einen ist Klee selbst für Benjamin ein Vertreter der neuen Gestaltungsweise, die die Armut nicht verdrängt, sondern annimmt; das Prinzip der Konstruktion findet sich auch in seiner Zeichnung Angelus Novus. ${ }^{131}$ Zum anderen verbinden sich darin Raubtierartiges und Angelisches sowie ein Zukunftsprinzip, das der Engel, „Bote realeren Humanismus“, den verarmten Gegenwartsmenschen mitteilt.

Der Engel ist bei Benjamin also eine hochgradig moderne Figur, die auf die kapitalistische Gesellschaft und die sich im Ersten Weltkrieg mit Gewalt manifestierenden technischen Entwicklungen reagiert. Gleichzeitig bewahrt und verändert der Engel Fragmente einer religiösen Tradition als zerstörende und selbst durch den Erzähler - gestörte Figur. Dadurch erhalten religiöse Bilder und Strukturen in neuen Zusammenhängen neue Bedeutungen. Der Erzähler unterbricht den liturgischen Kreislauf der Engel, sodass einer von ihnen aus seinem angestammten Traditions- und Repräsentationszusammenhang herausgerissen und individuiert wird. Die Verbindung der Lobpreis singenden Engel mit der Namensthematik und einer ambivalenten Engelsgestalt in „Agesilaus Santander“ geht zurück auf eine biblische Episode beziehungsweise deren rabbinische Auslegungsgeschichte, nämlich auf jenen Kampf von Jakob mit einem Mann an der Furt des Jabbok. ${ }^{132}$ Dieser unter anderem im Midrasch Bereschit Rabba mit einem Engel (oder Satan) ${ }^{133}$ identifizierte Mann weigert sich im Anschluss an den Kampf, seinen Namen zu verraten. Aber nicht nur ein geheim gehaltener Name, sondern

der ihn erschlagen hat“ (Benjamin, Karl Kraus, S. 360). Diese Überwindung der mythischen Schuld vollzieht sich über „die Solidarisierung der Kreatur mit der zerstörenden Natur“, die „das neue Verhältnis zur Technik schafft“ (Benjamin, Zur Theorie des Unmenschen, S. 1106).

129 Benjamin, Zur Theorie des Unmenschen, S. 1106.

130 Benjamin, Erfahrung und Armut, S. 218.

131 Vgl. Kapitel 4.2.1 dieser Studie.

132 Für Deutungen im Zusammenhang mit Agesilaus Santander vgl. Lang, Mimetisches oder semiologisches Vermögen?, S. 260, Ebach, Agesilaus Santander und Benedix Schönflies, S. 151 und Hörisch, Vom Geheimnis zum Rätsel, S. 171. Vgl. außerdem die Kapitel 2.2. und 3.2.3 dieser Studie. 133 Vgl. Lang, Mimetisches oder semiologisches Vermögen?, S. 260. 
auch ein neuer im emphatischen Sinne kommt hier vor, da Jakob nach dem Kampf den neuen Namen Israel mitsamt dem erzwungenen Segen des Mannes/Engels/Satans erhält. Da der Engel bei Anbruch der Morgenröte gehen möchte, wird er in der rabbinischen Tradition verstanden als einer der Engel, der am Morgen Gottes Lobpreis singen soll. Dass der Engel sich weigert, seinen Namen zu nennen, wird begründet mit einer späteren Namensveränderung der Engel. ${ }^{134}$

In „Agesilaus Santander“ setzt sich mit dieser Unterbrechung zunächst die Verselbstständigung des Mediums Engel fort. Der Engel, der dazu bestimmt ist, vor Gottes Thron sein Lob zu singen, wird gestört. Daraufhin verhält er sich in einer von keiner Tradition gedeckten Weise. Er, der eigentlich sofort wieder „in Nichts zergehen“ sollte, kehrt schließlich am Ende zurück in eine Zukunft, aus der er gekommen war (vgl. AS 521, erste Fassung). So wie die abtrünnigen Engel mit der Abweichung von Gott eine geschichtsphilosophische Dynamik anstoßen, so erhält der Engel auch hier plötzlich zeitlichen Handlungsspielraum und Zukunftsbezug. Nicht nur wird seine Funktionalisierung auf den absoluten Signifikaten Gott hin als vor dessen Thron singender Engel allegorisch aufgebrochen; neben der Reflexion von Bildgebungsprozessen weist diese Herauslösung aus einem in sich geschlossenen Kreislauf auch auf die geschichtsphilosophische Dynamik, die den ganzen Text durchzieht. ${ }^{135}$ Indem der Engel mit der Vermittlung numinoser Inhalte auf der Erde und so auch mit deren notwendiger Verweltlichung betraut ist, wirkt er als Prisma auf der Schwelle zwischen theologischer Tradition und modernem Traditionsbruch. ${ }^{136}$ Dieselbe Position nimmt der Name in Benjamins Sprachphilosophie ein, die untrennbar mit einer geschichtsphilosophischen Sündenfallerzählung verknüpft ist.

Der Name stellt darin als absolutes Medium den sprachphilosophischen Angelpunkt des prälapsarischen Zustands dar. Der Sündenfall ist die prädikative Sprache, die die Unmittelbarkeit des Namens zerstört. In dieser soll das Wort nun „etwas mitteilen (außer sich selbst)“137. Indem der Mensch aus der Namenssprache heraustritt und sich aus dem paradiesischen Idyll herausbewegt, kündigt er nach Benjamin auch den Verbund mit der Natur auf, da er der

134 Vgl. Bibliotheca Rabbinica. Übersetzt von August Wünsche, Leipzig 1880, S. 379-381.

135 Sigrid Weigel erkennt in der Unterbrechung des Engels ,in nuce eine Dialektik jenes Vorgangs [...], bei dem eine ephemere Erscheinung im Bild festgehalten wird und genau damit ihrer eigentlichen Bedeutung oder Bestimmung entfremdet wird - während doch gleichzeitig dem materiellen Bild die Rolle zufällt, auf jene andere Sphäre zu verweisen“ (Weigel, Grammatologie der Bilder, S. 328-329).

136 Vgl. Sigrid Weigel, Schauplätze, Figuren, Umformungen. Zu Kontinuitäten und Unterscheidungen von Märtyrerkulturen. In: Märtyrer-Porträts. Von Opfertod, Blutzeugen und heiligen Kriegern, hg. von Sigrid Weigel, Berlin 2007, S. 11-38, hier S. 19.

137 Benjamin, Über Sprache überhaupt, S. 153. 
Mitteilung, die er von ihr empfängt, nicht mehr gerecht wird. Stattdessen maßt er sich in der instrumentellen Degradierung des Wortes ein Urteil an, wobei dieses richtende Wort, in dessen Anrufung die Schuld des Menschen besteht, ihn auch aus dem Paradies verbannt: Das Wissen um gut und böse als Grundlage des Urteils ist als das Böse selbst gegenstandsloses „Geschwätz“ und kennt „nur eine Reinigung und Erhöhung, unter die denn auch der geschwätzige Mensch, der Sündige, gestellt wurde: das Gericht“"138. Der Sündenfall beziehungsweise die Sünde wird bei Benjamin also nicht als Resultat eines inneren Bruchs gedacht, sondern als etwas Äußerliches und wesentlich Substanzloses, zu dem der Mensch sich hinwendet, indem er aus dem Bereich der Namenssprache heraustritt: „Gut und böse nämlich stehen als unbenennbar, als namenlos außerhalb der Namensprache, die der Mensch eben im Abgrund dieser Fragestellung verläßt"“139.

Der im Stadium der Vielzahl der Menschensprachen schon ,welkende ${ }^{6140}$ Name weist ebenso wie der Engel in seiner Zwischenstellung nicht nur zurück auf die paradiesische Einheitssprache, sondern auch voraus auf das Ende der geschichtlichen Zeit, in der die auf Trennung basierende Sinnzuweisung aufgehoben ist. ${ }^{141}$ Darin liegt insofern auch ein ethischer Imperativ, als der Mensch durch seine Hybris die „tief[e] Traurigkeit der Natur“142 zu verantworten hat. Vergleicht man diese Ursprungserzählung mit der Rilkes, wird deutlich, dass das Unterbrechungsmoment des Engels verschiedene Konnotationen hat. Während es in Rilkes „Märchen“ im Ursprung selber wirksam ist, weist der Engel hier mit seiner Unterbrechung eines bereits gebrochenen historischen Zustands auf eine ursprüngliche beziehungsweise wiederzuerringende Einheit hin. Während bei Rilke die Vorstellung der Sünde irrelevant ist - es ist ja Gott beziehungsweise der Engel und nicht der Mensch, der die Trennung verursacht hat -, kommt der Sünde in dieser sprachphilosophischen Sündenfallerzählung als aktive Übertretung des Menschen eine wichtige Bedeutung zu.

Allerdings beginnt nach dieser Übertretung keine geradlinige Entfremdungsgeschichte. Vielmehr ist es nötig, bei der Frage nach der Beschaffenheit des Numinosen in der geschichtlichen Zeit zu differenzieren und die Figuren jeweils im

138 Benjamin, Über Sprache überhaupt, S. 153.

139 Benjamin, Über Sprache überhaupt, S. 154.

140 Vgl. zu diesem Phänomen: „Benannt zu sein - selbst wenn der Nennende ein Göttergleicher und Seliger ist - bleibt vielleicht immer eine Ahnung von Trauer. Wieviel mehr aber benannt zu sein, nicht aus der einen seligen Paradiesessprache der Namen, sondern aus den hunderten Menschensprachen, in denen der Namen schon welkte, und die dennoch nach Gottes Spruch die Dinge erkennen“ (Benjamin, Über Sprache überhaupt, S. 155).

141 Vgl. Benjamin, Die Aufgabe des Übersetzers, S. 19.

142 Benjamin, Über Sprache überhaupt, S. 155. 
Zusammenhang mit den konkreten historisch-politischen Umständen zu sehen. Dazu gehört die Differenz von Engel und Dämon, der in „Karl Kraus“ durch den Engel überwunden wird. So sind auch im Stadium der nachparadiesischen Zeit der Gegenwart keineswegs alle theologischen Figuren dem Bereich dämonischer Degenerierung zuzuschlagen, ebenso wenig wie es nur „,[h]eresy and disorder in the realm of tradition, based on erotic impulses“ sind, die reflektiert werden in den „demonic transformations of the human appearance“143. Denn wie gezeigt ist gerade die mangelnde Menschenähnlichkeit vor dem Hintergrund einer gesellschaftlichen Deformation zu verstehen. Die Zerstörung der menschlichen Erscheinung heißt hier, sich von den dämonisch-mythischen Verstrickungen in Zweideutigkeiten zu lösen. Berücksichtigt man das Anagramm „der Angelus Satanas“ in „Agesilaus Santander“, wirkt statt eines eindeutig Luziferischen der Engel ebenfalls als eine Schwellenfigur, die zwischen der Zwielichtigkeit des Dämons und dessen Überwindung in der Figur des unmenschlichen Engels schwankt.

Die Bedeutung der Theologie liegt darin, dass auch im Stadium der weltlichen Anverwandlung theologischer Gedankenfiguren ein Rest von deren kontrafaktischer Andersartigkeit bestehen bleibt, allerdings in einer gestörten, unterbrochenen, nur flüchtig erscheinenden Form - im Modus des Engels. So lässt sich mit Adorno festhalten, dass Benjamin ,einzig von der radikalen, schutzlosen Profanisierung die Chance fürs theologische Erbe“ erwartet, „das in jener sich verschwendet“"144. Analog zum Gedanken der Bewahrung in der Zerstörung steht der Engel hier für die von Adorno so bezeichnete ,invers[e] Theologie““145, eine „Säkularisierung der Theologie um ihrer Rettung willen“"146.

143 Shahar, In the Name of the Devil, S. 105.

144 Theodor W. Adorno, Charakteristik Walter Benjamins. In: Adorno, Über Walter Benjamin, hg. von Rolf Tiedemann, Frankfurt am Main 1970, S. 11-29, hier S. 19.

145 Theodor W. Adorno, Brief an Walter Benjamin, 17. Dezember 1934. In: Adorno, Über Walter Benjamin, hg. von Rolf Tiedemann, Frankfurt am Main 1970, S. 103-110, hier S. 103. Diese Bezeichnung verwendet Adorno in seiner Reaktion auf Benjamins Kafka-Essay, um die gemeinsame Grundlage ihrer Positionen zu charakterisieren. Daniel Weidner meint dazu: „Eine inverse Theologie ist offensichtlich eine Rettung theologischer Gehalte von einem Standpunkt aus, der selbst nicht theologisch oder jedenfalls nicht der einer geraden, nicht-invertierten Theologie ist“" (Daniel Weidner, Religious turns, heute und damals. Giorgio Agamben liest Kafka - anders als Theodor W. Adorno, Gershom Scholem und Walter Benjamin [http://www. literaturkritik.de/public/rezension.php?rez_id=17298\&ausgabe=201211]). Vgl. dazu auch Hans Martin Dober, Die Moderne wahrnehmen. Über Religion im Werk Walter Benjamins, Gütersloh 2002. Damit hängt auch zusammen, dass sich Benjamin nicht auf eine Tradition reduzieren lässt (vgl. Dober, Die Moderne wahrnehmen, S. 204).

146 Theodor W. Adorno, Einleitung zu Benjamins „Schriften“. In: Adorno, Über Walter Benjamin, hg. von Rolf Tiedemann, Frankfurt am Main 1970, S. 33-51, hier S. 41. 


\subsubsection{Das Ethos des Wartens}

In „Agesilaus Santander“ führt die Störung der Engelshymne dazu, dass sich der Engel (scheinbar) gegen den Erzähler wendet. In ungeklärter Weise für die Verhinderung der Auftragsausführung verantwortlich, wird ihm dies auf sonderbare Weise entgolten:

Indem er [der Engel, L.Z.] nämlich sich den Umstand zunutze machte, daß ich unterm Saturn zur Welt kam - dem Gestirn der langsamsten Umdrehung, dem Planeten der Umwege und der Verspätungen - schickte er seine weibliche Gestalt der männlichen im Bilde auf dem längsten, verhängnisvollsten Umweg nach, obschon doch beide einmal nur kannten sie einander nicht, aufs innigste benachbart gewesen waren.

(AS 522, zweite Fassung)

Auch dieser Bruch der androgynen Vollkommenheit in die geschlechtliche Zweiheit derer, die einst „aufs innigste benachbart gewesen waren“, ist Teil des Sündenfallnarrativs. Als androgyne Figur bildet der Engel den Einheitszustand vor dem Sündenfall ab. ${ }^{147}$ Hier ist diese Androgynie gebrochen, der Engel gespalten in eine männliche und eine weibliche Gestalt, die erst nachträglich und verspätet zusammengeführt werden sollen. Auch dieses Geschehen vollzieht sich im Bild. Allerdings greift eine Lesart, die darin nur den Rekurs auf Klees Angelus Novus erblickte, zu kurz. Weniger ein konkretes Bild ist es hier vielmehr der Modus des Bildhaften, über den das Geschehen sich auf Umwegen, auch medialer Art, vollzieht. Mit Saturn als „dem Gestirn der langsamsten Umdrehung, dem Planeten der Umwege und der Verspätungen“148 und dem Umweg der weiblichen Gestalt wird daher weniger angespielt auf den problematischen Verlauf von Benjamins Liebesleben. ${ }^{149}$ Vielmehr lässt sich auch darin ein programmatischer Hinweis auf Benjamins Philosophie erkennen, und zwar sowohl methodisch als Ausdruck einer Theorie, für die die Figur des Umwegs konstitutiv ist, ${ }^{150}$ als auch inhaltlich in der

147 Vgl. Kapitel 2.2 dieser Studie.

148 Auch der Hinweis auf die Geburt „unterm Saturn“ ist einer auf die Ähnlichkeit und zwar in ihrer frühen Ausprägung der Sternenkonstellation, bevor sich das mimetische Vermögen nach Benjamin in der Sprache sedimentierte: „Was der Gestirnstand vor Jahrtausend[en] im Augenblicke des Geborenwerdens in einem Menschendasein wirkte, wob sich auf Grund der Ähnlichkeit hinein [...], kraft deren sich hier die Lebensgeister und -gewalten nach einem Vorbild formten, das zugleich im Kosmos ihnen vorgezeichnet war“ (Walter Benjamin, Nachträge zu den Anmerkungen [Lehre vom Ähnlichen, Über das mimetische Vermögen]. In: Benjamin, Gesammelte Werke, Bd. VII.2, hg. von Rolf Tiedemann u. Hermann Schweppenhäuser, Frankfurt am Main 1991, S. 791-796, hier S. 792).

149 Vgl. Scholem, Walter Benjamin und sein Engel, S. 116.

150 Vgl. Menke, Sprachfiguren, S. 7. Die Verbindung von sprachlichem Umweg und Warten in erotischer Hinsicht wird auch in „Karl Kraus“ thematisiert, dort allerdings ohne Gewaltver- 
messianischen Konnotation des Umwegs als ein Aufschub der Erlösung beziehungsweise in einem weiteren Sinne gegenstandsbezogen, insofern Benjamin sich augenscheinlich viel mit Obskuritäten und Abwegigem beschäftigt hat. ${ }^{151}$ Der Engel als „Störer der ,Unmittelbarkeit““152 (hier nun nicht instrumentell, sondern medial verstanden) steht exemplarisch für dieses Prinzip, verkörpert er doch als Medium der bildlichen Darstellung und sprachlichen Vermittlung im Beziehungsgefüge Gott - Mensch den Umweg schlechthin, samt der Konnotationen von (Wahrheits-)Verfälschung in der Tradition der abendländischen Philosophie.

Aus der weiblichen Gestalt des Engels, die sich in „Agesilaus Santander“ über einen Umweg zur männlichen bewegt, wird in der zweiten Fassung eine Charakteristik des Erzählers entwickelt. Wenn eine Frau ihn „bannte“, war er „unversehens entschlossen, auf ihrem Lebensweg sich auf die Lauer zu legen und zu warten bis sie krank, gealtert, in zerschlissenen Kleidern ihm in die Hände fiele“ (AS 522, zweite Fassung). Die Geduld als mentales Pendant zum Warten kommt durch die Verspätung der weiblichen Gestalt des Engels besonders zur Geltung: „Er [der Engel, L.Z.] wußte vielleicht nicht, daß sich die Stärke dessen, den er so treffen wollte, derart am besten zeigen konnte: nämlich wartend.“ (AS 522, zweite Fassung) Der auf der Lauer liegende Mann und das letztliche In-die-Hände-Fallen evozieren das Gebaren eines Raubtiers, das den kurz darauf beschriebenen Raubtierattributen des Engels entspricht. So hat dieser „Klauen“ und „spitze, ja messerscharfe Schwingen“. Er wurde möglicherweise, so wie ein Raubtier von frischem Blut, „angelockt von einem Schenkenden, der leer ausgeht“ (AS 523, zweite Fassung). In diesem Engel klingt der unmenschliche „Raubenge[1]“ mit seinen „Krallenfüße[n]“153 an, der in „Karl Kraus“ auftritt.

zicht: „Ist nun die Sprache - das legen wir zwischen die Zeilen - ein Weib, wie weit entrückt ein unbetrüglicher Instinkt den Autor jenen, die sich beeilen, bei ihr die Ersten zu sein, wie vielfach macht er den Gedanken, der sie nur immer mehr mit Ahnung stachelt als mit Wissen sättigt, wie läßt er ihn in Haß, Verachtung, Bosheit sich verstricken, wie hält er seinen Schritt hintan und sucht den Umweg des Epigonentums; um schließlich ihr die Lust der Reihe mit dem letzten Stoße, den Jack für Lulu in Bereitschaft hält, zu enden“ (Benjamin, Karl Kraus, S. 353).

151 Aufschub der Erlösung im Sinne eines Verzichts auf eine unmittelbare, das heißt menschliche Realisierung von Glück und Frieden (vgl. Hans Blumenberg, Die Botschaft vor aller spaltenden Theologie. Trilogie von Engeln, zweiter Teil: Undeutlicher Chorgesang. In: Frankfurter Allgemeine Zeitung, 300, 1996, S. N6). Zu Benjamins Beschäftigung mit Obskurem vgl. Hörisch, Vom Geheimnis zum Rätsel, S. 168.

152 Hans Blumenberg, Die Weltzeit erfassen. Trilogie von Engeln, erster Teil: Anfang, Mitte und Ende der Geschichte. In: Frankfurter Allgemeine Zeitung, 300, 1996, S. N5.

153 Walter Benjamin, Fragmente einer früheren Niederschrift [Karl Kraus], Blatt 42. In: Benjamin, Gesammelte Schriften, Bd. II.3, hg. von Rolf Tiedemann u. Hermann Schweppenhäuser, Frankfurt am Main 1991, S. 1108-1115, hier S. 1112. 
Auch diese Stelle erinnert an Jakobs Kampfgegner, den der Theologe Hermann Gunkel in seinem Genesis-Kommentar folgendermaßen beschreibt: „Es ist wenn wir die Erzählung verallgemeinern dürfen - ein den Menschen feindliches Wesen, das hier an der Furt des Jabboq ,wie ein Panther am Wege lauert' (Hos 137), den arglosen Wanderer überfällt und auf Leben und Tod mit ihm ringt.“154

Nicht nur die mangelnde Menschenähnlichkeit, auch das Warten ist in einem größeren Moderne-Kontext zu situieren. Denn im Exil weitet sich das Warten zu einem krisenhaften Zustand von unbestimmter Dauer aus. Bereits Rilke hatte den Ersten Weltkrieg als einen solchen identitätsbedrohenden, paralysierenden Wartezustand beschrieben. ${ }^{155}$ Mit dem Hitler-Regime verschärft sich die Bedrohung dieses Wartens existentiell. Es bedeutet nicht nur potentiellen Sinn- und Identitätsverlust, sondern auch eine existenzgefährdende Situation für Exilantinnen und Exilanten. Deren Leben war häufig von dem Kampf um und das Warten auf Papiere dominiert. Darüber hinaus ist das Warten aber auch eine Signatur der Epoche. Es ist ein weiterer Schwellenzustand, ${ }^{156}$ der nach Benjamin als Effekt einer administrativen Normung des Lebens genuin mit der Moderne verbunden ist. ${ }^{157}$

Das Ethos des Wartens, das der Erzähler in „Agesilaus Santander“ für sich reklamiert, erinnert an die Bestimmung des Wartens, wie Sigfried Kracauer es entwirft. Dieser versteht das Warten als eine Reaktionsform auf das „metaphysische Leiden an dem Mangel eines hohen Sinnes in der Welt“158. Für alle Menschen, die sich nicht Zerstreuungen hingeben oder „konfliktlos in den echten Glauben eingehen“ ${ }^{159}$, gibt es nach Kracauer drei Verhaltensweisen: die Haltung des „prinzipiellen Skeptikers“160, der bewusst dem Glauben entsagt, die des „Kurzschluß-Menschen“161, der sich in seiner Ungeduld in den Bereich des

154 Gunkel, Göttinger Handkommentar zum Alten Testament, S. 364.

155 Vgl. Kapitel 3.1.3 dieser Studie.

156 Vgl. dazu die Stelle aus der Berliner Kindheit: „Unter den Karyatiden und Atlanten, den Putten und Pomonen aber, die mich damals angesehen hatten, waren mir nun die liebsten jene angestaubten aus dem Geschlecht der Schwellenkundigen, die den Schritt ins Dasein oder in ein Haus behüten. Denn sie verstanden sich aufs Warten“ (Walter Benjamin, Berliner Kindheit um Neunzehnhundert. In: Benjamin, Gesammelte Schriften, Bd. IV.1, hg. von Tillman Rexroth, Frankfurt am Main 1991, S. 235-304, hier S. 238).

157 Vgl. für diesen Zusammenhang folgende Stelle aus dem Passagen-Werk: „Je mehr das Leben administrativ genormt wird, desto mehr müssen die Leute das Warten lernen. Das Hasardspiel hat den großen Reiz, die Leute vom Warten freizumachen“ (Benjamin, Das Passagen-Werk, S. 178).

158 Kracauer, Die Wartenden, S. 106.

159 Kracauer, Die Wartenden, S. 113.

160 Kracauer, Die Wartenden, S. 113.

161 Kracauer, Die Wartenden, S. 114. 
Glaubens stürzt, wo er sich „nur künstlich und kraft unfreiwilligen Selbstbetrugs zu behaupten“162 vermag, und schließlich die des Wartens. Wer wartet, versperrt sich weder den Weg zum Glauben, noch versucht er, diesen über eine Abkürzung zu erschleichen. Der Wartende akzeptiert die volle Wucht der gegenwärtigen Leere. Er harrt allerdings nicht müßig aus, sondern hält sich im Zustand eines Geöffnetseins, das ,angespannte Aktivität und tätiges Sichbereiten ist“"163. Die Wendung aus dem metaphysisch entleerten Raum in die religiöse Sphäre, die hier angestrebt, aber nicht auf unlautere Weise erzwungen wird, erfordert gerade keine Abwendung von der Realität. Vielmehr geht es darum, ,aus der atomisierten unwirklichen Welt der gestaltlosen Kräfte und der des Sinnes baren Größen einzukehren in die Welt der Wirklichkeit und der von ihr umschlossenen Sphären“"164. So ist der Mensch nicht nur vom Bereich des Absoluten abgetrennt; auch „die von leibhaftigen Dingen und Menschen“ erfüllte Wirklichkeit, die es konkret zu sehen gilt, ist aufgrund „der Überspannung des theoretischen Denkens [...] in einem entsetzenerregenden Maße ferngerückt“165. In dieser Einkehr in die Welt der Wirklichkeit „mag er [der Mensch, L.Z.] sich denn langsam umstellen und emportasten in vormals ihm unzulängliche Bezirke“166. Aufgrund der Nichterzwingbarkeit darf bei dieser Form des Wartens allerdings paradoxerweise die Frage, wann und ob überhaupt die gewünschte Wandlung eintritt, „die Sich-Mühenden nicht kümmern“167. So bleibt das messianische Warten bei Kracauer auf die materielle Ebene und den Bereich der Geschichte fokussiert. ${ }^{168}$

Im Warten verschränken sich in „Agesilaus Santander“ einmal mehr Epochencharakteristik und Lebenserzählung, allerdings mit unerwarteten Implikationen. Entgegen der Schwächung, die das von Pikulik so titulierte „leere Warten“169 der Moderne bedeutet, ,als die Figur [...], die das Subjekt in Frage stellt“170, wird das

162 Kracauer, Die Wartenden, S. 115.

163 Kracauer, Die Wartenden, S. 117-118.

164 Kracauer, Die Wartenden, S. 118.

165 Kracauer, Die Wartenden, S. 118.

166 Kracauer, Die Wartenden, S. 118.

167 Kracauer, Die Wartenden, S. 119.

168 Vgl. Barbara Thums, Kracauer und die Detektive: Denk-Räume einer ,Theologie im Profanen'. In: Deutsche Vierteljahrsschrift für Literaturwissenschaft und Geistesgeschichte, 84/3, 2010, S. 390-406, hier S. 400.

169 Pikulik, Warten, Erwartung, S. 11.

170 Annette Keck, Merkwürdiges Warten. Imre Kertész' Beitrag zu einer Poetik des Wartens zwischen Erinnern und Vergessen im ,Roman eines Schicksallosen'. In: Überleben schreiben. Zur Autobiographie der Shoah, hg. von Manuela Günter, Würzburg 2002, S. 139-154, hier S. 142. 
Warten hier zu einer Demonstration der Überlegenheit. Denn die Wartesituation, die das Exil als Entortungserfahrung charakterisiert, verkehrt sich in „Agesilaus Santander“ unverhofft in eine Position der Stärke. Das Warten, das der Engel der bedrohlichen Konnotation des „leeren Wartens“ entsprechend als eine Art Bestrafung gedacht hatte, stellt nicht nur die Stärke dieses Subjekts heraus, dessen Geduld „mit nichts [...] zu entkräften“ (AS 522, zweite Fassung) ist. Sie bewirkt nach der identitätsbedrohenden, unauflösbaren Vermischung von Namensträger, Name, Bild und Engel in der Wandlungspassage zuvor nun auch die klare Konturierung des Erzählers.

Eine messianische Konnotation wie bei Kracauer wird schließlich auch hier sichtbar, wenn man sich in Erinnerung ruft, worauf eigentlich zunächst zu warten war. Es ging darum, dass die männliche und die weibliche Gestalt des Engels zusammentreffen und eine mit göttlicher Vollkommenheit assoziierte Androgynität des Engels sich wieder einstellt. Es geht also, könnte man sagen, um die Überwindung der irdischen, hier geschlechtlichen Dualität in einer überirdischen Form. Darin klingt das Warten auf den Messias an. Dieses Warten stellt einen spezifisch jüdischen Topos dar, dessen Aufschub-Zeit „den säkularisierten Horizont der Moderne [sprengt]“171. Charakteristisch für das Judentum ist, dass das Warten auf den Messias bis zum gegenwärtigen Tag andauert. Dies steht im Gegensatz zur „zeitverkürzende[n], sogar gegenwartsnahe[n] Verheißung““172 im

171 Andreas Greiert, Geschichte als Katastrophe. $\mathrm{Zu}$ einem theologisch-politischen Motiv bei Walter Benjamin. In: Zeitschrift für Religions- und Geistesgeschichte, 64/4, 2012, S. 359-376, hier S. 369. Charakteristisch für das Judentum ist „bis heute eine ungelöste, die ,Weite des Horizontes“ aufreißende Zukunftsspannung, da das Warten auf den Messias anhält“ (Pikulik, Warten, Erwarten, S. 22). Dies steht im Gegensatz zu der „zeitverkürzende[n], sogar gegenwartsnahe[n] Verheißung“ im Christentum (Pikulik, Warten, Erwarten, S. 23), dem zwar durch die Parusieverzögerung ebenfalls die Struktur des Aufschubs des Heils eingeschrieben ist, das aber den Kreuzestod Christi schon als die ersehnte Erlösung und aus diesem Grund Erfüllung bereits in der Gegenwart sehen kann. Vgl. auch Benjamins in dem Fragment „Die Bedeutung der Zeit in der moralischen Welt“ explizierte Haltung: „Die Vergeltung steht im Grunde indifferent der Zeit gegenüber, sofern sie durch die Jahrhunderte unvermindert in Kraft bleibt und noch heute wird eine eigentlich heidnische Vorstellung sich in diesem Sinne das jüngste Gericht zurechtlegen: als den Termin, an welchem allem Aufschub Einhalt, aller Vergeltung Einbruch geboten wird. Allein dieser Gedanke, der des Aufschubs gleich als leeren Säumens spottet, begreift nicht, welche unermeßliche Bedeutung jener ständig zurückgedrängte, von der Stunde jeder Untat so unablässig ins Zukünftige flüchtend〈e〉, der Gerichtstag hat. Diese Bedeutung erschließt sich nicht in der Welt des Rechts, wo die Vergeltung herrscht, sondern nur, wo ihr, in der moralischen Welt, die Vergebung entgegentritt“ (Walter Benjamin, Die Bedeutung der Zeit in der moralischen Welt. In: Benjamin, Gesammelte Schriften, Bd. VI, hg. von Rolf Tiedemann u. Hermann Schweppenhäuser, Frankfurt am Main 1991, S. 97-98).

172 Pikulik, Warten, Erwartung, S. 23. 
Christentum, dem zwar durch die Parusieverzögerung ebenfalls die Struktur des Aufschubs des Heils eingeschrieben ist, das aber den Kreuzestod Christi schon als die ersehnte Erlösung und damit als Erfüllung in der Gegenwart betrachtet.

\subsubsection{Armut des Exils und der Moderne}

Neben dem Warten verkörpert der Engel in „Agesilaus Santander“ einen zweiten zentralen Exiltopos. Er macht den Verlust einer erzwungenen Trennung sichtbar: „Der Engel aber ähnelt allem, wovon ich mich habe trennen müssen: den Menschen und zumal den Dingen“ (AS 523, zweite Fassung). Dabei wird nicht nur an dieser Stelle eine Beziehung über die Figur der (mangelnden) Ähnlichkeit gestiftet: Die Züge des unterbrochenen Engels haben „nichts Menschenähnliches“, das Bild/der Erzähler verliert die Gabe, „menschenähnlich zu erscheinen“, die Schwingen der Geduld des Erzählers ähneln denen des Engels in ihrer fixierenden Kraft und der Engel ähnelt den Dingen und Menschen, die der Erzähler verloren hat (sodass er an dieser Stelle die ihm vorher abgesprochene Menschenähnlichkeit zurückzugewinnen scheint).

Da nach Benjamin „,[d]ie Einsicht in die Bereiche des ,Ähnlichen“ [...] von grundlegender Bedeutung für die Erhellung großer Bezirke des okkulten Wissens“"173 ist, wundert es nicht, dass die Ähnlichkeit von wissenschaftlicher Seite mit einem entsprechenden „Unbehagen“174 rezipiert wird. Das liegt daran, dass die psychologische, kulturanthropologische und kognitionswissenschaftliche Bedeutsamkeit der Ähnlichkeit evident ist, sie gleichzeitig aber auch ebenso unabweisbar vage ist und sich logischen Begriffsfixierungen entzieht. ${ }^{175}$ Ähnlichkeit stellt eine Irritation für dualistische Schematisierungen dar und steht in der Reihe der Schwellenfiguren, die das Gerüst von „Agesilaus Santander“ bilden und reflektieren. ${ }^{176}$ Als das „Manifesteste und Verborgenste“"177, wie Foucault die Ähnlichkeit beschreibt, steht sie überdies auch auf der Schwelle zwi-

173 Walter Benjamin, Lehre vom Ähnlichen. In: Benjamin, Gesammelte Schriften, Bd. II.1, hg. von Rolf Tiedemann u. Hermann Schweppenhäuser, Frankfurt am Main 1991, S. 204-210, hier S. 204.

174 Anil Bhatti u. Dorothee Kimmich, Einleitung. In: Ähnlichkeit. Ein kulturtheoretisches Paradigma, hg. von Anil Bhatti u. Dorothee Kimmich, Konstanz 2015, S. 7-31, hier S. 10.

175 Vgl. Bhatti u. Kimmich, Einleitung, S. 10-11.

176 Winfried Menninghaus verweist darauf, dass Schwellenerfahrungen nicht nur das Sujet „fast aller seiner [Benjamins, L.Z.] größeren Arbeiten“ darstellen, sondern „auch Form und Intention seiner Werke hüten oder besser: [sie] produzieren eine Schwelle, die es zu durchmessen, zu ,passieren' gilt“" (Menninghaus, Schwellenkunde, S. 8-9).

177 Michel Foucault, Die Ordnung der Dinge, Frankfurt am Main 1974, S. 56. 
schen Öffentlichkeit und Geheimnis, die die Architektur des gesamten Textes durchzieht.

Die Ähnlichkeit des Engels mit etwas Abwesendem evoziert die „unsinnliche Ähnlichkeit“, deren Konzeption Benjamin in der „Lehre vom Ähnlichen“ (1933) und dann, in unmittelbarem zeitlichem Zusammenhang mit „Agesilaus Santander“, in deren Überarbeitung „Über das mimetische Vermögen“ (1933) als Weiterführung seiner sprachphilosophischen Reflexionen entwickelt. Der Engel ist aus mehreren Gründen eine Figur der unsinnlichen Ähnlichkeit beziehungsweise der sinnlichen Unähnlichkeit. ${ }^{178}$ Da Engel einen unsichtbaren Gott versinnlichen, müssen sie ihm einerseits ähnlich, andererseits, weil sie eben nicht göttlich sind, auch unähnlich sein. Die Ähnlichkeit ist unsinnlich, weil es sich, theologisch gedacht, bei dem Abstand zwischen Gott und Engeln um eine nicht ermessbare, qualitative Differenz handelt. Die Unähnlichkeit wiederum ist sinnlich, insofern es die ästhetische Wahrnehmbarkeit von Engeln ist, die sie von dem unsichtbaren Gott trennt.

Darüber hinaus unterscheiden sich auch die biblischen Engelsdarstellungen untereinander erheblich. Sowohl in der Heterogenität ihrer Attribute als auch in den verschiedenen Darstellungsformen sind Engel überaus hybride Phänomene. ${ }^{179}$ Um die Unantastbarkeit der biblischen Verfasser zu bewahren, macht Pseudo-Dionysius in seiner einflussreichen Angelologie Über die himmlische Hierarchie daraus eine Notwendigkeit. Engel sind nur in einer Vielzahl entgegensetzter Darstellungen einigermaßen angemessen dargestellt, so lautet zugespitzt die These. Denn einerseits stellt ihre idealschöne, anthropomorphe Darstellung die für den menschlichen Verstand adäquate sinnliche Übersetzung der geistigen Engelsqualitäten dar, die wiederum die göttliche Vollkommenheit spiegeln. Andererseits aber bedienen sich die Verfasser der Bibel für die Darstellung von Engeln auch monströser und abwegiger Bilder. Die offensichtliche Widersinnigkeit dieser Bilder soll die Menschen, so Pseudo-Dionysius' Erklärung, zur Einsicht in die unsinnliche Beschaffenheit und letztlich die Unabbildbarkeit der göttlichen Eigenschaften führen. ${ }^{180}$

Während es in den Angelologien um hierarchische Differenzen geht, die vor allem topologisch illustriert werden, expliziert Benjamin seinen Begriff der unsinnlichen Ähnlichkeit über eine zeitliche Differenz. Im Hinblick auf die Astrologie erläutert er, „daß wir in unserer Wahrnehmung dasjenige nicht mehr besitzen, was es einmal möglich machte, von einer Ähnlichkeit zu sprechen, die bestehe zwischen

178 Zum Engel als Figur der unsinnlichen Ähnlichkeit vgl. Weigel, Grammatologie der Bilder, S. 343 .

179 Vgl. Kapitel 2.2 dieser Studie.

180 Vgl. Kapitel 2.4 dieser Studie. 
einer Sternkonstellation und einem Menschen“181. Die unsinnliche Ähnlichkeit ist hier also als weitere geschichtsphilosophische Figur Teil einer Verlust- beziehungsweise Wandlungsgeschichte der Menschheit. So ist „im Laufe der Jahrhunderte die mimetische Kraft, und damit später die mimetische Auffassungsgabe gleichfalls, aus gewissen Feldern, vielleicht um sich in andere zu ergießen, geschwunden“"182. In dieser Reaktivierung einer vormodernen Zeichentheorie unter den Bedingungen der Moderne verbinden sich untrennbar repräsentativ-semiotische und magischmimetische Momente. ${ }^{183}$ Es kann „[a]lles Mimetische der Sprache [...], der Flamme ähnlich, nur an einer Art von Träger in Erscheinung treten“184, nämlich dem Semiotischen. Auch die unsinnliche Ähnlichkeit beziehungsweise ihre Wahrnehmung erweist sich damit als ein Sekundär- und Schwellenphänomen. Ihr blitzartiges Auftreten ist durch die geschichtliche Konstellation bedingt - sie hat „den Charakter einer Anamnesis, die einer verlornen Ähnlichkeit, die frei von der Verflüchtigungstendenz war, sich bemächtigt“"185.

181 Benjamin, Lehre vom Ähnlichen, S. 207.

182 Benjamin, Lehre vom Ähnlichen, S. 205. Als Resultat dieser Entwicklung, die sich von dem Lesen aus Eingeweiden und in Sternen über das von Runen und Hieroglyphen vollzogen habe, wäre, so mutmaßt Benjamin, „die Sprache die höchste Stufe des mimetischen Verhaltens und das vollkommenste Archiv der unsinnlichen Ähnlichkeit“ (Walter Benjamin, Über das mimetische Vermögen. In: Benjamin, Gesammelte Schriften, Bd. II.1, hg. von Rolf Tiedemann u. Hermann Schweppenhäuser, Frankfurt am Main 1991, S. 210-213, hier S. 213).

183 Die Bedeutung von Benjamins geschichtsphilosophischer Konzeption der Sprache lässt sich aber auch in einem systematischen Problemzusammenhang erkennen. So sieht Bettine Menke in dem geschichtsphilosophischen Einsatz eine „Strategie, die Bedeutung und die Dignität eines Moments der Sprache, das nur in Rudimenten aufzufinden ist, dadurch abzusichern, daß es als in einem Verfallsprozeß zerschlagenes Früheres beschrieben wird“ (Menke, Sprachfiguren, S. 162). Es geht also nicht zuletzt auch um die Frage nach dem Verhältnis von Historizität, systematischer Logik und Logik der Darstellung, wobei in der Konstruktion der historischen Genese das logisch Nachgeordnete als primordiales Fundament nicht nur aufgewertet, sondern überhaupt erst erkennbar wird. Narrratologisch betrachtet handelt es sich hier bei dem prälasparischen Zustand um das, was Ingo Stöckmann als „bloße[s] Erzählkorrelat“ bezeichnet, durch das „Modernisierungsprozesse allererst darstellbar werden“ (Ingo Stöckmann, Erkenntnislogik und Narrativik der Moderne. Einige Bemerkungen zu Anke-Marie Lohmeiers Aufsatz „Was ist eigentlich modern?“ und Thomas Anz’ Kritik. In: Internationales Archiv für Sozialgeschichte der deutschen Literatur 34, 2009, S. 221-234, hier S. 230). Darin liegt die (logisch) unhintergehbare Nachträglichkeit des Ursprungs, der erst im Zustand seiner Nicht-mehr-Präsenz als solcher erkennbar und (in Rudimenten) erfahrbar wird, was bei Benjamin neben der (un-)sinnlichen Ähnlichkeit auch für die Aura gilt (vgl. Menke, Sprachfiguren, S. 321-322). Zu diesem Aspekt vgl. auch Adorno, Ästhetische Theorie, S. 131-132 u. S. 158.

184 Benjamin, Über das mimetische Vermögen, S. 213.

185 Benjamin, Nachträge zu den Anmerkungen [Lehre vom Ähnlichen, Über das mimetische Vermögen], S. 795. 
Dieser menschheitsgeschichtliche Schwund der ursprünglichen Ähnlichkeit, der in der flüchtigen, unsinnlichen Ähnlichkeit aufscheint, verschränkt sich in „Agesilaus Santander“ in der Figur des Engels mit dem individualgeschichtlichen Verlust des Erzählers. So aktualisiert der Engel das Verlorene, Vergangene des präexilischen Zustands unter den Bedingungen des Exils, indem er wie der Name über epistemische Subjekt-Objekt-Scheidungen hinweg Korrespondenzen zwischen Mensch- und Dingwelt stiftet. In seinem Ähnlich-Werden hält er überdies ein Vermögen präsent, das als Verlorenes eines früheren phylo- und ontogenetischen Zustands gedacht wird. ${ }^{186}$ Den unheimlichen, traumartigen Schwebezustand der Ähnlichkeit, ${ }^{187}$ in dem distinkte Grenzen von Subjekt und Objekt ebenso wie von Raum, Zeit und Identität diffundieren, stellt der Engel performativ als Medium der Erinnerung vor, das ähnlich ist und macht: Er „haust“ in den verlorenen Dingen und „macht sie durchsichtig“ (AS 523, zweite Fassung) auf die Menschen hin, für die sie gedacht sind. In der schwebenden Gleichzeitigkeit von Vergangenem und Gegenwärtigem lässt der Engel Zeitgrenzen kollabieren.

Auch dieser Passus ist rückgebunden an die materiell fundierte Zeitdiagnose, die Benjamin in „Erfahrungsarmut“ entwirft: „Das Glas ist überhaupt der Feind des Geheimnisses. Es ist auch der Feind des Besitzes. Der große Dichter André Gide hat einmal gesagt: Jedes Ding, das ich besitzen will, wird mir undurchsichtig.“188 In „Agesilaus Santander“ führt die erzwungene Trennung von Besitz folgerichtig zu einer Durchsicht. „,Das neue Glas-Milieu wird den Menschen vollkommen umwandeln““189, zitiert Benjamin Scheerbart, die spurenlose Transparenz ist Ausdruck einer äußeren und inneren Armut. Allerdings ist das emphatische Bekenntnis zu dieser nicht Ausgangspunkt, sondern

$186 \mathrm{Vgl}$. zu diesem Verhältnis: „Die Gabe, Ähnlichkeit zu sehen, die er [der Mensch, L.Z.] besitzt, ist nichts als ein Rudiment des ehemals gewaltigen Zwanges, ähnlich zu werden und sich zu verhalten“ (Benjamin, Über das mimetische Vermögen, S. 210).

187 Die Wahrnehmung der Ähnlichkeit „schwebt [...] ohne genauen Ort in der Übergangszone zwischen dem Selben und dem Anderen, dem Eigenen und dem Fremden“ (Albrecht Koschorke, Ähnlichkeit. Valenzen eines post-postkolonialen Konzepts. In: Ähnlichkeit. Ein kulturtheoretisches Paradigma, hg. von Anil Bhatti u. Dorothee Kimmich, Konstanz 2015, S. 3545, hier S. 36). Entsprechend bleibt sie bei Benjamin rückbezogen auf den Schwellenzustand des Traums: „Die Ähnlichkeit des Einen mit dem Andern, mit der wir rechnen, die im Wachen uns beschäftigt, umspielt nur die tiefere der Traumwelt, in der, was vorgeht, nie identisch, sondern ähnlich: sich selber undurchschaubar ähnlich, auftaucht“ (Walter Benjamin, Zum Bilde Prousts. In: Benjamin, Gesammelte Schriften, Bd. II.1, hg. von Rolf Tiedemann u. Hermann Schweppenhäuser, Frankfurt am Main 1991, S. 310-324, hier S. 314). Dieser Raum des Dazwischen ist ein unheimlicher, die Ähnlichkeit selbst führt ein „Geisterdasein“ (Benjamin, Anmerkungen [Lehre vom Ähnlichen, Über das mimetische Vermögen], S. 956).

188 Benjamin, Erfahrung und Armut, S. 217.

189 Benjamin, Erfahrung und Armut, S. 218. 
Folge der Armut, und ebenso zweischneidig ist die Behauptung des Erzählers, er sei „von niemandem im Schenken zu übertreffen“ (AS 523, zweite Fassung). Denn er hat sich von den Dingen und den Menschen ,trennen müssen [meine Hervorhebung, L.Z.]“ (AS 523, zweite Fassung). Insofern geht die Hervorhebung der verbürgten Freude Benjamins am Schenken an der durch die politische Entwicklung erzwungenen Trennung und damit an den zeithistorischen Umständen vorbei. ${ }^{190}$ Die Kunst des Schenkens ist ebenso wie die des Wartens eine Reaktion auf Verlusterfahrungen, die Exilantinnen und Exilanten durch Hitlers Verfolgungs- und spätere Vernichtungspolitik erleiden mussten. So wie sich der Schwerpunkt vom Warten auf die Geduld verlagert, so steht hier statt des Verlusts das Schenken und damit ein Akt der Selbstbehauptung, der die Mängel der Moderne und ihre Verschärfung im realhistorischen Exil nach 1933 in positive Qualitäten ummünzt. Was hier im Modus einer autobiographischen Erzählung vom geduldigen Warten und freigiebigen Schenken veranschaulicht wird, entspricht Benjamins zeitgeschichtlichem Postulat, die Verarmung in der Moderne anzunehmen und ihr in Form neuer Gestaltung positive Qualitäten abzuringen.

Der Armut des Exils wie der Moderne entsprechend geht der Schenkende in „Agesilaus Santander“ „leer“ aus. Gerade das scheint ihn für den Engel attraktiv zu machen: „[V]ielleicht war der Engel angelockt von einem Schenkenden, der leer ausgeht.“ (AS 523, zweite Fassung) Und auch das ist ein Hinweis auf Benjamins Moderne-Programm: Der unmenschliche Engel erscheint in einer unmenschlichen Zeit demjenigen, der ihre Armut verkörpert, die in einem Mangel an Menschenähnlichkeit und Humanismus besteht. Auch der Engel geht zunächst leer aus: „Denn auch er selbst, der Klauen hat und spitze, ja messerscharfe

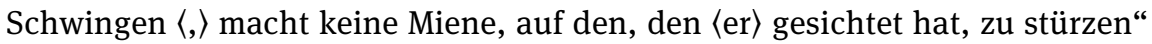
(AS 523, zweite Fassung) - so transkribieren Rolf Tiedemann und Hermann Schweppenhäuser. Scholem hingegen gibt die Stelle folgendermaßen wieder: „Denn auch er selbst, der Klauen hat und spitze, ja messerscharfe Schwingen

190 Zur Freude Benjamins am Schenken vgl. Scholem, Walter Benjamin und sein Engel, S. 57. Der Sammler Benjamin fragt zwar in einer handschriftlichen Variante von „Erfahrung und Armut“: „Aber wer kann denn ernstlich annehmen, die Menschheit werde den Engpaß, der vor ihr liegt, mit dem Gepäck eines Sammlers oder Antiquitätenhändlers beladen, je überschreiten?“ (Walter Benjamin, Anmerkungen [Erfahrung und Armut]. In: Benjamin, Gesammelte Schriften, Bd. II.3, hg. von Rolf Tiedemann u. Hermann Schweppenhäuser, Frankfurt am Main 1991, S. 960-963, hier S. 961-962). Burkhardt Lindner wendet aber treffend ein: „Doch ein solches Gepäck trug Benjamin mit sich ins Exil. Und er wollte sich davon nicht trennen, vielmehr hat er alles dazu getan, daß seine Bücher und seine Manuskripte aus Berlin herausgeholt werden“ (Burkhardt Lindner, Zu Traditionskrise, Technik, Medien. In: Benjamin-Handbuch. Leben - Werk - Wirkung, Stuttgart 2011, S. 451-464, hier S. 455). 
[,] macht keine Miene, auf den, der gesichtet hat, zu stürzen“191 (zweite Fassung). Fraglich ist also, wer wen gesichtet hat und wie das mit möglichen Auslassungen in Einklang zu bringen ist. ${ }^{192}$ Dabei wirkt auch der nichtreflexive Gebrauch von ,stürzen' befremdlich, der die Bedeutung des Hinfallens anklingen lässt. Der Vorgang steht seltsam unbestimmt zwischen Aggression und Kontrollverlust und ruft darin den Topos des Engelssturzes auf. Während die erste Version konsequent im Raubtiernarrativ verbleibt, etabliert Scholems Lesart ein reziprokes Verständnis. Unabhängig von der Frage nach einer richtigen Variante verweisen auch diese verschiedenen Lektüren auf den konstitutiven Bereich der Schwelle, in dem in mimetischen Anverwandlungen klare Zuordnungen verschwimmen. Dem Blick kommt dabei entscheidende Bedeutung zu, der bei Benjamin ein Medium der Verähnlichung ist. ${ }^{193}$

Diese Ambivalenz von Aktivität und Passivität setzt sich fort. So wie der Engel sich nicht auf jemanden, sondern bloß stürzt, so greift er auch nicht an, sondern tritt im Gegenteil den Rückzug an. Dabei zieht er kraft seines Blicks den Gesichteten mit sich, indem er „stoßweise und unaufhaltsam weicht“ (AS 521, erste Fassung). Dieser scheinbare Rückzug erweist sich allerdings als besondere Stärke, mit der er den anderen ohne Gewaltanwendung per Blick in Beschlag nimmt. Der Blick ist bei Benjamin mindestens so mächtig wie die Raubtierklauen des Engels, tödlich und bewahrend. ${ }^{194}$ Das verbindet ihn mit der Geduld des Erzählers, dem die geliebte Frau am Ende ihres Lebens doch noch in die Hände fällt. Entsprechend ähneln die „Schwingen“ der Geduld des Erzählers den „Schwingen“ (AS 522, zweite Fassung) des Engels, und die Geduld „lernt vom Engel, wie er seinen Partner im Blick umfaßt“ (AS 521, erste Fassung).

Nachdem er ihn derart fixiert hat, zieht der Engel seinen „Partner“ (AS 521, erste Fassung) beziehungsweise den, den er oder der ihn gesichtet hat, nach, in der ersten Version „auf jener Flucht in eine Zukunft, aus der er vorgestoßen ist“

191 Scholem, Walter Benjamin und sein Engel, S. 101-102.

192 So meint Scholem im kommentierenden Teil: „Es ist schwer zu entscheiden, ob in diesem Relativsatz etwa das Wort ,ihn' durch eine Unterlassung Benjamins ausgefallen ist oder ob er auch ohne diese Ergänzung sinnvoll bleibt. Ich neige zu der ersteren Auffassung“ (Scholem, Walter Benjamin und sein Engel, S. 122).

193 Vgl. Benjamin, Anmerkungen [Lehre vom Ähnlichen, Über das mimetische Vermögen], S. 958.

194 So heißt es im Ursprung des deutschen Trauerspiels: „Wird der Gegenstand unterm Blick der Melancholie allegorisch, läßt sie das Leben von ihm abfließen, bleibt er als toter, doch in Ewigkeit gesicherter zurück, so liegt er vor dem Allegoriker, auf Gnade und Ungnade ihm überliefert“ (Walter Benjamin, Ursprung des deutschen Trauerspiels. In: Benjamin, Gesammelte Schriften, Bd. I.1, hg. von Rolf Tiedemann u. Hermann Schweppenhäuser, Frankfurt am Main 1991, S. 207-430, hier S. 359). 
(AS 521, erste Fassung). Der Begriff der Flucht lässt erneut die Exilsituation anklingen, auch hier aber ist das Epochenspezifische geschichtsphilosophisch überformt. So erinnert die eigentümliche Bewegung der Flucht in eine Zukunft, aus der man gekommen war, strukturell an das bei Benjamin prominente KrausZitat „Ursprung ist das Ziel“ als „Gottes Trost und Verheißung“ für den „sterbenden Menschen“"195. Der Ursprung ist auch hier, indem er als Zukunft zugleich das Unbekannte bedeutet, „Gegenstand einer Entdeckung, die in einzigartiger Weise sich mit dem Wiedererkennen verbindet“196. Die paradoxe Unbestimmtheit des Ursprungs als „eine Zukunft“ und die Verkehrung und Weitung eines linearen Zeitstrahls eröffnen zugleich einen Möglichkeitsraum des Kommenden. Umgekehrt wird die Gegenwart, in die der Engel aus der Zukunft kam, aus angelischer Perspektive durch das „vor“ zu einem neuen, vorne liegenden Terrain.

Im Gegensatz dazu entwirft die zweite Fassung ein konventionelleres Zeitund Raumbild: Der Engel fasst den Gesichteten respektive den Sichtenden ins Auge, „[u]m ihn sich nachzuziehen, auf jene $\langle\mathrm{m}\rangle$ Wege in die Zukunft, auf dem er kam und den er so gut kennt, daß er ihn durchmißt ohne sich zu wenden und den, den er gewählt hat, aus dem Blick zu lassen“ (AS 523, zweite Fassung). Während hier grammatikalisch der Relativsatz eindeutig (auf den Weg bezogen) und die Möglichkeit von Hin- und Rückweg auf jenem Weg logisch plausibel ist, erscheint die strukturanaloge und zugleich asymmetrische Flucht aufgrund ihrer Einmaligkeit und der Unbestimmtheit „einer Zukunft“ ungleich ambivalenter. Die Flucht bildet auch einen Kontrast zu der expliziten Souveränität des Engels in der zweiten Fassung: Hier kennt er den Weg, den er „durchmißt ohne sich zu wenden“; er kann ihn also rückwärts beschreiten und bewegt sich, wenn man annimmt, dass er vorwärtsgewandt aus der Zukunft kam, wie der Engel der Geschichte mit dem Rücken zu ihr. ${ }^{197}$ Von dieser Zukunft erhofft der Engel „nichts Neues mehr als nur den Blick des Menschen, dem er zugewandt bleibt“ (AS 521, erste Fassung).

195 Benjamin, Karl Kraus, S. 360.

196 Benjamin, Karl Kraus, S. 360. Dieser Ursprung impliziert bei Benjamin über Kraus hinausgehend auch eine Überwindung des mythischen Schuldzustands, die nicht Gericht und Urteil

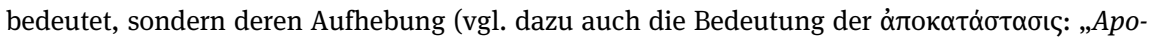
katastasis ist in frühjüdischer Apokalyptik und in gnostischer Spekulation die ,Wiederbringung aller', die Wiederherstellung des paradiesischen Zustandes und der ursprünglichen Schuldlosigkeit: Es wird kein Gericht geben und keinen Urteilsspruch“ (Menke, Sprachfiguren, S. 530)).

197 Vgl. Kapitel 4.2 dieser Studie. 
In der zweiten Fassung steht ein Wunsch, den Benjamin in „Zum Bilde Prousts“ (1929) als „Dialektik des Glücks““198 bezeichnet: „Er [der Engel, L.Z.] will das Glück: den Widerstreit, in dem die Verzückung des Einmaligen, Neuen, noch Ungelebten mit jener Seligkeit des Nocheinmal, des Wiederhabens, des Gelebten liegt.“ (AS 523, zweite Fassung) Die hymnisch-elegische Verflechtung des Glücks ist eng verknüpft mit der Figur der Erlösung und des Eingedenkens. ${ }^{199}$ Sie liegt Benjamins Bestimmung von Kraus' Ursprung zugrunde und weist zugleich auf den Untergang des Irdischen, ${ }^{200}$ der hier mit der Perspektive des unirdischen Engels antizipiert ist. Und obwohl diese Verbindung mit dem bereits begangenen Weg und dem neuen Menschen gegeben zu sein scheint, richtet sich die Hoffnung auch in der zweiten Fassung dann nicht, wie zu erwarten wäre, auf das Glück, sondern auf das Neue: „Darum hat er [der Engel, L.Z.] auf keinem Wege Neues zu hoffen als auf dem der Heimkehr, wenn er einen neuen Menschen mit sich nimmt.“ (AS 523, zweite Fassung) Auch das Attribut des Neuen zählt zu jenem Ensemble an Leitfiguren, die „Agesilaus Santander“ durchziehen: Neues Mannbarwerden, neuer Name und neuer Engel (als Klees Angelus Novus), die „Unzahl neuer Engel“, die Gott ihr Lob singen und vergehen, und schließlich der neue Mensch. Dieser ist doppeldeutig: Zum einen verweist der Begriff darauf, dass der Mensch für den Engel neu ist, zum anderen ist er aber auch anthropologisch und geschichtsphilosophisch konnotiert, als ein neuer, das heißt, ein anderer Mensch einer transhumanistischen Zukunftsvision. Dieser Mensch wäre dann einer, der das im Krieg zerstörte Menschliche des klassischen Humanismus überwunden und sich dem unmenschlichen Engel angenähert hat, der ihn in die Zukunft mitnimmt. Das Neue ist dabei nicht das unveränderliche Neueste, das die Moderne für Benjamin als „Zeit der Hölle“201 charakterisiert und das sich in den Presse-Sensationen als beständige Wiederholung derselben Phrase findet. ${ }^{202}$

198 Benjamin, Zum Bilde Prousts, S. 313.

199 Vgl. Benjamin, Das Passagen-Werk, S. 600; vgl. Marchesoni, Walter Benjamins Konzept des Eingedenkens, S. 110-111.

200 Zum Ursprung vgl. folgende Explikation: „Dieser ,Ursprung“ - das Echtheitssiegel an den Phänomenen - ist Gegenstand einer Entdeckung, die in einzigartiger Weise sich mit dem Wiedererkennen verbindet“ (Benjamin, Karl Kraus, S. 360); analog dazu: „Das Echte - jenes Ursprungssiegel in den Phänomenen - ist Gegenstand der Entdeckung, einer Entdeckung, die in einzigartiger Weise sich mit dem Wiedererkennen verbindet“ (Benjamin, Ursprung des deutschen Trauerspiels, S. 227). Zum Eingedenken vgl. Walter Benjamin, Theologisch-politisches Fragment. In: Benjamin, Gesammelte Schriften, Bd. II.1, hg. von Rolf Tiedemann u. Hermann Schweppenhäuser, Frankfurt am Main 1991, S. 203-204, hier S. 204.

201 Benjamin, Das Passagen-Werk, S. 676.

202 Vgl. Benjamin, Karl Kraus, S. 345. Der Presse-Sensation wird „die ewig neue ,Zeitung‘ gegenüber[gestellt], die von der Geschichte der Schöpfung zu melden ist: die ewig neue, die un- 
Das Neue, auf das der Engel hofft, entsteht vielmehr durch ein Re-entry des bereits Bekannten, nämlich in der Heimkehr, die der Neuentdeckung eingeschrieben ist.

Die beiden Fassungen klingen schließlich, nur mit einer leichten Dissonanz und wieder unauflösbar mehrdeutig, in einer zur Nüchternheit des Anfangs zurückkehrenden Wendung auf ein Ich aus, das ein unbestimmtes Du adressiert: „So fuhr ich, kaum daß ich zum ersten Male dich gesehen hatte, mit dir dahin zurück, woher ich kam“ (AS 521, erste Fassung), beziehungsweise „So wie ich, kaum daß ich zum ersten Male dich gesehen hatte, mit dir dahin zurückfuhr, woher ich kam“ (AS 523, zweite Fassung). Nachdem der Engel zuvor die Trennung von Menschen und Dingen sichtbar machte, die durch das realhistorische Exil erzwungen wurde, die aber auch geschichtsphilosophisch auf die exilische und verarmte Moderne verweist, steht am Schluss die Perspektive einer Vereinigung. Wessen Vereinigung? Scholem bringt neben der von ihm präferierten Deutung einer Anrede der Geliebten auch den Engel als Adressaten ins Spiel. ${ }^{203}$ Das scheint als Verkehrung der vorigen Aussagen nicht unbedingt naheliegend, ist aber grammatikalisch möglich. Angesichts des Kontextes stringenter, aber unerwarteter wäre ein Wechsel der Sprecherposition hin zum Engel, der sich an den Erzähler wendet. Spricht der Erzähler, so nimmt er nun offenkundig selbst eine engelhafte Position ein: Wie der Engel kam er von einem anderen Ort und wie der Engel nimmt er einen anderen Menschen mit dorthin zurück.

Bemerkenswerterweise ist hier aber nicht von „mitnehmen“ (wie in der zweiten Fassung in Bezug auf die Heimkehr des Engels samt Partner), sondern von „fahren“ die Rede, und zwar in beiden Fassungen. Weiter stand in der ersten Fassung zunächst die später gestrichene „Fahrt“ anstelle der „Flucht“ des Engels in eine Zukunft. ${ }^{204}$ Der Begriff des Fahrens vereinigt den Bereich des Technischen, der für Benjamin den „Fetisch schöpferischen Daseins“205 demoliert, mit altbiblischer Zerstörungskraft. Beide sind über Gestaltungs- und Wirkungsweise des Engels, genauer des Cherubs, vermittelt. ${ }^{206}$ So ist der Cherub

ausgesetzte Klage“ (Benjamin, Karl Kraus, S. 345). Vgl. auch Walter Benjamin, Ankündigung der Zeitschrift: Angelus Novus. In: Benjamin, Gesammelte Schriften, Bd. II.1, hg. von Rolf Tiedemann u. Hermann Schweppenhäuser, Frankfurt am Main 1991, S. 241-246, hier S. 241-242.

$203 \mathrm{Vgl}$. Scholem, Walter Benjamin und sein Engel, S. 125.

204 Vgl. Rolf Tiedemann u. Hermann Schweppenhäuser, Aufzeichnungen 1933-1939 [Agesilaus Santander]. In: Benjamin, Gesammelte Schriften, Bd. VI, hg. v. Rolf Tiedemann u. Hermann Schweppenhäuser, Frankfurt am Main 1991, S. 808-815, hier S. 815.

205 Benjamin, Karl Kraus, S. 367.

206 So heißt es in „Erfahrung und Armut“: „Klees Figuren sind gleichsam auf dem Reißbrett entworfen und gehorchen, wie ein gutes Auto auch in der Karosserie vor allem den Notwendigkeiten des Motors, so im Ausdruck ihrer Mienen vor allem dem Innern“ (Benjamin, Erfah- 
wortwörtlich der fahrbare Untersatz Gottes. Die Mobilität dieser in ihrer grenzsetzenden Funktion eigentlich statischen Figur geht mit radikalen Konsequenzen einher. In Davids Beschreibung von Gottes Rettung in Psalm 18 etwa wird gleich der ganze Himmel in Bewegung versetzt:

Die Erde bebte und wankte, und die Grundfesten der Berge bewegten sich und bebten, da er [Gott, L.Z.] zornig war. Rauch stieg von seiner Nase und verzehrend Feuer aus seinem Munde; Flammen sprühten von ihm aus. Er neigte den Himmel und fuhr herab, und Dunkel war unter seinen Füßen. Und er fuhr auf dem Cherub und flog daher, er schwebte auf den Fittichen des Windes [meine Hervorhebung, L.Z.].

(Ps 18,8-11)

Entgegen dem zitierten Mythos der unzähligen entstehenden und nach ihrem Lobpreis wieder vergehenden Engel weisen die (raub-)tierhaften Attribute des Engels und das Fahren auf den Cherub. Im Buch des Propheten Ezechiel, das zu Beginn des 20. Jahrhunderts ausgiebig rezipiert wurde, sind die Cherubim der hybride Brennpunkt einer visionsliterarischen Überwältigungsästhetik. ${ }^{207}$ Auch in der revidierten Lutherbibel von 1912 werden sie noch als „Tiere“ (Ez 1,13) bezeichnet, da sie im Gegensatz zu den üblichen Botenengeln (vier) Flügel, also Schwingen, und neben einem menschlichen Antlitz auch das eines Stiers beziehungsweise eines Cherubs (vgl. Ez 10,14), eines Löwen und eines Adlers haben; vor allem aber sind sie im Gegensatz zu ihrer grenzsetzenden Funktion als Wächterfigur auch hier eine Art Mobilitätsträger:

Als ich die Tiere so sah, siehe, da stand ein Rad auf der Erde bei den vier Tieren und war anzusehen wie vier Räder. Und die Räder waren wie Türkis und waren alle vier eins wie das andere, und sie waren anzusehen, als wäre ein Rad im andern. Wenn sie gehen wollten, konnten sie nach allen ihren vier Seiten gehen und sie mußten nicht herumlenken, wenn sie gingen. [...] Auch wenn die vier Tiere gingen, so gingen die Räder auch neben ihnen; und wenn die Tiere sich von der Erde emporhoben, so hoben sich die Räder auch empor.

(Ez 1,15-19; Lutherbibel 1912)

Neben den animalischen Eigenschaften und dem technischen Anstrich liegt eine weitere Verbindung in dem Exilkontext, den Ezechiel als „einer der ersten Heimatvertriebenen“ ${ }^{208}$ aufruft. Aber auch die talmudische Legende der ent-

rung und Armut, S. 216). Zum technischen Aspekt des Engels bei Benjamin vgl. Kapitel 4.2 dieser Studie. Über Karl Kraus’ Leistung, „selbst die Zeitung zitierbar zu machen“, heißt es: „Er versetzt sie [die Zeitung, L.Z.] in seinen Raum, und mit einem Mal muß die Phrase es inne werden: im tiefsten Bodensatze der Journale ist sie nicht sicher vor dem Zustoß der Stimme, die auf den Schwingen des Wortes herabfährt, um sie ihrer Nacht zu entreißen [meine Hervorhebungen, L.Z.]“ (Benjamin, Karl Kraus, S. 363).

$207 \mathrm{Zu}$ dem überwältigungsästhetischen Aspekt des Cherubs bei Kleist vgl. Polaschegg, Von der Vordertür des Paradieses, S. 490-491.

208 Der Spiegel, Raumflug nach Jerusalem, 1, 1973, S. 85-96, hier S. 85. 
stehenden und vergehenden Engel klingt hier nach. Sie stammt aus dem zweiten Kapitel des Traktats Chagiga, ${ }^{209}$ wo jene Vision der מֶרְָָָָּ (hebräisch für „Wagen“) des ersten und zehnten Kapitels von Ezechiel thematisiert wird. Um diese entwickelte sich eine ganze Mystik, wobei in der entsprechenden Literatur, der Hekhalot-Literatur (von hebräisch הִיכָ: „Palast“, „Tempel“, „Halle“), Name und Engel wie in „Agesilaus Santander“ eine zentrale Rolle spielen. ${ }^{210}$ Bei der Offenbarung der מֶרְָָּּה handelt es sich überdies um eine geheime Materie, die Unbefugten verboten ist. Galili Shahar weist darauf hin, dass daher die Episode der transitorischen Engel in „Agesilaus Santander“ als Teil jener „discussion on the forbidden visions of the merkavah" ${ }^{211}$ selbst zu einem Geheimnis gehört. Insofern spiegelt der mit diesen flüchtigen assoziierte und von ihnen doch so verschiedene Engel zugleich die konstitutive Struktur des Textes, der zwischen Veröffentlichung und Geheimhaltung schwankt.

\subsection{Der Engel zwischen Apparatur und Apparition: „Über den Begriff der Geschichte“ (1940)}

Das Spiel mit dem Geheimnis scheint in „Über den Begriff der Geschichte“ endgültig vorbei. In der zwischen Februar und März 1940 verfassten Thesensammlung ist im Angesicht unmittelbarer existentieller Gefährdung der mystische Gestus von „Agesilaus Santander“ höchster sprachlicher Präzision und einer klaren politischen Marschrichtung gewichen. Es geht um den „Kampf gegen den Faschismus“"212. Diesen gilt es in Form einer Allianz von historischem Materialismus und Theologie siegreich zu bestreiten. Entsprechend steht in der Sprache, in der die Bestimmung des historischen Materialismus entwickelt wird, nicht die opake Ausstellung von hermetischen Prozessen zwischen Geheimnis und Veröffentlichung im Vordergrund. Statt um den Name als Modus reiner Medialität, der in „Agesilaus Santander“ im Zentrum steht, geht es hier um „das Gedächtnis der

209 Vgl. Shahar, In the Name of the Devil, S. 108.

210 Vgl. Peter Schäfer, Der göttliche Name. Geheimnis und Offenbarung in der Merkava-Mystik. In: Schleier und Schwelle. Archäologie der literarischen Kommunikation V, Bd. 2: Geheimnis und Offenbarung, hg. v. Aleida Assmann u. Jan Assmann, München 1998, S. 143-159, hier S. 143.

211 Shahar, In the Name of the Devil, S. 108.

212 Walter Benjamin, Über den Begriff der Geschichte. In: Benjamin, Gesammelte Schriften, Bd. I.2, hg. von Rolf Tiedemann u. Hermann Schweppenhäuser, Frankfurt am Main 1991, S. 693-794, hier S. 697. Im Folgenden T (Thesen). 


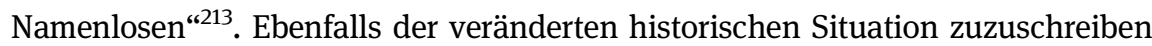
ist, dass der „Kampfwert““214 marxistischer Thesen fruchtbar gemacht wird, die, wie es in dem 1935 verfassten „Kunstwerk“-Aufsatz heißt, „eine Vielzahl überkommener Begriffe [...] beiseite“ setzen. Zu diesen gehört auch das „Geheimnis“215, das in „Agesilaus Santander“ eine entscheidende Rolle spielt. Unbrauchbar sind diese Begriffe für Benjamin in der gegenwärtigen Situation, da ihre „unkontrollierte (und augenblicklich schwer kontrollierbare) Anwendung zur Verarbeitung des Tatsachenmaterials in faschistischem Sinn führt“216.

Welche Rolle kommt dem Engel in der von der faschistischen Bedrohung gezeichneten Schrift „Über den Begriff der Geschichte“ zu? Um das zu erkennen, ist es nötig, das besondere Verständnis von politischer Praxis nachzuvollziehen, das ihr zugrunde liegt. Deren Ausgangspunkt ist eine bestimmte Form der Geschichtsschreibung, die ein herkömmliches Konzept von Zeit als Serie abgegrenzter und einander unbeteiligt folgender Momente ablehnt. Um vergangene Momente zu erkennen und im gegenwärtigen Moment eine politische Veränderung herbeizuführen, ist für Benjamin eine Offenheit und Kollision chronologisch unverbundener Zeitpunkte nötig. So ist das Vergangene nicht endgültig vergangen, sondern steht in Verbindung zu den gegenwärtig lebenden Menschen, die sich in einer bestimmten Verantwortung für, aber auch in einer Angewiesenheit auf diese Vergangenheit befinden. Da aktuelle Sprengkraft nur erzeugt werden kann, wenn ein dem gegenwärtigen Moment korres-

213 Walter Benjamin, Anmerkungen [Über den Begriff der Geschichte]. In: Benjamin, Gesammelte Schriften, Bd. I.3, hg. von Rolf Tiedemann u. Hermann Schweppenhäuser, Frankfurt am Main 1991, S. 1223-1266, hier S. 1241.

214 Walter Benjamin, Das Kunstwerk im Zeitalter seiner technischen Reproduzierbarkeit. In: Benjamin, Gesammelte Schriften, Bd. I.2, hg. von Rolf Tiedemann u. Hermann Schweppenhäuser, Frankfurt am Main 1991, S. 435-508, hier S. 435.

215 Benjamin, Das Kunstwerk im Zeitalter seiner technischen Reproduzierbarkeit, S. 473.

216 Benjamin, Das Kunstwerk im Zeitalter seiner technischen Reproduzierbarkeit, S. 473. Das Adjektiv „geheim“ fällt in den Thesen, wenn es darum geht, die offenkundig nicht näher zu ergründende Verbindung zwischen Vergangenheit und Gegenwart zu charakterisieren: „Ist dem so, dann besteht eine geheime Verabredung zwischen den gewesenen Geschlechtern und unserem“ (T 694) und „Wie Blumen ihr Haupt nach der Sonne wenden, so strebt kraft eines Heliotropismus geheimer Art, das Gewesene der Sonne sich zuzuwenden, die am Himmel der Geschichte im Aufgehen ist“ (T 694-695). Das Geheime gehört hier zum beschriebenen Phänomen, ist aber nicht Teil der sprachlichen Einkleidung. Gleiches gilt für die Allegorie der I. These, in der „der Erfolg des Automaten auf seinem Geheimnis, und dieses wiederum auf optischer Täuschung und einem Konstruktionstrick“ beruht (Jeanne Marie Gagnebin, „Über den Begriff der Geschichte“. In: Benjamin-Handbuch. Leben - Werk - Wirkung, hg. von Burkhardt Lindner, Stuttgart 2011, S. 284-300, hier S. 296), deren Wirkungsweise selbst aber nicht im Dunkeln gelassen, sondern erläutert wird. 
pondierender Moment der Vergangenheit mit ihrem „heimlichen Index, [...] durch den sie auf die Erlösung verwiesen wird“ (T 693), erfasst wird, konvergieren in der Geschichtsschreibung die Rettung des Verlorenen der Vergangenheit und die Möglichkeit zur Revolution.

Revolutionäre Aktion ergibt sich aus der jeweiligen politischen Situation heraus, aber genauso auch „durch die Schlüsselgewalt dieses Augenblicks über ein ganz bestimmtes, bis dahin verschlossenes Gemach der Vergangenheit““217, wie es in den Anmerkungen zu den „Thesen“ heißt. Erst durch das Eintreten in dieses Gemach zeigt sich die politische Aktion als „eine messianische“218. Dem Historisten, der nach Benjamin mit seinem ideologischen Anspruch von Neutralität und Objektivität die Siegergeschichte zum Götzenbild seiner Einfühlung macht, bleibt dieser Zugang hingegen verwehrt. Während es diesem um „das ,ewige“ Bild der Vergangenheit“ (T 702) geht, gilt die gespannte Aufmerksamkeit des historischen Materialisten dem „wahre[n] Bild der Vergangenheit“, das als vorbeihuschendes im Moment seiner „Erkennbarkeit“ (T 695) nur flüchtig gegeben ist. Damit ist ein erster Anhaltspunkt für die Bedeutung des Engels gegeben, in dem sich vergangene, gegenwärtige und zukünftige Zeiträume verdichten, die messianisch durchwirkt sind. Modus und Zeitmaß der historischen Erkenntnis, wie Benjamin sie skizziert, entsprechen überdies dem flüchtigen Bild der Engelserscheinung. Sie vollzieht sich nämlich in sogenannten dialektischen Bildern: „Nicht so ist es, daß das Vergangene sein Licht auf das Gegenwärtige oder das Gegenwärtige sein Licht auf das Vergangene wirft, sondern Bild ist dasjenige, worin das Gewesene mit dem Jetzt blitzhaft zu einer Konstellation zusammentritt. Mit anderen Worten: Bild ist Dialektik im Stillstand.“219 Wie der Engel sind auch dialektische Bilder mediale Grenzgänger - „der Ort, an dem man sie antrifft, ist die Sprache“ ${ }^{\text {2220. }}$

Mit dieser Beziehung von vergangenem und gegenwärtigem Moment ist eine weitere mit dem Engel verknüpfte Operation verbunden, die des Unterbrechens. „Geschichte schreiben heißt also Geschichte zitieren. Im Begriff des Zitierens liegt aber, daß der jeweilige historische Gegenstand aus seinem Zusammenhange gerissen wird“ (T 595), schreibt Benjamin im Passagen-Werk. Folglich ist Geschichte „Gegenstand einer Konstruktion“ und zwar nicht in der „homogene[n] und leere [n] Zeit“, die den Nährboden für das Fortschrittsdogma bildet, das Benjamin verwirft, sondern in der „von Jetztzeit erfüllte[n]“ (T 701). In dieser Zeit stellt ,jedes

217 Benjamin, Anmerkungen [Thesen], S. 1231.

218 Benjamin, Anmerkungen [Thesen], S. 1231.

219 Benjamin, Das Passagen-Werk, S. 577.

220 Benjamin, Das Passagen-Werk, S. 577. 
Jetzt [...] das Jetzt einer bestimmten Erkennbarkeit“ ${ }^{221}$ dar. Die Bewegung des Zitierens schlägt sich in „Über den Begriff der Geschichte“ auch strukturell in Form der getrennten Thesen nieder, die nicht diskursiv auseinander entwickelt werden, sondern eine fragmentarische Formation darstellen. Neben der grundsätzlichen Möglichkeit einer „geheime[n] Verabredung zwischen den gewesenen Geschlechtern und unserem“ (T 694) ist es das Moment der Gefahr, das die Verbindung zwischen Toten und Lebenden stiftet und die Aufsprengung der historischen Kontinuität der Sieger motiviert. Diese Gefahr stellt auch die Verbindung zur Situation des Schreibenden her: Die weltpolitische Lage verdüsterte sich nach dem Hitler-Stalin-Pakt und dem Beginn des Zweiten Weltkriegs zunehmend, und auch Benjamins persönliche Situation als ,an den Rand der Existenznot in jedem Sinne geführte[r] Flücht$\operatorname{lin}[\mathrm{g}]^{\text {‘222 }}$ war bedrohlich.

Die Bildqualität, das Prinzip der Relationalität, die diskontinuierliche Zeitstruktur und die flüchtige Erscheinung sind für Benjamin die Bedingungen der Möglichkeit von historischer Erkenntnis. Gleichzeitig stellen sie epistemische und mediale Parameter dar, die allesamt mit der Engelsfigur verknüpft sind. Es liegt daher nahe, dass sich die Aussagekraft des Engels der Geschichte nicht auf die IX. These beschränkt, in der dieser vergeblich versucht, die Trümmer vergangener Zeiten zusammenzufügen und die Toten zu erwecken. Diese Annahme ist insofern keine Selbstverständlichkeit, als das offensichtlich Allegorische dieser Figur dazu geführt hat, in ihr nur den Verweis, beispielsweise auf allgemein Theologisches, zu sehen. Gerade die Berühmtheit des Engels der Geschichte birgt die Gefahr, dass er zum leeren Emblem wird, etwa für eine melancholisch-pessimistische Weltsicht. ${ }^{223}$ Entgegen dieser Tendenz soll dem angelischen Sujet im Folgenden auf inhaltlicher und strukturell-methodischer Ebene nachgegangen, die medienästhetische Spezifik des Engelsblicks eruiert und die Bedeutung des Scheiterns des Engels beleuchtet werden.

Liest man die IX. These vor der Folie von Benjamins geschichtsphilosophisch eingefasster Filmästhetik, so lassen sich mehrere funktionale Analogien beobachten. Dazu gehört vor allem die zwischen Kamera und Engel, die beide eine Perspektive zur Anschauung bringen, die der unmittelbaren menschlichen Wahrnehmung verschlossen ist. Mit der Funktionsweise einer technischen Apparatur macht der Engel die Gebrochenheit des historischen Geschehens und damit das Verdrängte der Geschichte sichtbar. Gleichzeitig trägt der Engel in die Funktionalität moderner Technik jenes gegenläufiges Moment, das die An-

221 Benjamin, Das Passagen-Werk, S. 578.

222 Scholem, Walter Benjamin und sein Engel, S. 110.

223 Vgl. Scholem, Walter Benjamin und sein Engel, S. 67. 
gelophanie als intensive und einzigartige Erfahrung auszeichnet. Die Ausgangsthese dieses Kapitels besagt, dass die spezifische Medialität des Engels in den „Thesen“ im Spannungsfeld von technischer Apparatur und auratischer Apparition (als „Himmelserscheinung“224) situiert ist, und in einem spezifischen historischen Moment, nämlich dem faschistischer Bedrohung, in Erscheinung tritt. In dieser Spannung macht der Engel als unmenschlich-technisches Medium unsichtbares Leid sichtbar und evoziert als religiöse Figur die Möglichkeit, das vergangene Leid zu etwas Unabgeschlossenem zu machen.

\title{
4.2.1 Die Medialität des Engelsblicks
}

\author{
IX \\ Mein Flügel ist zum Schwung bereit \\ ich kehrte gern zurück \\ denn blieb' ich auch lebendige Zeit \\ ich hätte wenig Glück. \\ Gerhard Scholem, Gruß vom \\ Angelus
}

\begin{abstract}
Es gibt ein Bild von Klee, das Angelus Novus heißt. Ein Engel ist darauf dargestellt, der aussieht, als wäre er im Begriff, sich von etwas zu entfernen, worauf er starrt. Seine Augen sind aufgerissen, sein Mund steht offen und seine Flügel sind ausgespannt. Der Engel der Geschichte muß so aussehen. Er hat das Antlitz der Vergangenheit zugewendet. Wo eine Kette von Begebenheiten vor uns erscheint, da sieht er eine einzige Katastrophe, die unablässig Trümmer auf Trümmer häuft und sie ihm vor die Füße schleudert. Er möchte wohl verweilen, die Toten wecken und das Zerschlagene zusammenfügen. Aber ein Sturm weht vom Paradiese her, der sich in seinen Flügeln verfangen hat und so stark ist, daß der Engel sie nicht mehr schließen kann. Dieser Sturm treibt ihn unaufhaltsam in die Zukunft, der er den Rücken kehrt, während der Trümmerhaufen vor ihm zum Himmel wächst. Das, was wir den Fortschritt nennen, ist dieser Sturm.

(T 697-698)
\end{abstract}

Im Gegensatz zu der Notiz „Agesilaus Santander“, in der nur von dem „Neuen Engel“ die Rede ist, wird hier explizit auf das Bild Angelus Novus von Paul Klee Bezug genommen. Klee steht für Benjamin in der Reihe jener „Barbaren“ im positiven Sinn, die als Vertreter des ästhetischen Rationalismus den technisch inspirierten Prinzipien der Reduktion und Konstruktion folgen. ${ }^{225}$ Auch das Bild

224 Adorno, Ästhetische Theorie, S. 125.

225 Vgl. folgende Stelle: „Denn wohin bringt die Armut an Erfahrung den Barbaren? Sie bringt ihn dahin, von vorn zu beginnen; von Neuem anzufangen; mit Wenigem auszukommen; aus Wenigem heraus zu konstruieren und dabei weder rechts noch links zu blicken“ (Benjamin, Erfahrung und Armut, S. 215). Vgl. dazu auch Detlev Schöttker, Reduktion und Montage. Ben- 
Angelus Novus entspricht in der ,groteske[n] Zusammengesetztheit der Figur aus divergenten Einzelteilen“'226 dieser Gestaltungsform. Die IX. These setzt also ein mit der Bildbeschreibung des existenten Kunstwerks von Paul Klee, aus der dann eine zweite Bildbeschreibung, die des Engels der Geschichte, entwickelt wird. Dessen Existenz scheint ebenso gesichert, nur sein Aussehen nicht völlig klar. Zwischen beiden Engeln besteht eine Ähnlichkeitsbeziehung, die auf einer Art spekulativer Gewissheit beruht, aber keine Identität („der Engel der Geschichte muß so aussehen“). ${ }^{227}$ In dieser Doppelung der Engel potenziert sich der angelische Modus der Repräsentation als Zusammenspiel von Identität und Differenz. ${ }^{228}$

Abgesehen von den wellenförmigen Haaren und der Farbschattierung des Gesichts, die eine gewisse Plastizität suggeriert, ist die Gestaltung des Klee-Engels mit seinen gezeichneten Umrissen und den segmentären Unterteilungen des Körpers flächig. Gleiches gilt für den Textkörper der XI. These. Sowohl in dem Bild Angelus Novus als auch in der Beschreibung des Engels der Geschichte ist es jeweils erst der Blick, der eine Dynamik erzeugt und einen multidimensionalen Raum ausspannt. Der Blick des Angelus Novus ist auffällig, weil beide Augen sich unabhängig voneinander zu bewegen scheinen. Während das linke Auge nach innen und tendenziell nach unten weist, wirkt das rechte Auge in den Raum hin und nach oben geöffnet. Die Spezifik dieser Blicklinien impliziert eine Mehrdimensionalität, die nur durch das Blickfeld des Engels, nicht durch

jamin, Brecht und die konstruktivistische Avantgarde. In: global benjamin, Bd. 2, hg. von Klaus Garber u. Ludger Rehm, München 1999, S. 745-773, hier S. 765.

226 Rösch, Die Hermeneutik des Boten, S. 38. Auch das Ineinander von Text und Bild, das den Engel der Geschichte charakterisiert, ist typisch für Klees Engelsbilder. So weist Perdita Rösch darauf hin, dass die Engel ohne den Titel gar nicht unbedingt als solche erkennbar sind, sie zu Engeln also erst durch das Zusammenspiel von Bild und Text werden (vgl. Rösch, Die Hermeneutik des Boten, S. 34). In der IX. These wird diese Besonderheit insofern fortgesetzt, als der These ein Scholem-Zitat, das sich auf das Bild bezieht, vorangestellt ist.

227 Vgl. Sigrid Weigel, Walter Benjamin. Die Kreatur, das Heilige, die Bilder, Frankfurt am Main 2008, S. 272.

228 Diese Doppelung des Bilds lässt sich auch bei dem Klee-Bild Angelus Novus beobachten: Klee fertigte zunächst eine Bleistiftzeichnung der Figur an und pauste sie per Öldruckverfahren durch. Auf dieser Grundlage entstand dann der (zweite) Angelus Novus (vgl. Johann Konrad Eberlein, „Angelus Novus“. Paul Klees Bild und Walter Benjamins Deutung, Freiburg im Breisgau; Berlin 2006, S. 31). Weiter verweist Eberlein darauf, dass es „nicht die erste Fassung eines solchen Bilds in seinem [Klees, L.Z.] Euvre, sondern die zweite“ ist - „[d]er ,Angelus novus“ ist eine Wiederholung des ,Angelus descendens““ (Eberlein, „Angelus Novus“, S. 49). Und nicht zuletzt lässt sich auch in der untrennbar verzahnten Rezeption von Klees Bild und Benjamins Texten eine weitere Ausprägung dieses Doppelgängertums erblicken. 
die zweidimensionale Beschaffenheit seines Körpers oder seine unbestimmte Umwelt entsteht. Analog dazu ist es auch beim Engel der Geschichte der Blick, der eine Räumlichkeit aufspannt, in dem sich das folgende Geschehen abspielt. Diese bildhafte Konstruktion - also ein Bild im (Sprach-)Bild, das wiederum auf das dialektische Bild verweist - zeigt eine andere Geschichte, die nicht gleichmäßig, sondern eruptiv-katastrophisch verläuft. Auffällig ist weiter die aktive Dimension, die sowohl den Engelsblick als auch die Katastrophe kennzeichnet, die durch diesen sichtbar wird. Der Kontrast zwischen angelischer Blickaktivität und passiver menschlicher Wahrnehmung wird durch die Kursivierung von „uns“ und „er“ betont: Eine unpersönliche „Kette von Begebenheiten [...] erscheint“ vor „uns“, während der Engel, der „das Antlitz der Vergangenheit zugewendet“ hat, „eine einzige Katastrophe“ als die Akteurin „sieht“, die die Trümmer „,ihm vor die Füße schleudert“. Diese Katastrophe setzt sich aus einzelnen Schock-Momenten zusammen, ${ }^{229}$ die der Engel für uns Menschen sichtbar macht.

Der Fokus auf dem Sehen und der unmittelbaren Betroffenheit des Engels stellt die aisthetische Fundierung von Erkenntnis aus. Damit ist sie der olympisch-indifferenten Position entgegengesetzt, die Benjamin dem Historismus zuschreibt. Indem der Engel dem Sturm entgegenblickt und dadurch ein heterogenes und geweitetes Wahrnehmungsfeld sichtbar macht, entlarvt er die historische Kontinuität als Produkt eines eindimensionalen menschlichen Blicks. Dieser GegenBlick des Engels ermöglicht es, Geschichte als die einer zerstörerischen Unterdrückung zu erkennen. Zugleich wird die Gegenwart in einem anderen Licht sichtbar: Diese Perspektive „,belehrt uns darüber, daß der ,Ausnahmezustand', in dem wir leben, die Regel ist“ (T 697), wie es in der VIII. These heißt. Das Postulat, zu einem Begriff von Geschichte zu gelangen, der diesem Sachverhalt Rechnung trägt, verweist neben seiner geschichtsphilosophischen Bedeutung auch auf das Faktum, dass das NS-Regime juristisch bis zu seinem Ende einen Ausnahmezustand darstellte. ${ }^{230}$

Angesichts dieser Erkenntnis zeichnet sich ,als unsere Aufgabe die Herbeiführung des wirklichen Ausnahmezustands“ ab, wodurch auch „unsere Position im Kampf gegen den Faschismus sich verbessern“ (T 697) wird. Der Engel übernimmt dabei als Visualisierungsgehilfe jene im Passagen-Werk mit einem Zitat von Rudolf Borchardt formulierte „[p]ädagogische Seite dieses Vorhabens: ,Das

229 So sei „[d]as Ideal des chockförmigen Erlebnisses [...] die Katastrophe“ (Benjamin, Das Passagen-Werk, S. 642).

230 Vgl. Giorgio Agamben, Ausnahmezustand, Frankfurt am Main 2004, S. 8 u. S. 70-71. 
bildschaffende Medium in uns $\mathrm{zu}$ dem stereoskopischen und dimensionalen Sehen in die Tiefe der geschichtlichen Schatten zu erziehen ““231. Dass der Blick des Engels keinen anderen, nichtirdischen Schauplatz eröffnet, sondern das dem Menschen Unsichtbare entbirgt, wird explizit gesagt: Wo uns die eindimensionale Geschehenskette erscheint, da sieht er Trümmer sich im Raum der Geschichte stapeln. Auf diese Weise wird die Aufgabe des Engels, dem Unsichtbaren Sichtbarkeit zu verleihen, von der Vermittlung des Numinosen im Profanen in die Horizontale des geschichtlichen Raumes verlagert. Die damit verbundene Rekonfiguration von Raum und Zeit vollzieht sich über das Bild, das in dem Anwesendmachen von etwas Abwesendem eine eigene Realität schafft.

Insofern stimmt die Bemerkung nicht, der Engel der Geschichte könne „nur versuchen, den Schaden zu benennen“ “232. Tatsächlich benennt er ihn als schweigender ja gerade nicht und seine Bedeutung besteht auch nicht in einem etwaigen Versuch, über den Aussagen notwendig spekulativ bleiben müssen. Der Engel macht den Schaden vielmehr performativ für die Rezipientinnen und Rezipienten der „Thesen“ sichtbar. Das Bild, bei Benjamin Modus der unwillkürlichen Erinnerung und Konsequenz aus der „Liquidierung des epischen Momentes in der Geschichtsdarstellung “233, ist weder in seinem Aufblitzen noch in seinem Inhalt kontrollierbar. Es bedeutet wesentlich „Unordnung“234. Darin entspricht es den Engeln, die sich sowohl in ihrer unergründbaren Vielzahl als auch in Form der Angelophanie menschlicher Steuerung entziehen. Verstärkt wird dieser Aspekt der Unverfügbarkeit durch den Engel als unmenschlichen Bilderproduzenten, der hier für einen qualitativ anderen Zugang zur Geschichte steht.

Vor diesem Hintergrund wird deutlich, wie sich die in „Agesilaus Santander“ in Rückgriff auf den Essay „Karl Kraus“ ausgemachte zerstörerische Dimension des Engels verschiebt. Dort trat der Engel als menschenfresserische Überwindung des historisch obsolet gewordenen idealistischen Humanismus

231 Benjamin, Das Passagen-Werk, S. 571. Vgl. zum stereoskopischen Sehen: „Das Stereoskop trennt die beiden Augen und zeigt ihnen jeweils ein einzelnes Bild. Dieses technische Verfahren dient dazu, einen räumlichen Effekt hervorzurufen, da durch die Übereinanderblendung beider Bilder diese als dreidimensionale Staffelung von Flächen erscheinen. Nicht die Präzision der Projektion der Außenwelt in die Camera obscura des Auges, sondern die transformierende Synthese der beiden Bilder, die zerebrale Bildverarbeitung also ist Grundlage der Wahrnehmung und Voraussetzung des stereoskopischen Effekts“ (Bernd Stiegler, Objektives Sehen und subjektiver Blick. Zur Theorie der Fotographie in den zwanziger Jahre. In: Mediengebrauch und Erfahrungswandel. Beiträge zur Kommunikationsgeschichte, hg. von Detlev Schöttker, Göttingen 2003, S. 157-169, hier S. 162).

232 Gagnebin, „Über den Begriff der Geschichte“, S. 297.

233 Benjamin, Anmerkungen [Über den Begriff der Geschichte], S. 1243.

234 Benjamin, Anmerkungen [Über den Begriff der Geschichte], S. 1243. 
auf. ${ }^{235}$ Auch in den „Thesen“ ist die entscheidende Wirkung des Engels eine destruktive. Allerdings bringt er keine Zerstörung auf der Inhaltsebene, im Gegenteil, die einzige Aussage über seine Intention ist die, dass er die Trümmer der Geschichte zusammenfügen möchte. Seine zerstörerische Potenz greift vielmehr im Bereich der Medialität: Er zertrümmert das kohärente Geschichtsbild, das den Herrschenden zugutekommt, und stellt dagegen die Konstruktion von fragmentarischen Bildern, die das hegemoniale Geschichtsnarrativ bisher verdeckte. Der Aspekt der Medialität ist also von entscheidender Bedeutung für Benjamins Gegen-Bild von Geschichte, das an den technischen Gestaltungsprinzipien der Konstruktivisten geschult ist. ${ }^{236}$

\subsubsection{Geschichte als Katastrophenfilm}

Die Frontstellung gegen die Einfühlung in die Sieger der Geschichte wird in den „Thesen“ überwiegend diskursiv entwickelt. Anders in der IX. These, die die Parteinahme für die Unterdrückten als eine über den Engel ermöglichte filmästhetische Konstruktion vorführt. Die Szenerie der gesamten These ähnelt

235 Diese Wandlung lässt sich anhand der Verwendung des Barbarenbegriffs bei Benjamin zeigen. In „Erfahrung und Armut“, also zur Abfassungszeit von „Agesilaus Santander“, nutzte Benjamin den Begriff programmatisch: „Ja, gestehen wir es ein: Diese Erfahrungsarmut ist Armut nicht nur an privaten sondern an Menschheitserfahrungen überhaupt. Und damit eine Art von neuem Barbarentum. Barbarentum? In der Tat. Wir sagen es, um einen neuen, positiven Begriff des Barbarentums einzuführen“ (Benjamin, Erfahrung und Armut, S. 215). Während Benjamin in „Erfahrung und Armut“ das Barbarische dialektisch aufwertet - das Unmenschliche der Gesellschaft wird genutzt, um den Humanismus neu zu denken -, steht in den Thesen der Impetus der Distanzierung im Vordergrund: „Es ist niemals ein Dokument der Kultur, ohne zugleich ein solches der Barbarei zu sein. Und wie es selbst nicht frei ist von Barbarei, so ist es auch der Prozeß der Überlieferung nicht, in der es von dem einen an den andern gefallen ist. Der historische Materialist rückt daher nach Maßgabe des Möglichen von ihr ab“ (T 696-697). Gleichzeitig wird in dieser Aussage der Begriff gewissermaßen in sich selbst zurückgeführt, verhandeln doch ,[i]n der Thematik des Barbarischen [...] die europäischen Kulturen die Sache der Kultur selbst“ (Manfred Schneider, Der Barbar. Endzeitstimmung und Kulturrecycling, München; Wien 1997, S. 11). $\mathrm{Zu}$ Benjamins Konzept des Barbarischen vgl. auch Georgios Sagriotis, Barbarians and Their Cult: On Walter Benjamin's Concept of New Barbarism. In: Thamyris/Intersecting: Place, Sex \& Race, 29, 2015, S. 255-265. Benjamins gewandelter Gebrauch des Begriffs mag auch mit dessen Inanspruchnahme durch die Nationalsozialisten zusammenhängen, die insbesondere 1933 auf den Barbaren als positive Identifikationsfigur zurückgriffen (vgl. Schneider, Der Barbar, S. 210).

236 Die Theorie der Montage, die mit der Praktik des Zitierens unmittelbar zusammenhängt (vgl. Benjamin, Das Passagen-Werk, S. 572), hat Benjamin ab den 1930er Jahren für den Umgang mit Geschichte fruchtbar gemacht (vgl. allgemein Schöttker, Reduktion und Montage). 
Brechts epischem Theater, wie Benjamin es in „Der Autor als Produzent“ (1934) beschreibt. So wirkt auch im Falle des Engels die Unterbrechung „einer Illusion im Publikum entgegen“237. Die Zustände, die durch die Unterbrechung entdeckt werden und die ,in dieser oder jener Gestalt immer die unsrigen sind [...], werden dem Zuschauer nicht nahegebracht, sondern von ihm entfernt “238. Dieses Entfremdungsmoment bildet die Grundlage von Erkenntnis. Es wird hier über die Figur des unmenschlichen Engels erzeugt und zwar „[i]m Zeitalter der aufs Höchste gesteigerten Entfremdung der Menschen voneinander“‘239 ebenso wie ihrer (Erfahrungs-)Armut.

Analog zum Blick des Engels, der die ,Bühne‘ einer anderen Geschichte entwirft,

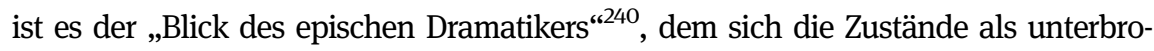
chene Handlungen erschließen. In „Der Autor als Produzent“ verfolgt Benjamin die These, dass der künstlerische Produzent sich für „die richtige politische Tendenz “241 auf der Höhe der technischen Entwicklung befinden muss, da zwischen beiden Komponenten eine „funktional[e] Abhängigkeit“242 bestehe. Mag der Gehalt der Werke beziehungsweise die Gesinnung der Kunstschaffenden revolutionär sein, solange sie den Produktionsapparat nur beliefern, bleiben sie reaktionär. Den Kern der Argumentation bildet der Begriff der Technik, der „die literarischen Produkte einer unmittelbaren gesellschaftlichen, damit einer materialistischen Analyse zugänglich“243 macht. Gleichzeitig stellt er „den dialektischen Ansatzpunkt dar, von dem aus der unfruchtbare Gegensatz von Form und Inhalt zu überwinden ist“ ${ }^{244}$. Während das althergebrachte Theater nach Benjamin einen hinfälligen Apparat beliefert und mit Film und Rundfunk zu konkurrieren versucht, wendet das epische Theater die neuen Produktionsmittel an und kann so „den Funktionszusammenhang zwischen Bühne und Publikum, Text und Aufführung, Regisseur und Schauspieler [...] verändern“ ${ }^{245}$. Mit dem Prinzip der Unterbrechung

237 Walter Benjamin, Der Autor als Produzent. In: Benjamin, Gesammelte Schriften, Bd. II.2, hg. von Rolf Tiedemann u. Hermann Schweppenhäuser, Frankfurt am Main 1991, S. 683-701, hier S. 698.

238 Benjamin, Der Autor als Produzent, S. 698.

239 Walter Benjamin, Franz Kafka. Zur zehnten Wiederkehr seines Todestages. In: Benjamin, Gesammelte Schriften, Bd. II.1, hg. v. Rolf Tiedemann u. Hermann Schweppenhäuser, Frankfurt am Main 1991, S. 409-438, hier S. 436.

240 Benjamin, Der Autor als Produzent, S. 698.

241 Benjamin, Der Autor als Produzent, S. 686.

242 Benjamin, Der Autor als Produzent, S. 686.

243 Benjamin, Der Autor als Produzent, S. 686.

244 Benjamin, Der Autor als Produzent, S. 686.

245 Benjamin, Der Autor als Produzent, S. 697. 
nimmt das epische Theater ,ein Verfahren auf, das [...] in den letzten Jahren aus Film und Rundfunk, Presse und Photographie geläufig ist“ ${ }^{426}$ : das der Montage.

Dass der Engel der Geschichte nicht nur als episch-theatrale, sondern spezifischer noch als filmästhetische Figur wirkt, hängt mit der Funktionalität seines Blicks zusammen, die dieselbe wie die technischer Medien ist. So unterbricht und irritiert zwar der Engel der Geschichte als religiöse Figur den siegerfixierten Zugang der modernen Geschichtsbetrachtung. Allerdings stellt er in der Moderne kein unverbunden anachronistisches Moment dar, sondern ist selbst von ihr durchdrungen. Wendet man sich nämlich der spezifischen Beschaffenheit des bildgenerativen Blicks des (sprachbildlichen) Engels zu, so zeigt sich, dass dieser im Kontext moderner Wahrnehmungsformen zu situieren ist. Diesem Gedanken liegt die benjaminsche These zugrunde, dass „[d]ie Art und Weise, in der die menschliche Wahrnehmung sich organisiert - das Medium, in dem sie erfolgt [...] nicht nur natürlich sondern auch geschichtlich bedingt ${ }^{* 247}$ ist. Mit den Prinzipien von Unterbrechung (des herrschenden Geschichtsnarrativs) und Konstruktion/Montage (der Geschichtsbilder, die der Engelsblick entstehen lässt) sind jene Verfahren auf den Plan gerufen, die nach Benjamin den Film konstituieren. ${ }^{248}$

Stand in „Agesilaus Santander“ die Eigenlogik der mimetischen Figuren Name und Engel im Vordergrund, geht es bei dem Engel der Geschichte um die konkrete politische Bedeutung von Medialität und ihren historischen Index. Hervorzuheben ist neben der aktiven Dimension des Engels die Dynamik des Geschichtsbilds, das sein Blick entwirft, wobei er als „Bildspender“ sich selbst in fortlaufender Bewegung durch den Sturm befindet. Die Folge ist eine zweifache Dynamisierung: In der Starre seines Blicks entfaltet sich die Dynamik der sich dem Engel darbietenden Geschichtslandschaft im Modus des fortlaufenden Präsens und damit als unabgeschlossene - die Katastrophe häuft „unablässig Trümmer auf Trümmer“, die sie dem Engel „vor die Füße schleudert“ (T 697). Dem entspricht der Blick des Angelus Novus: In seinen asymmetrischen Blickachsen, die durch die Inkongruenz der Augenstellung entstehen, wird das Prinzip der zentralperspektivischen Bündelung in einem Fixpunkt zugunsten einer fluiden, multiperspektivischen Räumlichkeit verabschiedet. In der Montage der Geschichtsbilder, die der Blick des Engels der Geschichte entstehen lässt, greifen statisches Bild und dessen Bewegung, greifen Momente von Flüchtigkeit und Arretierung ineinander und suspendieren auf diese Weise die chronometrische Ordnung eines homogenen Blickfelds. ${ }^{249}$

246 Benjamin, Der Autor als Produzent, S. 697.

247 Benjamin, Das Kunstwerk im Zeitalter seiner technischen Reproduzierbarkeit, S. 439.

248 Vgl. Benjamin, Der Autor als Produzent, S. 697-698.

249 „Tiraient sur les cadrans pour arrêter le jour“ (T 702), wird ein Augenzeuge des TurmuhrSchießens der Juli-Revolution zitiert. 
So kann - zumindest in der Logik des Denkbilds selbst - diese Bilderfolge wie die Filmaufnahme „nicht fixiert werden, weder wie ein Gemälde noch wie etwas Wirkliches“250. Dieses Zusammenspiel von Stillstand und Bewegung hat seine medienpoetische Grundlage in der Verbindung aus bildlicher Ruhe und narrativer Dynamik, die überdies das epistemische Spannungsverhältnis von Stillstand und monadischer Abgeschlossenheit auf der einen und der Wucht der Unterbrechung auf der anderen Seite reflektiert. In diese Spannung fließen die Statik des grenzsetzenden Cherubs und die Mobilität des grenzüberschreitenden Botenengels beziehungsweise des Cherubs in seiner Funktion als rasender Thron zusammen. In seinem Scheitern, die zeitlich-räumlichen Grenzen zu überschreiten, macht der Engel der Geschichte diese Grenzen sichtbar und antizipiert zugleich ihre in der historischen Zeit nicht realisierbare Überschreitung. Was Andrea Polaschegg im Zusammenhang mit Kleists Cherub feststellt, gilt ebenso auch für den Engel der Geschichte: Die Überschreitung der Grenze von Erde und Himmel, Leben und Tod setzt die Bewegung des Cherubs voraus, die wiederum „ausschließlich im Wirkungsbereich der Poesie als transitorischer Kunst“ ${ }^{251}$ möglich ist, die sich bei Benjamin als Spezifikum des Sprachbilds ausweist.

Folglich konstituiert erst das Zusammenspiel von Bild und Text die medienpoetische Grundlage, auf der die Grenze und ihre Transgression gezeigt werden können. Dieser Überschreitung der „Schranke zwischen Schrift und Bild“252 wiederum wird in „Der Autor als Produzent“ revolutionäres Potential zugesprochen als eine Möglichkeit, den Produktionsapparat nicht nur zu beliefern, sondern auch zu verändern. Darin liegt für Benjamin ein Merkmal politisch und damit auch künstlerisch avancierter Kunst. Entsprechend hat die Ästhetik des Films unmittelbar lebenspraktischen Bezug. In „Das Kunstwerk im Zeitalter seiner technischen Reproduzierbarkeit“ (1935) heißt es dazu:

Der Film ist die der betonten Lebensgefahr, in der die Heutigen leben, entsprechende Kunstform. Er entspricht tiefgreifenden Veränderungen des Apperzeptionsapparats - Veränderungen wie sie im Maßstab der Privatexistenz jeder Passant im Großstadtverkehr, wie sie im weltgeschichtlichen Maßstab jeder Kämpfer gegen die heutige Gesellschaftsordnung erlebt. ${ }^{253}$

250 Benjamin, Das Kunstwerk im Zeitalter seiner technischen Reproduzierbarkeit, S. 464.

251 Polaschegg, Von der Vordertür des Paradieses, S. 498.

252 Benjamin, Der Autor als Produzent, S. 693.

253 Benjamin, Das Kunstwerk im Zeitalter seiner technischen Reproduzierbarkeit, S. 464. 
Der Film ist das dem aktuellen Lebensmodus der Gefahr adäquate Medium, das den „tiefgreifenden Veränderungen des Apperzeptionsapparats“ gerecht wird. Diese sind im Kampf gegen die Gesellschaftsordnung (und damit auch gegen die Dominanz eines unreflektierten Geschichtsverständnisses) zentral. Da in den „Thesen“ der blitzhafte Zusammenschluss von Vergangenheit und Gegenwart in einem Moment der Gefahr erfolgt, ist die mit dem Film verbundene Wahrnehmungsästhetik auch auf epistemischer Ebene für Benjamins Konzeption entscheidend. Das andere Geschichtsbild, das der Engelsblick entwirft, verbirgt sich in der dominanten Siegererzählung und ihrer Terminologie - „Das, was wir den Fortschritt nennen, ist dieser Sturm“. Wie der Film, der der fundamentalen Erschütterung der Wahrnehmungsgewohnheiten entspricht und diese gleichzeitig intensiviert, erschüttert der Engel der Geschichte die apologetische Betrachtung der Geschichte.

Nicht nur die Konstruktion der Bilder durch ihn, auch der Blick des Engels selbst ist damit Teil einer Ästhetik des Films. Im „Kunstwerk“-Aufsatz schreibt Benjamin die Funktion des Sichtbarmachens dem „Optisch-Unbewußten“ der Kamera zu und setzt sie mit der Psychoanalyse parallel, die das „Triebhaft-Unbewußte“254 zum Vorschein bringt. Auch das „Unterbrechen“ als wesentliches Moment von Benjamins Historiographie ist explizit eines der „Hilfsmitte[1]“255 der Kamera. In der Unterbrechung der hegemonialen Geschichtserzählung ebenso wie in dem Sichtbarmachen des „Optisch-Unbewußten“ “256 als verschütteter Dimension der Vergangenheit, das der Engel mit seiner Blick-Komposition entbirgt, nimmt er eine analoge Position zur Kamera ein. Wie die technisch-medialen Apparaturen ist der Engel in der Lage, jene Bilder zur Sichtbarkeit zu bringen, ,die sich der natürlichen Optik“ - das heißt dem menschlichen Blick - „schlechtweg entziehen“ ${ }^{257}$. Ein weiteres verbindendes Merkmal ist die zerstörerische und in der Zerstörung bewahrende Seite, die, wie gezeigt, dem Engel und auch dem Film eignet. Dessen „gesellschaftliche Bedeutung ist auch in ihrer positivsten Gestalt, und gerade in ihr, nicht ohne diese seine destruktive, seine kathartische Seite denkbar: die Liquidierung des Traditionswertes am Kulturerbe“ ${ }^{258}$.

254 Benjamin, Das Kunstwerk im Zeitalter seiner technischen Reproduzierbarkeit, S. 461. 255 Benjamin, Das Kunstwerk im Zeitalter seiner technischen Reproduzierbarkeit, S. 461. 256 Benjamin, Das Kunstwerk im Zeitalter seiner technischen Reproduzierbarkeit, S. 461. Das Sichtbarmachen des „Optisch-Unbewußten“ schreibt Benjamin hier der Kamera zu. Auch das „Unterbrechen“ wird explizit als eines ihrer „Hilfsmitte[1]“ genannt (Benjamin, Das Kunstwerk im Zeitalter seiner technischen Reproduzierbarkeit, S. 461).

257 Benjamin, Das Kunstwerk im Zeitalter seiner technischen Reproduzierbarkeit, S. 476. 258 Benjamin, Das Kunstwerk im Zeitalter seiner technischen Reproduzierbarkeit, S. 439. 
Der bei Benjamin wesentliche zerstörerische Impuls manifestiert sich im Fall des Engels der Geschichte in Analogie zur Konstruktionsästhetik des Films: Ebenso wie die gebrochene Konstruktion von Bildern durch den Engel mit dem Trugbild eines organischen Geschichtsverlaufs sowie mit dessen „natürlicher Wahrnehmung“ bricht, ist das filmische Kunstwerk „nichts weniger als eine Schöpfung aus einem Wurf, e[s] ist aus sehr vielen einzelnen Bildern und Bildfolgen montiert“259. Indem im Film Entwicklungszusammenhänge und damit Stabilität und Einheit des Kunstwerks zerschlagen werden, trägt er nicht nur Erkenntnis-, sondern auch Revolutionspotential. ${ }^{260}$

Die Reproduktionstechnik, die der filmischen Ästhetik zugrunde liegt, geht mit „einer Erschütterung der Tradition“ ${ }^{261}$ einher, die in der Gestaltung des Engels der Geschichte auch die theologische Tradition betrifft. Diese Unterbrechung wiederum ist in der ordnungsstörenden Komponente des Engels selbst angelegt. So wird für die Illustration eines nichtlinearen Geschichtsbilds eine Seite der Engelsfigur aktiviert, die schon in der Aufklärung jenem entwicklungslogischen Denken Unbehagen bereitete, das Benjamin ablehnt. ${ }^{262}$ Problematisch für aufklärerisches Denken war - neben aller grundsätzlichen Fragwürdigkeit der Existenz von Engeln per se -, dass Engel als freie Wesen keine sittliche Entwicklung im Sinne eines Subjektwerdungsprozesses durchlaufen und so auch die Plötzlichkeit des Abfalls einiger Engel nicht aus einer kausal rekonstruierbaren Abfolge linearer Willensakte heraus erklärt werden kann. ${ }^{263}$ Der Engel erscheint in der IX. These entsprechend als kulturkritischer Bürge einer einzigartigen Erfahrung und Entscheidung, die ein lineares Zeitverständnis und damit auch

259 Benjamin, Das Kunstwerk im Zeitalter seiner technischen Reproduzierbarkeit, S. 446.

260 Vgl. auch Günter Riederer: „Der ephemere Charakter von Filmbildern räumt mit der Vorstellung auf, es gäbe eine Ordnung in der Welt, die fest und unverrückbar steht“ (Günter Riederer, Film und Geschichtswissenschaft. Zum aktuellen Verhältnis einer schwierigen Beziehung. In: Visual History. Ein Studienbuch, hg. von Gerhard Paul, Göttingen 2006, S. 96-113, hier S. 101-102). 261 Benjamin, Das Kunstwerk im Zeitalter seiner technischen Reproduzierbarkeit, S. 439.

262 Vgl. Benjamins Notiz zu einer Unterhaltung über „Methodenfragen der Geschichte“: „Mein Versuch eine Konzeption von Geschichte zum Ausdruck zu bringen, in der der Begriff der Entwicklung gänzlich durch den des Ursprungs verdrängt wäre. Das Historische, so verstanden, kann nicht mehr im Flußbett eines Entwicklungsverlaufes gesucht werden. Es tritt, wie ich wohl schon an anderer Stelle bemerkt habe, hier für das Bild des Flußbetts das des Strudels ein. In solchem Strudel kreist das Früher und Später - die Vor- und Nachgeschichte eines Geschehens oder besser noch eines status um diesen“ (Walter Benjamin, Tagebuch vom siebenten August Neunzehnhunderteinunddreissig bis zum Todestag. In: Benjamin, Gesammelte Schriften, Bd. VI, hg. von Rolf Tiedemann u. Hermann Schweppenhäuser, Frankfurt am Main 1991, S. 441-446, hier S. 442-443). 263 Vgl. Dürr, Der Engel Mächte, S. 93-102. 
die unreflektierte Traditionskultivierung eines engen Erfahrungsbegriffs ${ }^{264}$ ebenso sprengt wie eine „evolutionistische Geschichtsbetrachtung“265.

Dass Benjamin an der Figur des Engels vor allem die unmenschliche wahrnehmungsästhetische Dimension interessiert, wird daran deutlich, dass Engel hier mit dem Schönen nichts $\mathrm{zu}$ tun haben und völlig unpoetische Figuren sind. Neben ihrer Unmenschlichkeit ist es insbesondere dies, was sie mit der technischen Reproduktion verbindet, in der „das Schöne keine Stelle“266 hat. Der Engel ist bei Benjamin keine Figur der ästhetischen Fülle, sondern im Gegenteil die Verkörperung einer bewussten Reduktion, einer Verarmung. Darin spiegelt er die Konsequenz aus der realgesellschaftlichen Armut, die das ganze Leben umfasst und deren bewusste Reflexion und Radikalisierung die Ausgangslage des von Benjamin geforderten künstlerischen Tätigseins bildet. Der Engel wird hier nicht als Zielpunkt menschlicher Perfektibilität gedacht, sondern als dessen abrupte Störung. Auf diese Weise wirkt der Engel der Geschichte selbst aufklärerisch und zwar über seine spezifische Ästhetik: Er entlarvt den Mythos eines organisch-teleologischen Verlaufs der Geschichte und macht ein kollektives Unbewusstes sichtbar, das die Typologie von „Optisch-Unbewußtem“, das die Kamera aufdeckt, und „TriebhaftUnbewußtem“, das die Psychoanalyse bloßlegt, um das „Geschichtlich-Unbewusste“ erweitert, das in der Siegererzählung verborgen liegt.

\subsubsection{Eingedenken im Exil}

Der Engel der Geschichte vereinigt zwei historisch gegenläufige Tendenzen: vergangene Aura und aktuelle Technik. So läuft die irreduzible, einzigartige Erfahrung, für die der Engel steht, der Technizität seiner Blickkonstruktion entgegen. Seine Affinität zu technisch-medialen Apparaturen und seine mehrfach vermittelte Darstellung wird durch den religiös-ästhetischen Überschuss der Angelophanie gebrochen. Der Engel sperrt sich gegenüber dem „leidenschaftli-

264 Eine frühe Auseinandersetzung Benjamins mit dem engen Erfahrungsbegriff der kantischen Schriften findet sich in „Über das Programm der kommenden Philosophie“ (1918). Benjamin erwartet von der gegenwärtigen Philosophie, „unter der Typik des Kantischen Denkens die erkenntnistheoretische Fundierung eines höhern Erfahrungsbegriffes vorzunehmen“ (Walter Benjamin, Über das Programm der kommenden Philosophie. In: Benjamin, Gesammelte Schriften, Bd. II.1, hg. v. Rolf Tiedemann und Hermann Schweppenhäuser, Frankfurt am Main 1991, S. 157-171, hier S. 160), um so religiöse Erfahrung logisch zu ermöglichen.

265 Walter Benjamin, Eduard Fuchs, der Sammler und der Historiker. In: Benjamin, Gesammelte Schriften, Bd. II.2., hg. von Rolf Tiedemann u. Hermann Schweppenhäuser, Frankfurt am Main 1991, S. 465-505, hier S. 487.

266 Benjamin, Über einige Motive bei Baudelaire, S. 646. 
che[n] Anliegen der gegenwärtigen Massen“, das darin besteht, „[d]ie Dinge

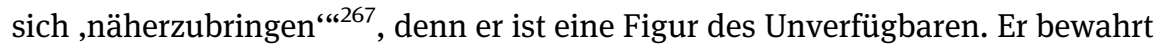
den „Zauber der Ferne““268 und seine Singularität lässt sich nicht im Denken einer „quantitativen Akkumulation“269 überwinden. Aus diesem Grund steht er ein für eine Erfahrung im emphatischen Sinne, die für Benjamin in der Moderne von vielen Seiten verstellt ist. Die Verschränkung von religiöser und ästhetischer Dimension, die den Engel auszeichnet, ist dabei konstitutiv für Benjamins Begriff der Aura: Das Auratische des Kunstwerks ist in seiner Verankerung im Ritual unlösbar theologisch fundiert. ${ }^{270}$

Der Engel selbst wirkt in zweifacher, historisch spannungsreicher Hinsicht auratisch, das heißt als „einmalige Erscheinung einer Ferne, so nah sie sein mag“271. Zum einen durch seinen Bezug zum Paradies, zum anderen durch seine Antizipation der Erlösung. In beiden Fällen transportiert seine Erscheinung Modi einer anderen Zeitlichkeit. Im ersten Fall ruft er den Schöpfungszustand auf, an dessen Schwelle er postiert ist, im zweiten Fall die endgültige Rettung in der messianischen Zeit, die den Abbruch der Historie bedeutet. So wie die Aura erst in ihrem Verlorensein wahrnehmbar wird, ${ }^{272}$ so wird auch der Engel auf eine bestimmte Art erst wahrnehmbar in der Moderne als dem Zeitalter der technischen Reproduzierbarkeit, in dem seine auratischen Qualitäten verloren gehen. In dieser Hinsicht ist er eine für Benjamin typische Figur, der „[i]n den abgestorbenen, der aktuellen Beziehung entrückten Werken und $\mathrm{Zu}$ ständen seine Ernten ein[heimst] ${ }^{\text {‘273 }}$, wie Kracauer es formuliert. Es ist also gerade die Unzeitgemäßheit des Engels und seiner Aura, die hier als „neue Schönheit in dem Entschwindenden“"274 erscheinen.

Die geschichtsphilosophischen Besonderheiten der auratischen Dimension des Engels stehen in einem direkten Zusammenhang zu seiner Qualität als exilische Figur. Denn sowohl in „Agesilaus Santander“ als auch in den „Thesen“ macht der Engel das Ferne als das Abwesende beziehungsweise Unsichtbare der Vergangenheit in der Gegenwart wahrnehmbar. Dazu gehören auch das Leid und die Verluste von Exilantinnen und Exilanten, die wegen politischer

267 Benjamin, Das Kunstwerk im Zeitalter seiner technischen Reproduzierbarkeit, S. 440.

268 Walter Benjamin, Zentralpark. In: Benjamin, Gesammelte Schriften, Bd. I.2, hg. von Rolf Tiedemann u. Hermann Schweppenhäuser, Frankfurt am Main 1991, S. 655-690, hier S. 670.

269 Benjamin, Anmerkungen [Über den Begriff der Geschichte], S. 1240.

270 Vgl. Benjamin, Das Kunstwerk im Zeitalter seiner technischen Reproduzierbarkeit, S. 441.

271 Benjamin, Das Kunstwerk im Zeitalter seiner technischen Reproduzierbarkeit, S. 440.

272 Vgl. Menke, Sprachfiguren, S. 321-322.

273 Siegfried Kracauer, Zu den Schriften Walter Benjamins. In: Kracauer, Das Ornament der Masse, Frankfurt am Main 1963, S. 249-255, hier S. 252.

274 Benjamin, Der Erzähler, S. 442. 
und/oder antisemitischer Verfolgung vor der sich ausweitenden NS-Herrschaft geflohen sind und in der gegenwärtigen historischen Situation als Verliererinnen und Verlierer der Geschichte erscheinen müssen. In dieser Eigenschaft als Medium des Exils wird der Engel zum Sinnbild der unsinnlichen Ähnlichkeit, ${ }^{275}$ die nach Benjamin ein „Geisterdasein“276 führt, in dem eine verlorene einstige Ähnlichkeit nachhallt. Individualgeschichtlich ist der Engel in „Agesilaus Santander" als unheimlicher, polymorpher Doppelgänger von verlorenen Dingen und Menschen wirksam. Dieses Vermögen wird in den „Thesen“ auf einen weltgeschichtlichen Maßstab ausgeweitet, wobei für Benjamin auch das ,im Jetzt seiner Erkennbarkeit aufblitzende Bild der Vergangenheit [...] seiner weiteren Bestimmung nach ein Erinnerungsbild“ ${ }^{277}$ ist. Als individuelles Alter Ego und weltgeschichtlicher Akteur verbindet der Engel beide Aspekte im Begriff der Erfahrung, die wie der Engel verschiedene Zeitformen kurzschließt: „Wo Erfahrung im strikten Sinn obwaltet, treten im Gedächtnis gewisse Inhalte der individuellen Vergangenheit mit solchen der kollektiven in Konjunktion.“278

Dass Benjamin für seine mediale Entfaltung der individuellen und kollektiven Exilerfahrung ausgerechnet den Engel heranzieht, hängt neben dessen reflexivem Potential in Bezug auf mediale und epistemische Fragestellungen von Geschichte mit einer ästhetisch vermittelten Kritik des modernen Wissenschaftsbegriffs zusammen. „Die falsche Lebendigkeit der Vergegenwärtigung, die Beseit[ig]ung jedes Nachhalls der ,Klage‘ aus der Geschichte, bezeichnet ihre endgültige Unterwerfung unter den modernen Begriff der Wissenschaft ${ }^{\text {‘279 }}$, heißt es in den Paralipomena zu den „Thesen“. Gegenüber einer gleichgültigen Form der Geschichtsschreibung betont Benjamin die „ursprüngliche Bestimmung“ von Geschichte „als Eingedenken“280. Diese Gegenüberstellung von Geschichte als moderner Wissenschaft und als Eingedenken liegt auch einer Stelle im Passagen-Werk zugrunde, die mit einem Briefzitat von Max Horkheimer beginnt:

Über die Frage der Unabgeschlossenheit der Geschichte Brief von Horkheimer vom 16. März 1937: „Die Feststellung der Unabgeschlossenheit ist idealistisch, wenn die Abgeschlossenheit nicht in ihr aufgenommen ist. Das vergangene Unrecht ist geschehen und abgeschlossen. Die Erschlagnen sind wirklich erschlagen ... Nimmt man die Unabgeschlos-

275 Vgl. Kapitel 4.1.5 dieser Studie.

276 Walter Benjamin, Anmerkungen [Lehre vom Ähnlichen, Über das mimetische Vermögen]. In: Benjamin, Gesammelte Schriften, Bd. II.2, hg. von Rolf Tiedemann u. Hermann Schweppenhäuser, Frankfurt am Main 1991, S. 950-960, hier S. 956.

277 Benjamin, Anmerkungen [Über den Begriff der Geschichte], S. 1243.

278 Benjamin, Über einige Motive bei Baudelaire, S. 611.

279 Benjamin, Anmerkungen [Über den Begriff der Geschichte], S. 1231.

280 Benjamin, Anmerkungen [Über den Begriff der Geschichte], S. 1231. 
senheit ganz ernst, so muß man an das jüngste Gericht glauben ... Vielleicht besteht in Beziehung auf die Unabgeschlossenheit ein Unterschied zwischen dem Positiven und Negativen, so daß nur das Unrecht, der Schrecken, die Schmerzen der Vergangenheit irreparabel sind. Die geübte Gerechtigkeit, die Freuden, die Werke verhalten sich anders zur Zeit, denn ihr positiver Charakter wird durch die Vergänglichkeit weitgehend negiert. Dies gilt zunächst im individuellen Dasein, in welchem nicht das Glück, sondern das Unglück durch den Tod besiegelt wird.“281

Benjamin kommentiert dies folgendermaßen:

Das Korrektiv dieser Gedankengänge liegt in der Überlegung, daß die Geschichte nicht allein eine Wissenschaft sondern nicht minder eine Form des Eingedenkens ist. Was die Wissenschaft ,festgestellt‘ hat, kann das Eingedenken modifizieren. Das Eingedenken kann das Unabgeschlossene (das Glück) zu einem Abschlossenen [sic] und das Abgeschlossene (das Leid) zu einem Unabgeschlossenen machen. ${ }^{282}$

Der Engel ist die Figur, die das von der Wissenschaft Festgestellte wieder in Frage stellt und deren axiomatische Annahmen erschüttert. Denn wie schon in „Agesilaus Santander“ hält der Engel auch in den „Thesen“ das Verlorene und Vergangene präsent und steht damit für ein affektives Verhältnis zum Leid der Vergangenheit. Weiter opponiert der Engel dem „modernen Begriff der Wissenschaft“ und ihren Vermessungsbemühungen, insofern er für eine grundsätzliche Unverfügbarkeit und Nichtquantifizierbarkeit steht. Er verkörpert exemplarisch eine Mitteilung, die nicht aus bloßer Information besteht, sondern mit der irreduziblen Erfahrung seiner auratischen Erscheinung verbunden ist.

Dieses Korrektiv erfährt aber selbst wiederum sofort eine Einschränkung, wenn Benjamin zu dem Gedanken, das abgeschlossene Leid zu etwas Unabgeschlossenem zu machen, bemerkt: „Das ist Theologie; aber im Eingedenken machen wir eine Erfahrung, die uns verbietet, die Geschichte grundsätzlich atheologisch zu begreifen, so wenig wir sie in unmittelbar theologischen Begriffen zu schreiben versuchen dürfen. “283 In diesem Spannungsverhältnis steht der Engel bei Benjamin als eine Figur, die theologischen Zusammenhängen entstammt und zugleich mit ihnen bricht, indem sie losgelöst von Traditionen analog zu modernen technischen Medien funktioniert. Darüber hinaus ist hier aber auch die spezifische Zeitlichkeit der Medialität des Engels wesentlich, da seine Erscheinung in der Moderne grundsätzlich einen „Nachhall“ von

281 Benjamin, Das Passagen-Werk, S. 588-589.

282 Benjamin, Das Passagen-Werk, S. 589.

283 Benjamin, Das Passagen-Werk, S. 589. Vgl. die fast wortgleiche Formulierung im Umfeld der Notizen zu den Thesen: „Im Eingedenken machen wir eine Erfahrung, die es uns verbietet, die Geschichte grundsätzlich atheologisch zu begreifen, so wenig wir sie in theologischen Begriffen zu schreiben versuchen dürfen“ (Benjamin, Anmerkungen [Über den Begriff der Geschichte], S. 1235). 
Vergangenem (und einen „Vorhall“ von Zukünftigem) transportiert. Der Engel aktualisiert in seiner Erscheinung so verschiedene Formen der Gleichzeitigkeit des Ungleichzeitigen. Auf der Grundlage der Kritik an der epistemischen Absolutsetzung des Subjekts wie eines positivistischen, planen Geschichtsverständnisses ist dem Engel der Geschichte eine profundere Erkenntnis möglich als „uns“, den modernen Menschen. In diesem Sinne lässt sich die Präsenz des Engels, der als Doppelgänger immer auch eine Figur der Spaltung ist, bei Benjamin grundsätzlich als Hinweis auf die Fragwürdigkeit von klar abgrenzbaren Zeitebenen ebenso wie eines in sich geschlossenen Ichs in der Moderne verstehen.

In den „Thesen“ betrifft das insbesondere die Zeit: Der Engel ist im Raum der Geschichte als eine Art Geisterblicker unterwegs, nicht der Zukunft, sondern der Vergangenheit zugewandt. Auf diese Weise stellt er ein Prisma für die in den „Thesen“ postulierte Korrespondenz der Zeiten dar und figuriert darüber hinaus den Gedanken geschichtlicher Unabgeschlossenheit (aber nicht die entsprechende Handlung, die theologisch wäre). Diese Relation zwischen gegenwärtigem und vergangenem Moment ist deshalb unheimlich, weil sie keine chronologisch oder kausal motivierte ist und daher erst im Moment des Aufblitzens überhaupt erkennbar wird (das meint das „Jetzt der Erkennbarkeit“). Während nämlich „die Beziehung der Gegenwart zur Vergangenheit eine rein zeitliche ist, ist die des Gewesnen zum Jetzt eine dialektische: nicht zeitlicher sondern bildlicher Natur. Nur dialektische Bilder sind echt geschichtliche, d. h. nicht archaische Bilder“284. Diese Heimsuchung durch Bilder, die jene Gegenwart bestimmt, die mit ihnen „synchronistisch ist“ ${ }^{\text {¿285}}$, setzt voraus, dass es keine Kette von Bildern gibt, sondern diese Konstellation plötzlich entsteht und unberechenbar ist.

Hannah Arendt spricht in diesem Zusammenhang von der „gespenstische[n] Kraft, sich stückweise in der Gegenwart anzusiedeln und ihr den falschen Frieden der gedankenlosen Selbstzufriedenheit zu rauben “286, die mit der von Benjamin erkannten Substitution der Tradierbarkeit durch die Zitierbarkeit der Vergangenheit freigesetzt wird. Die „gespenstische Kraft“, die in der plötzlichen Aktualisierung einer verschütteten Vergangenheit entsteht, realisiert der Engel, indem er das Verdrängte der Geschichte sichtbar macht. ${ }^{287}$ Unheimlich ist diese Bewegung auch, weil der Gedanke der Zitierbarkeit der Vergangen-

284 Benjamin, Passagen-Werk, S. 578.

285 Benjamin, Passagen-Werk, S. 578.

286 Hannah Arendt, Der Perlentaucher. In: Arendt und Benjamin. Texte, Briefe, Dokumente, hg. von Detlev Schöttker u. Erdmut Wizisla, Frankfurt am Main 2006, S. 85-97, hier S. 85.

287 Sigrid Weigel verweist darauf, dass sich „das Konzept der ,unsinnlichen Ähnlichkeit“ auch als Figur einer Wiederkehr des Verdrängten lesen“ lässt (Weigel, Entstellte Ähnlichkeit, S. 90). 
heit das Koordinatensystem von Leben und Tod ins Wanken bringt. So steht im Passagen-Werk: „Das Interesse das der materialistische Historiker am Gewesnen nimmt, ist an einem Teil stets ein brennendes Interesse an dessen Verflossensein, an seinem Aufgehörthaben und gründlich Totsein.“ ${ }^{288}$ Das Bewusstsein dafür ist die Voraussetzung „für jede Zitierung (Belebung) von Teilen dieses Phänomens“289. Auf diese Weise wirkt der materialistische Historiker entgegengesetzt zum Allegoriker, unter dessen melancholischem Blick die Dinge absterben und zugleich bewahrt werden. Der Engel, der weder tot noch endliches Lebewesen ist, versinnlicht diese Operation des momenthaften Belebens von Totem aus einem strukturell exilischen Bereich heraus.

\subsubsection{Engel auf Abwegen}

Eine weitere Affinität zwischen Engel und historischem Materialisten liegt in der Reflexionsform, die den „Thesen“ zugrunde liegt. So heißt es in der X. These: „Die Gegenstände, die die Klosterregel den Brüdern zur Meditation anwies, hatten die Aufgabe, sie der Welt und ihrem Treiben abhold zu machen. Der Gedankengang, den wir hier verfolgen, ist aus einer ähnlichen Bestimmung hervorgegangen.“ (T 698) Die Grundlage des in den „Thesen“ entwickelten Denkens wird also aus der Überwindung weltlicher Gebundenheit gewonnen. Illustriert wird diese Bewegung über eine monastische Vorstellung, auf die auch das bios angelikos als asketische Haltung der Reflexion zurückgeht. ${ }^{290}$ Einer Verstrickung in weltliches Treiben entspricht hier der Zustand der Umgarnung des „politische[n] Weltkind[s]“ (T 698) durch jene konformistischen, gescheiterten Politiker, denen nach Benjamin einst die Hoffnung im Kampf gegen den Faschismus gegolten hat. Ihre ungute Weltfixierung manifestiert sich in ihrem „sture[n] Fortschrittsglaube [...], ihr[em] Vertrauen in ihre ,Massenbasis“ und schließlich ihre[r] servile[n] Einordnung in einen unkontrollierbaren Appa-

288 Benjamin, Passagen-Werk, S. 459.

289 Benjamin, Passagen-Werk, S. 459.

290 Eine ähnliche Gedankenfigur findet sich zum Schluss der „Erkenntniskritischen Vorrede“ des Trauerspiel-Buchs, wo es heißt: „Nur eine von weither kommende, ja sich dem Anblick der Totalität zunächst versagende Betrachtung kann in einer gewissermaßen asketischen Schule den Geist zu der Festigung führen, die ihm erlaubt, im Anblick jenes Panoramas [das der deutschen Barockliteratur, L.Z.] seiner selbst mächtig zu bleiben. Der Gang dieser Schulung ist es, der hier zu beschreiben war“ (Benjamin, Ursprung des deutschen Trauerspiels, S. 237). 
rat“ (T 698). Der Begriff des „Weltkinds“ erinnert an die „Kinder dieser Welt“, die im Lukas-Evangelium das Gegenbild des engelsgleichen Lebens verkörpern:

Und Jesus sprach zu ihnen: Die Kinder dieser Welt heiraten und lassen sich heiraten; welche aber gewürdigt werden, jene Welt zu erlangen und die Auferstehung von den Toten, die werden weder heiraten noch sich heiraten lassen. Denn sie können hinfort nicht sterben; denn sie sind den Engeln gleich und Gottes Kinder, weil sie Kinder der Auferstehung sind.

(Lk 20,34-36)

Dem Zugang der Politiker ist jene Perspektive entgegengestellt, die in der vorigen These über den Engel entwickelt wurde. Die mehrfache, (sprach-)bildliche Vermittlung, die ex-zentrische Position des Engels und eine Gegenwartserkenntnis, die aus der Rückwendung erfolgt, schaffen alle mediale Distanz. Sie sind weiter Teil jenes im Kapitel zu „Agesilaus Santander“ entfalteten Prinzips des Umwegs und kontrastieren darin der Verwicklung in das aktuelle Weltgeschehen. Gleiches gilt für den Blick des Engels selbst, der nicht der Gegenwart zugewandt und in sie verstrickt ist. Dass der Position des Engels trotz beziehungsweise gerade aufgrund seiner Rückwendung eine dialektische Bedeutung für die Zukunft erwachsen kann, das zeigt die konstitutive Gedankenfigur der „Thesen“. Nach dieser ist Veränderung in der Gegenwart nur möglich, wenn man sich zur Vergangenheit wendet und damit die messianisch durchwirkte Verbindung aktiviert. ${ }^{291}$

291 Eine andere Figur, in der Benjamin diesen Gedanken reflektiert und die dem Engel verwandt ist, ist der rückwärtsgewandte Prophet. Positionierung und Blick des Engels der Geschichte entsprechen diesem Propheten, wie Benjamin ihn in einigen Notizen und Vorarbeiten zu den Thesen wiederholt behandelt hat. Unter dem Titel „Das Jetzt der Erkennbarkeit“ heißt es beispielsweise: „Das Wort, der Historiker sei ein rückwärts gekehrter Prophet kann auf zweierlei Weise verstanden werden. Die überkommene meint, in eine entlegene Vergangenheit sich zurückversetzend, prophezeie der Historiker, was für jene noch als Zukunft zu gelten hatte, inzwischen aber ebenfalls zur Vergangenheit geworden ist. [...] Man kann das Wort aber auch ganz anders deuten und es so verstehen: der Historiker wendet der eignen Zeit den Rücken, und sein Seherblick entzündet sich an den immer tiefer ins Vergangene hinschwindenden Gipfeln der früheren Menschengeschlechter. Dieser Seherblick eben ist es, dem die eigene Zeit weit deutlicher gegenwärtig ist als den Zeitgenossen, die ,mit ihr Schritt halten“. Nicht umsonst definiert Turgot den Begriff einer Gegenwart, die den intentionalen Gegenstand einer Prophetie darstellt, als einen wesentlich und von Grund auf politischen. ,Bevor wir uns über einen gegebnen Stand der Dinge haben informieren können, sagt Turgot, hat er sich schon mehrmals verändert. So erfahren wir immer zu spät von dem, was sich zugetragen hat. Und daher kann man von der Politik sagen, sie sei gleichsam darauf angewiesen, die Gegenwart vorherzusehen.' Genau dieser Begriff von Gegenwart ist es, der der Aktualität der echten Geschichtsschreibung zugrunde liegt“ (Walter Benjamin, Das Jetzt der Erkennbarkeit [Benjamin-Archiv, Ms 471]. In: Benjamin, Gesammelte Schriften, Bd. I.3, hg. von Rolf Schweppenhäuser u. Hermann Tiedemann, Frankfurt am Main 1974, S. 1237). 
Gerade in dem Augenblick der Niederlage jener gescheiterten Politiker soll nun „das politische Weltkind aus den Netzen“ (T 698) gelöst werden. Die geistige Grundlage dafür wird über das Bild der Klosterregeln beziehungsweise der sich an diese knüpfende Meditation gewonnen. Nach dem Eingangsbild, das sie als verborgene Fadenzieherin des historischen Materialismus zeigt, wird hier besonders deutlich, dass die Theologie in den „Thesen“ kein bloßes Metaphernarsenal darstellt, sondern die akute Bedrohung des Faschismus über eine rein weltimmanent orientierte Politik des Fortschritts und der Arbeit nicht gebannt werden kann, im Gegenteil:

Dieser vulgärmarxistische Begriff von dem, was die Arbeit ist, hält sich bei der Frage nicht lange auf, wie ihr Produkt den Arbeitern selber anschlägt, solange sie nicht darüber verfügen können. Er will nur die Fortschritte der Naturbeherrschung, nicht die Rückschritte der Gesellschaft wahr haben. Er weist schon die technokratischen Züge auf, die später im Faschismus begegnen werden.

(T 698)

Eine Revolution der Gegenwart funktioniert nicht über den blinden Fortschrittsglauben, sondern hat $\mathrm{zu}$ ihrer Bedingung eine Hinwendung $\mathrm{zu}$ dem Trümmerhaufen der Vergangenheit, wie ihn der retrograde Blick des Engels entwirft. So steht die im vorigen Kapitel beleuchtete Säkularisierungsdialektik hier wesentlich im Dienst einer wechselseitigen Korrektivfunktion: Eine ökonomistische Zukunftsfixierung, die auch die Arbeiterbewegung lähmt (vgl. T 700), wird durch den Einbruch religiöser Figuren aus ihrer immanenten Beschränkung gelöst. Umgekehrt wirkt die materialistische Fundierung der Verabsolutierung theologisch aufgeladener Begriffe wie „Schöpfertum und Genialität, Ewigkeitswert und Geheimnis““292 entgegen, die anfällig für faschistische Vereinnahmung sind.

Dieses gegenseitige Austarieren lässt sich auch in der Figur des Engels selbst beobachten, die zwar einer religiösen Tradition angehört, diese aber in der Form ihrer Aktualisierung auf den Kopf stellt. Fragt man über die medienästhetische Vermittlungsrolle des Engels der Geschichte hinaus nach seiner genuinen Bestimmung, stößt man bei Benjamin wiederholt auf jene im Kapitel zu „Agesilaus Santander“ bereits thematisierte talmudische Legende. Nach dieser werden „die Engel neue jeden Augenblick in unzähligen Scharen - geschaffen, um, nachdem sie vor Gott ihren Hymnus gesungen, aufzuhören und in Nichts zu vergehen““293. Misst man den Engel der Geschichte an dieser generischen Bestimmung - innerhalb der „Thesen“ selbst wird keine formuliert -, dann wirkt er in mehrfacher Hinsicht deplatziert: Er jubelt nicht, sondern ist stumm, er ist am falschen Ort, nämlich in der

292 Benjamin, Das Kunstwerk im Zeitalter seiner technischen Reproduzierbarkeit, S. 473.

293 Benjamin, Ankündigung der Zeitschrift: Angelus Novus, S. 246. 
menschlichen Trümmergeschichte statt in der Transzendenz ewiger göttlicher Glorie, und er ist ein seltsamer Solitär, ohne die Gefährten „unzähliger Scharen“. Er möchte verweilen, Tote wecken und Zerstörtes zusammenfügen und weicht darin wie in „Agesilaus Santander“ eklatant von jener Tradition der transitorischen talmudischen Engel (oder sonst einer bekannten) ab.

Der Engel der Geschichte besteht so aus einem zusammenhängenden zweifachen Bruch - dem mit „unserem“ historischen Diskurs, in dem Geschichte als Kette von Begebenheiten erscheint, und dem mit der theologischen Tradition, wobei der zweite den ersten Bruch erst möglich macht. Wie verwickelt das Verhältnis des Engels der Geschichte zur theologischen Tradition ist, das zeigen Scholems nicht ganz konsistente Ausführungen: Er spricht von der „einen und einzigartigen Mission“ ${ }^{294}$ des Engels der Geschichte, stellt dann fest, es sei „mehr als zweifelhaft, ob er seine angelische Mission überhaupt erfüllt““295, und meint schließlich:

Freilich, die Toten zu erwecken und das Zerschlagene, Zerbrochene wieder zusammenzufügen ist für die lurianische Kabbala Aufgabe nicht eines Engels, sondern des Messias. [...] Der Engel der Geschichte, wie ihn Benjamin hier sieht, versagt aber an dieser Aufgabe, die erst in der letzten These dieser Reihe vom Messias erfüllt werden kann. ${ }^{296}$

Scholem zeichnet den Engel der Geschichte als paradoxe Figur mit einer besonderen Mission, die eigentlich gar nicht die seine ist, die er trotzdem wahrzunehmen versucht und dabei scheitert. Vor diesem Hintergrund erscheint er eher als ein Engel auf Abwegen denn als einer von Agambens bürokratischen Vollstreckern. $^{297}$ So ist fraglich, ob es überhaupt eine Aufgabe gibt, wie Scholem meint. Weder von dieser noch von Gott als Weisungsgeber ist die Rede, und auch die Formulierung „er möchte wohl verweilen [meine Hervorhebung, L.Z.]“ lässt eher auf ein autonomes Verhalten schließen. Zu dieser Abweichung des Engels von

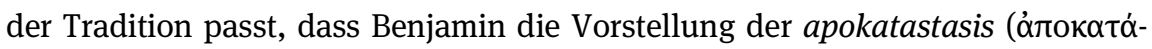

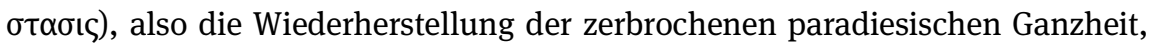
die dem Gedanken des תיקון der lurianischen Kabbala verwandt ist, im „Erzähler“-Essay mit Origenes und damit mit einer häretischen Praxis assoziiert. ${ }^{298}$

Seine Funktion des Sichtbarmachens des Historisch-Unbewussten kann der Engel nur wahrnehmen, weil es sich gerade nicht um einen Engel aus der tal-

294 Scholem, Walter Benjamin und sein Engel, S. 65.

295 Scholem, Walter Benjamin und sein Engel, S. 65-66.

296 Scholem, Walter Benjamin und sein Engel, S. 67.

297 Vgl. Kapitel 2.1 dieser Studie.

298 Benjamin erwähnt jene „von der römischen Kirche verworfene Spekulation des Origenes über die Apokatastasis - das Eingehen sämtlicher Seelen ins Paradies“ (Benjamin, Der Erzähler, S. 458); vgl. auch Gagnebin, „Über den Begriff der Geschichte“, S. 289. 
mudischen Legende handelt. Der zentrale Unterschied ist, dass die Flüchtigkeit als vorrangiges Merkmal jener Engel dem starrenden und getriebenen Engel der Geschichte fehlt. Das Ideal eines quasi im Erscheinen begriffenen Verschwindens des Engels bedeutet ein reibungsloses Erfüllen seines Auftrags. ${ }^{299}$ Nur wenn sie sofort und unverzüglich gelingt, kann der Engel hinter seine Tätigkeit zurücktreten. Eine Abweichung von seiner vorgeschriebenen Aufgabe hingegen lenkt den Fokus auf ihn anstelle von Gott und gilt damit innerhalb eines monotheistischen Systems als häretisch. Gerade diese Abweichung des Engels der Geschichte, also die unterbrochene Tradition, ermöglicht in den „Thesen“ die Erkenntnis der katastrophischen Geschichte, die für die Rezipientinnen und Rezipienten in einem (Sprach-)Bild fixiert wird und damit selbst Teil jener Profanisierungsdialektik ist.

Der Wunsch des Engels, die Toten zu wecken, lässt sich erkenntnistheoretisch im Umfeld des von Benjamin im Passagen-Werk postulierten „geschichtlichen Aufwachens“ aus einem Traumbewusstsein begreifen, dessen „Organ“ das „dialektische Denken“" ${ }^{300}$ ist. Der Anspruch des Passagen-Werks ist es, einen „Versuch zur Technik des Erwachens“ ${ }^{301}$ zu geben, beschrieben als „Versuch, der dialektischen, der kopernikanischen Wendung des Eingedenkens inne zu werden“ ${ }^{302}$, da „Erwachen der exemplarische Fall des Erin〈n〉erns“303 ist. Gleichzeitig ist der Wunsch, „die Toten [zu] wecken“, auch ein eschatologischer und verweist auf die endgültige Überwindung des Todes im Endgericht Gottes. So heißt es etwa in der ebenfalls im Exil entstandenen Jesaja-Apokalypse: „Aber deine Toten werden leben, deine Leichname werden auferstehen“ und „[d]ann wird die Erde offenbar machen das Blut, das auf ihr vergossen ist, und nicht weiter verbergen, die auf ihr getötet sind“ (Jes 26,19-21). In dieser inversen Bewegung des Engels, der gegen seine Bestimmung als Psychopomp nicht Sterbende ins Totenreich geleiten, sondern Tote wieder ins Leben führen will, artikuliert sich das Bestreben, auch die individuelle Geschichte eines Menschenlebens „gegen den Strich zu bürsten“ (T 697).

Die mit dem Engel verknüpfte Dialektik von Ordnungskonstitution und Ordnungsüberschreitung zeigt sich somit in seinem Versuch, die Verfallsgeschichte der profanen Zeit außer Kraft zu setzen und in dem Aufdecken und der Restitution des Zerstörten eine andere Zeit- und Weltordnung zu etablieren. In dieser Darstellung des anderen, neuen Engels finden sich machtkritische Aspekte, die

299 Vgl. Serres, Die Legende der Engel, S. 101.

300 Benjamin, Das Passagen-Werk, S. 59.

301 Benjamin, Das Passagen-Werk, S. 490.

302 Benjamin, Das Passagen-Werk, S. 490.

303 Benjamin, Das Passagen-Werk, S. 491. 
sich nicht auf einen planen Marxismus reduzieren lassen. Vielmehr sind sie auch im Sinne von Agambens an Benjamin geschulter Kritik der biopolitischen und gouvernementalistischen Vereinnahmung des Lebens zu verstehen, das der starren Form des Fortschritts unterworfen wird. ${ }^{304}$ Daher muss man hier mit Agamben seine eigene einseitige Deutung des Engels in Herrschaft und Herrlichkeit als Repräsentant und bürokratischer Exekutor der Macht entscheidend erweitern. ${ }^{305}$ Dass der Engel in seiner Wendung gegen den Niedergang der Verfallsgeschichte scheitert, wie immer wieder betont wird, spricht nicht für „die Machtlosigkeit der Zeugenschaft““306. Denn die eschatologische Perspektive der apokatastasis steht kontradiktorisch zur historischen Zeit und die Darstellung einer gelingenden Rettung durch den Engel in der geschichtlichen Zeit trüge den Schein falscher Versöhnung, der in den „Thesen“ ja gerade aufgesprengt werden soll.

Diese Bedeutung des Scheiterns, die im Sichtbarmachen liegt, scheint nicht ausreichend berücksichtigt, wenn der Engel auf ein Versagen und eine daraus resultierende melancholische Trauer reduziert wird. ${ }^{307}$ So ist die Erstarrung des Engels gerade nicht der acedia als „Trägheit des Herzens“308 geschuldet, die nach Benjamin eine zentrale Eigenschaft des Melancholikers darstellt. Vielmehr ist der Engel von dem Geschehen affiziert; er will sich gegen den Sturm des Fortschritts wenden und der Finalität von Sieg und Zerstörung entgegenwirken. Gegen eine solche Herzensträgheit spricht auch, dass die acedia in den „Thesen“

304 Vgl. Dieter Thomä, Benjamin, Wittgenstein. Schwierigkeiten beim Philosophieren gegen den Fortschritt. In: global benjamin, Bd. 2, hg. von Klaus Garber u. Ludger Rehm, München 1999, S. 1229-1250, hier S. 1229-1230.

305 Vgl. dazu Kapitel 2.1 dieser Studie.

306 Werckmeister, Benjamins „Engel der Geschichte“, S. 600.

307 Werckmeister sieht die IX. These quasi als negativen Höhepunkt der Mutlosigkeit ohne revolutionäres Potential: „Ein derartiger Geschichtsverlauf kann nicht mehr stillgestellt werden, sondern treibt im Gegenteil das Subjekt als ohnmächtiges Objekt vor sich her“ (Werckmeister, Benjamins „Engel der Geschichte“, S. 616). Zu der hoffnungslosen Sichtweise vgl. auch Scholem, Walter Benjamin und sein Engel, S. 67 sowie Friedmar Apel: „So wird der Engel [der Geschichte, L.Z.] zur Chiffre einer ohnmächtigen und melancholischen Geschichtserfahrung eines Subjekts, das sich nicht mehr zu dem imstande fühlt, was die Romantiker in der Nachfolge Hamanns dem Künstler noch zutrauten: das Zerschlagene neu zusammenzufügen zum Vorschein einer besseren Welt“ (Friedmar Apel, Himmelssehnsucht. Die Sichtbarkeit der Engel in der romantischen Literatur und Kunst sowie bei Klee, Rilke und Benjamin, Paderborn 1994, S. 170).

308 Vgl. die Aussage in Ursprung des deutschen Trauerspiels, nach der der „eigentlich theologisch[e] Begriff des Melancholikers [...] in dem einer Todsünde vorliegt. Das ist die Acedia, die Trägheit des Herzens“ (Benjamin, Ursprung des deutschen Trauerspiels, S. 332). 
mit der Einfühlung in die Sieger verbunden wird. ${ }^{309} \mathrm{Im}$ Gegensatz dazu wendet der Engel sich den Opfern der Geschichte zu. Er möchte sie, wie es heißt, rückblickend aus ihrer Totenstarre befreien. Dieser Wunsch scheint weitaus mehr seiner eigenen Herzensregung als einer höheren Weisung zu entspringen.

Die Evokation des Unerreichten liegt in der prophetischen Dimension des Engelblicks, ${ }^{310}$ die einen potentiellen Umschlag $\mathrm{zu}$ erkennen gibt, der in der Raum und Zeit verschränkenden Formulierung des Aufschichtens der Trümmer „bis zum Himmel“ angedeutet wird: So macht der Blick des Engels nicht nur die Katastrophen der Vergangenheit sichtbar, sondern er evoziert zugleich im Bild der Himmelsannäherung die Möglichkeit, dass sich so viele Trümmer anhäufen, bis sie den Himmel berühren, und dergestalt die neutrale Richtungsangabe (nach oben, bis zum Himmel) in ihrer eschatologischen Zuspitzung umschlägt in eine qualitative Aussage. Damit würden die Zerstörten gerettet und in den Himmel ewigen Reichs Gottes aufgenommen. ${ }^{311}$ In diesem Sinne ist gerade die Rückwärtsgewandtheit des Engels messianisch. Er visiert in einer Bilderfolge den Berührungspunkt einer umschlagenden Vermittlung von profaner in messianische Zeit und behält gleichzeitig den präeschatologischen Zustand der Zerstörung und des Leids im Blick.

\subsubsection{Humanismus zwischen Symbol und Allegorie}

Die ästhetischen, anthropologischen und geschichtsphilosophischen Dimensionen des Denkbilds des Engels der Geschichte lassen sich über Benjamins Unterscheidung von Symbol und Allegorie näher fassen. Das Symbol weist auf den paradiesischen Zustand vor aller subjektiven Bedeutungsgebung, die Allegorie

309 In der VII. These heißt es über das von dem französischen Historiker Fustel de Coulanges postulierte Verfahren der Einfühlung, sein Ursprung sei „die Trägheit des Herzens, die acedia“, die „bei den Theologen des Mittelalters als der Urgrund der Traurigkeit“ (T 696) gegolten habe. Der Grund für diese Traurigkeit „wird deutlicher, wenn man die Frage aufwirft, in wen sich denn der Geschichtsschreiber des Historismus eigentlich einfühlt. Die Antwort lautet unweigerlich in den Sieger“ (T 696). Über diesen wird ein vernichtendes Urteil gefällt: „Wer immer bis zu diesem Tage den Sieg davontrug, der marschiert mit in dem Triumphzug, der die heute Herrschenden über die dahinführt, die heute am Boden liegen“ (T 696).

310 An dieser Stelle sei an die strukturelle Ähnlichkeit von Engel und Prophet hinsichtlich ihrer „Doppelnatur von Objekt- und Subjekt-Sein, Zwang und Freiheit“ erinnert, wie Gabriela Wacker den Propheten charakterisiert (Wacker, Poetik des Prophetischen, S. 30).

311 Vgl. dazu auch Michael Pauen, Der Protest ist Schweigen. Zur Benjamin-Rezeption Th. W. Adornos. In: global benjamin, Bd. 3, hg. von Klaus Garber u. Ludger Rehm, München 1999, S. 1428-1452, hier S. 1439. 
hingegen setzt den Bruch der geschichtlichen Zeit voraus. Das Symbol bezeichnet seinem „echten“ Begriff nach für Benjamin „[d]ie Einheit von sinnlichem und übersinnlichem Gegenstand“312 und stammt aus dem theologischen Bereich. Das

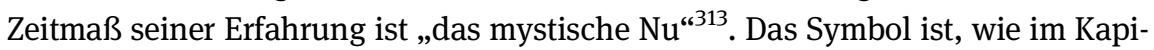
tel zu „Agesilaus Santander“ erläutert, mit dem Geheimnis verwoben.

Das Geheimnis wiederum erklärt Benjamin für die aktuelle historische Konstellation des Faschismus für untauglich, ja gefährlich, ${ }^{314}$ und auch die Adaption des Symbols ist problematisch, wenn sie die Differenz des Verlusts paradiesischer Einheit zu ignorieren versucht. So hat „[d]as Buhlen der romantischen Ästhetiker um glänzende und letztlich unverbindliche Erkenntnis eines Absoluten [...] in den simpelsten kunsttheoretischen Debatten einen Symbolbegriff heimisch gemacht, der mit dem echten außer der Bezeichnung nichts gemein hat“315. In diesem ,vulgären Sprachgebrauch“316, in dem die „Paradoxie“ der Einheit des theologischen Symbolbegriffs getilgt ist, soll das Schöne als „symbolisches Gebilde [...] bruchlos ins Göttliche übergehen“317. In den Notizen „Antithetisches über Wort und Name“ (so benannt von Gershom Scholem) heißt es über diese entstellte Form des Symbols, sie sei „definierbar als Zeichen, an dem keinerlei Ähnlichkeit erscheinen kann“318. Für diese Entstellung ist nach Benjamin die Klassik verantwortlich, in der die Allegorie nur als Kontrastfolie für die Profilierung des Symbols gedient habe, dabei in ihrer Ausdrucksform verkannt und als „ein[e] bloß[e] Weise der Bezeichnung،319 denunziert worden sei.

Mit dem Symbol ist außerdem ein bestimmter Begriff des Humanismus verbunden, den Benjamin mindestens in seiner degenerierten kapitalistischen Form ablehnt. ${ }^{320}$ Über den klassischen Humanismus schreibt er in Ursprung des deutschen Trauerspiels: „,Menschliches“ als die höchste ,Fülle des Wesens“ suchte der Klassizismus und griff in diesem Verlangen, wie es die Allegorie verschmähen mußte, auch nur ein Trugbild des Symbolischen.“321 Die der Klassik attestierte „Apotheose des Daseins“ betrifft nicht nur das „sittlich vollendet[e]

312 Benjamin, Ursprung des deutschen Trauerspiels, S. 336.

313 Benjamin, Ursprung des deutschen Trauerspiels, S. 342.

314 Vgl. Benjamin, Das Kunstwerk im Zeitalter seiner technischen Reproduzierbarkeit, S. 473.

315 Benjamin, Ursprung des deutschen Trauerspiels, S. 336.

316 Benjamin, Ursprung des deutschen Trauerspiels, S. 336.

317 Benjamin, Ursprung des deutschen Trauerspiels, S. 337.

318 Walter Benjamin, [Antithetisches über Wort und Name]. In: Benjamin, Gesammelte Schriften, Bd. VII.2, hg. von Rolf Tiedemann u. Hermann Schweppenhäuser, Frankfurt am Main 1991, S. 795796, hier S. 796.

319 Benjamin, Ursprung des deutschen Trauerspiels, S. 339.

320 Vgl. Kapitel 4.1.3 dieser Studie.

321 Benjamin, Ursprung des deutschen Trauerspiels, S. 341. 
Individuum“, sondern auch das „schöne Individuu[m]“3322. Der „gegensatzlose[n] Innerlichkeit“ der schönen Seele steht das „Umschlagen von Extremen“323 der Apotheose im Barock gegenüber. Gegen die Totalisierungsbewegung des klassischen Humanismus, dem es um den schönen ganzen Menschen geht, lotet Benjamin in seinem realen Humanismus den Grenzbereich des Menschlichen über barbarische Figuren wie den menschenfresserischen Engel aus. ${ }^{324}$ Nach dem Ersten Weltkrieg ist der Mensch so verarmt und entstellt, dass auch er nur über einen Umweg zu erreichen ist: den des Unmenschlichen.

Wie bei Rilke wird der Engel hier als ein Negativ des Menschen anthropologisch relevant, indem über ihn Unmenschliches gedacht und so das Menschliche, dessen klassische Bestimmung leer (geworden) ist, aus dem Außen des Unmenschlichen neu gefasst werden kann. Dieser Aspekt der anthropologischen Reflexion gerät aus dem Blick, wenn der Engel der Geschichte vorschnell als Sinnbild des materialistisch-theologisch informierten Historikers oder des Lebens seines Verfassers gedeutet, ${ }^{325}$ also nicht als ahumane Grenzform, sondern als Spiegel eines bestimmten Menschen gedacht wird. Dagegen hat der Engel in seiner radikalen Alterität hier eine Affinität zur „Grenzform“326 der Allegorie gegenüber der Ganzheit des Symbols, die immer auch das Sprengen einer Ordnungsform, also eine „,Grenzverletzung““327 darstellt, wie Benjamin Carl Horst als neukantianischen Kritiker des allegorischen Überschreitens von künstlerischen Grenzen zitiert. Bezeichnenderweise stößt sich gerade die neukantianische Schule, der Benjamin ihre „undialektische Denkweise“328 vorwirft, an der mit der Allegorie (und dem Engel) verbundenen Zweideutigkeit und Tendenz zur Grenzüberschreitung und Ordnungssprengung. ${ }^{329}$

322 Benjamin, Ursprung des deutschen Trauerspiels, S. 337.

323 Benjamin, Ursprung des deutschen Trauerspiels, S. 337.

324 Vgl. Kapitel 4.1.3 dieser Studie.

325 Vgl. Helmut Thielen, Eingedenken. Walter Benjamins theologischer Materialismus. In: global benjamin, Bd. 3, hg. von Klaus Garber u. Ludger Rehm, München 1999, S. 1371-1409, hier S. 1396, Marc de Wilde, Meeting Opposites: The Political Theologies of Walter Benjamin and Carl Schmitt. In: Philosophy \& Rhetoric, 44/4, 2011, S. 363-381, hier S. 377 sowie Susan Handelman, Walter Benjamin and the Angel of History. In: CrossCurrents, 41/3, 1991, S. 344-352, hier S. 345.

326 Benjamin, Ursprung des deutschen Trauerspiels, S. 366.

327 Benjamin, Ursprung des deutschen Trauerspiels, S. 353.

328 Benjamin, Ursprung des deutschen Trauerspiels, S. 353.

329 So zitiert Benjamin Hermann Cohens Ästhetik des reinen Gefühls: „Zweideutigkeit aber, Mehrdeutigkeit ist der Grundzug der Allegorie; auf den Reichtum von Bedeutungen ist die Allegorie, ist der Barock stolz. Diese Zweideutigkeit aber ist der Reichtum der Verschwendung; die Natur hingegen ist nach den alten Regeln der Metaphysik, wie nicht minder auch nach denen der Mechanik, nicht zuletzt an das Gesetz der Sparsamkeit gebunden. Zweideutigkeit ist 
Wesentlich für die anthropologische Reflexion, die Benjamin über Symbol und Allegorie verhandelt, ist die Unterscheidung zwischen Lebendigem und Totem beziehungsweise „Halblebendigem“: „Wenn die allegorische Intention auf die kreatürliche Dingwelt, das Abgestorbene, zuhöchst das Halblebendige sich richtet, so tritt der Mensch nicht in ihren Blickkreis“330, heißt es in Ursprung des Trauerspiels. Im Modus des Allegorischen ,prägt [...] die Geschichte nicht als Prozeß eines ewigen Lebens, vielmehr als Vorgang unaufhaltsamen Verfalls sich aus“331. Sinnbild dafür ist der Totenkopf. ${ }^{332}$ Die „Majestät der allegorischen Intention“ liegt in der „Zerstörung des Organischen und Lebendigen - Auslöschung des Scheins“"333. Zugleich wird es auf diese Weise als Zerschlagenes und Ausdrucksloses bewahrt.

Wesentlich für die Unterscheidung von Allegorie und Symbol sind also ihre unterschiedlichen Zeitformen. In dem Engel als prototypischer Figur der symbolischen Vermittlung von Unsinnlichem und Sinnlichem, der in den „Thesen“ gleichwohl allegorisch gezeichnet ist, wird der historische Index von Symbol und Allegorie reflektiert. So kann im Gegensatz zu den ephemeren talmudischen Engeln der bewegungsunfähige Engel der Geschichte unter den Bedingungen

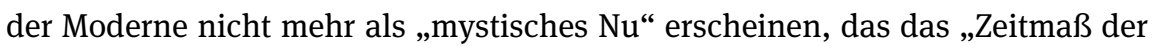
Symbolerfahrung، 334 darstellt. In der Starre seines Blicks entfaltet sich vielmehr die Dynamik der Vergangenheit, die im Modus des fortlaufenden Präsens und damit als unabgeschlossene gezeigt wird - die Katastrophe häuft „unablässig Trümmer auf Trümmer“, die sie dem Engel „vor die Füße schleudert“ (T 697). Der Erstarrung des Blicks korrespondieren die aus ihrem Zusammenhang gebrochenen Trümmer einer ruinenhaften, temporalisierten Landschaft, mit der die

daher überall der Widerspruch zur Reinheit und Einheit der Bedeutung“ (Hermann Cohen, Ästhetik des reinen Gefühls, Bd. 2 (System der Philosophie 3), Berlin 1912, S. 305, zit. n. Benjamin, Ursprung des deutschen Trauerspiels, S. 352-353). Weiter zitiert Benjamin Carl Horst, der über die Allegorie schreibt, „daß sie immer ein ,Überschreiten der Grenzen der anderen Art“, ein Übertreten der bildenden Künste ins Darstellungsgebiet der ,redenden` zu erkennen gibt. [...] In dem kaltsinnigen Durchdringen der verschiedenartigsten menschlichen Äußerungsweisen mit herrschsüchtigen Gedanken ... wird ... Kunstgefühl und -verständnis abgelenkt und vergewaltigt werden. Das verrichtet die Allegorie im Felde der ,bildenden‘ Künste. Man könnte ihr Eindringen deshalb als groben Unfug gegen Ruhe und Ordnung künstlerischer Gesetzmäßigkeit bezeichnen. Und doch hat sie niemals in ihrem Reiche gefehlt, und größte Bildner haben ihr große Werke gewidmet“ (Carl Horst, Barockprobleme, München 1912, S. 39-40, zit. n. Benjamin, Ursprung des deutschen Trauerspiels, S. 353).

330 Benjamin, Ursprung des deutschen Trauerspiels, S. 400-401.

331 Benjamin, Ursprung des deutschen Trauerspiels, S. 353.

332 Vgl. Benjamin, Ursprung des deutschen Trauerspiels, S. 343.

333 Benjamin, Zentralpark, S. 669-670.

334 Benjamin, Ursprung des deutschen Trauerspiels, S. 342. 
Geschichte, die sich in der allegorischen Modellierung „als Vorgang unaufhaltsamen Verfalls“ realisiert, „sinnlich [...] in den Schauplatz sich verzogen“335 hat. Dies entspricht insofern der explizit nachparadiesischen Situation des Engels, als für Benjamin das Allegorische „im Sündenfall zu Hause“336 ist, wobei der moderne Darstellungsmodus des Allegorischen nicht nur theologisch, sondern auch ökonomisch begründet ist. ${ }^{337}$ Wird der Universalgeschichte in den „Thesen“ die theoretische Armatur abgesprochen (vgl. T 702), ${ }^{338}$ so heißt es im „Zentralpark“: „Die Allegorie ist die Armatur der Moderne.“339 Über dem Symbol wie über der Universalgeschichte schwebt in der Moderne der falsche Schein politischer Affirmation, während die Darstellung der Geschichte als Trümmerlandschaft jene affirmative Lesart der Geschichte unterbricht, die Diskontinuierliches und Fragmentarisches ausblendet beziehungsweise zwanghaft homogenisiert und vereinnahmt.

Allerdings liegt ein zentraler Unterschied des Engels zum Melancholiker neben der fehlenden acedia darin, dass zwar der Blick des Engels die Trümmergeschichte konstruiert, dies aber kein kreativ-willkürlicher Akt ist, sondern vielmehr die visualisierende Entbergung von etwas, das sich real vollzogen hat und noch vollzieht. Der Modus des Allegorischen, in dem die Darstellung des Engels erfolgt, ist nicht auf eine Intentionalität des Engels zurückzuführen, sondern auf die historische Situation selbst. In diesem Sinne besetzt der Engel der Geschichte keine melancholische Subjektposition, sondern macht eine allegorische Szenerie sichtbar. In ihr wirkt er als Medium der Wahrnehmung eines anderen Geschichtsbilds, das in der Fortschrittserzählung verborgen ist. Im Gegensatz zu jenem Mythos der Kontinuität, dessen Schein von Homogenität und symbolhafter Geschlossenheit in der Moderne nur aufrechterhalten werden kann, wenn das Abgestorbene und Nichtrealisierte verdrängt wird, gewährt der

335 Benjamin, Ursprung des deutschen Trauerspiels, S. 353.

336 Benjamin, Ursprung des deutschen Trauerspiels, S. 407.

337 So ist das allegorische Herausgerissensein auch für die „Waren im Stadium ihrer Ausstellung“ charakteristisch (Benjamin, Zentralpark, S. 670), und die Entwertung der Dingwelt durch die Ware übersteigt die Entwertung der Dingwelt in der Allegorie (vgl. Benjamin, Ursprung des deutschen Trauerspiels, S. 660). Entsprechend hängt die Allegorie im modernen Kontext auch mit sozioökonomischen Umständen zusammen (vgl. Christine Schmider u. Michael Werner, Das Baudelaire-Buch. In: Benjamin-Handbuch. Leben - Werk - Wirkung, hg. von Burkhardt Lindner, Stuttgart 2011, S. 567-584, hier S. 582; zu der Allegorie in der Moderne vgl. Gérard Raulet, Allegorie und Moderne. In: global benjamin, Bd. 1, hg. von Klaus Garber u. Ludger Rehm, München 1999, S. 203-219).

338 Dieses Urteil bezieht sich auf die Universalgeschichte ohne konstruktives Prinzip (vgl. Benjamin, Anmerkungen [Über den Begriff der Geschichte], S. 1234).

339 Benjamin, Zentralpark, S. 681. 
Engel erstens Einblicke in das Verborgene und eröffnet zweitens einen Ausblick auf die Umkehrung historischer Fatalität. Dass er das Tote beleben will, verbindet ihn, wie gezeigt, mit dem historischen Materialisten.

Mit seinem konstruierenden Blick fungiert der Engel als Katalysator des Allegorischen, indem er das Zerstörte ausstellt und gleichzeitig das Allegorische als „Antidoton gegen den Mythos“340 sichtbar macht. Diesem allegorischen Modus gemäß handelt es sich bei dem Engel der Geschichte um keine Engelserscheinung, die plötzlich in die menschliche Profanität einbricht - diese Form wäre in ihrer auratischen Flüchtigkeit mit dem problematischen Symbolbegriff verknüpft -, sondern um ein über mehrfache Vermittlungen entwickeltes Denkbild. Gleichwohl geht das Bild des Engels der Geschichte nicht in der Erstarrung auf: Schon über das Klee-Bild wird gesagt, der Engel mache den Anschein, sich von etwas zu entfernen. Die Vergangenheit zeigt sich gerade in der Dynamik unausgesetzt sich stapelnder Trümmer. Und der Engel, dessen Blick die Szenerie konstituiert, befindet sich als vom Sturm Getriebener ebenfalls in fortwährender Bewegung.

Die Affinitäten des Engels zur Allegorie liegen nicht nur in der offensichtlichen Übereinstimmung hinsichtlich der „Geschichte als Leidensgeschichte der Welt“341, deren mortifizierte Teile sich zu Emblemen von Tod und Zerstörung schichten, sondern auch in der Spannung von Theologie und Ästhetik. Der Gehalt der Allegorie besteht nach Benjamin darin, dass die Dinge als beliebig semantisierbare einerseits abgewertet, sie andererseits aber auch durch ihre Sakralisierung zugleich unermesslich erhöht werden. Als „formales Korrelat“ bestimmt er die Dialektik von „Konvention und Ausdruck ${ }^{\text {“342 }}$ und verweist auf die Synthese, „die in der allegorischen Schrift aus dem Kampf von theologischer und künstlerischer Intention im Sinne nicht sowohl eines Friedens als einer treuga dei zwischen den widerstreitenden Meinungen sich ergibt“343.

Ohne mögliche Parallelen zur Figur des Engels hier überstrapazieren zu wollen, fällt doch die strukturell ähnliche Verbindung zwischen den spannungsträchtigen Komponenten der Weisung des Engels als religiöser Konvention und dem Ausdruck der ästhetischen Eigenqualität der Engelserscheinung ins Auge. So wirkt der Engel in den „Thesen“ als eine Figur der Darstellung, die die dialektische Spannung und unaufhebbare Differenz zwischen der Botschaft der heiligen Schrift und den Abbildungen ihrer historischen Modulationen zur Anschauung bringt; und dies in der historischen Zeit des Sündenfalls mit dem

340 Benjamin, Zentralpark, S. 677.

341 Benjamin, Ursprung des deutschen Trauerspiels, S. 343.

342 Benjamin, Ursprung des deutschen Trauerspiels, S. 351.

343 Benjamin, Ursprung des deutschen Trauerspiels, S. 353. 
Ausblick des Messianischen als mehrdeutigem Bild im Modus der Gleichzeitigkeit. Denn die Allegorie ist „am bleibendsten dort angesiedelt, wo Vergänglichkeit und Ewigkeit am nächsten zusammenstoßen““344. Neben den Bruchstücken, die sich bis zum Himmel türmen, verweist auch die Möglichkeit des Umschlags von Vergänglichkeitsdarstellung in Heilserfahrung auf den Modus des Allegorischen, in dem Todeserfahrung umspringt in die Allegorie der Erlösung. ${ }^{345}$ Auch dafür steht der Engel, genauer für das engelhafte Leben nach dem Tod: „Ja/ wenn der Höchste wird vom Kirch-Hof erndten ein/ So werd ich Todten-Kopff ein Englisch Antlitz seyn“346 - mit diesem Zitat aus Lohensteins „Redendem TodtenKopff Herrn Matthäus Machners“ (1680) beginnt das letzte Kapitel von Benjamins Ursprung des deutschen Trauerspiels.

Diesen Umschlag kann der Engel der Geschichte gerade aufgrund seiner Abweichung von der theologischen Tradition antizipieren. Mit seinem von keiner göttlichen Autorität und keiner Tradition gedeckten Restitutionswunsch verweist er auf die messianische Utopie eines Geschehens, das er selbst nicht herbeiführen kann, das er aber in seinem Scheitern unter den Bedingungen der historischen Zeit sichtbar macht. Dabei verhindert der Wunsch der Denkfigur des Engels, dass er selbst in dieser allegorischen Trauerlandschaft der Dissoziationen vollends aufgeht. Der Engel vermag zwar die Toten und Trümmer selbst nicht $\mathrm{zu}$ retten, aber in seinem unablässigen Schauen, das sich nicht von der Genealogie der Sieger ablenken lässt, bewahrt er ihre Erinnerung im Bild seines Blicks, hält sie gegenwärtig und wird so zu einer Figur des Eingedenkens, das die Möglichkeit der Reversibilität von Geschichte veranschaulicht. In seiner Absicht, den Katastrophen der Weltgeschichte Einhalt zu gebieten, positioniert er sich zu dem Geschehen der durch seinen Blick entworfenen Szenerie und lässt die Möglichkeit der Rettung aufscheinen.

Auf diese Weise hält der Engel die Spannung aufrecht zwischen dem Endlich-Zertrümmerten, dessen Ausdruck der Tod ist, und dem Unendlich-Ganzen, dem er kraft seiner unmenschlichen Abstammung verhaftet ist. Im Zustand der geschichtlichen Zeit verhindert seine theologische Ausrichtung, dass der Engel in der Geschichte aufgeht. Im Kontext theologischer Systeme bricht er umgekehrt mit seinem ästhetischen Erscheinen und der Möglichkeit des Sich-Abwendens von Gott die gleichförmige Statik eines reinen und entwicklungslosen Daseins. Der Engel der Geschichte ist keine theologische Figur, da er das Leid nicht ungeschehen machen kann. Dennoch kommt ihm mehr als eine bloß il-

344 Benjamin, Ursprung des deutschen Trauerspiels, S. 397.

345 Vgl. Benjamin, Ursprung des deutschen Trauerspiels, S. 405-406.

346 Benjamin, Ursprung des deutschen Trauerspiels, S. 390 u. S. 406. 
lustrative Funktion für die Reflexion des epistemisch-politischen Problemzusammenhangs zu, die sich auch ohne theologische Figuren entwickeln ließe; ${ }^{347}$ vielmehr ermöglicht es die Denkfigur des Engels auf einzigartige Weise, die spezifische Verbindung von Zeitverhaftung und Zeitüberschreitung in ihrer Gleichzeitigkeit zu denken und bildlich zur Darstellung zu bringen.

347 Vgl. etwa Benjamins Bemerkung in der „Erkenntniskritischen Vorrede“, dass ohne die „Gegenstände der Theologie [...] der Wahrheit nicht gedacht werden kann“ (Benjamin, Ursprung des deutschen Trauerspiels, S. 208). 